\title{
Sur l'impact socio-économique des pandémies en Afrique : Leçons tirées du COVID-19, de la trypanosomiase, du VIH, de la fièvre jaune, du choléra
}

\author{
Dirk Kohnert ${ }^{1}$
}

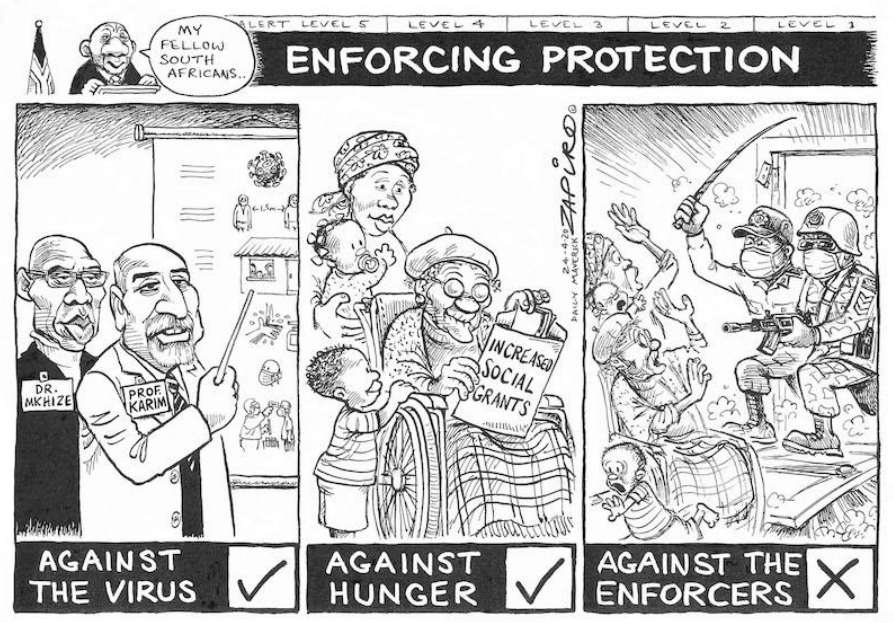

Application de la protection

Source: Zapiro, Daily Maverick, 24 Avril 2020

\begin{abstract}
Résumé : Au cours de l'histoire, rien n'a tué plus d'êtres humains que les maladies infectieuses et la fièvre hémorragique. Bien que les taux de mortalité dus aux pandémies aient chuté de près de $1 \%$ par an dans le monde, environ 0,8 \% par an, tout au long du XXe siècle, le nombre de nouvelles maladies infectieuses comme le Sars, le VIH et le Covid-19 a presque quadruplé par rapport au passé. En Afrique, on a signalé un total de 4522489 cas confirmés de COVID-19 et 119816 décès, au 23 avril 2021. La pandémie a eu de graves répercussions sur les secteurs économique et social dans presque tous les pays africains. Il menace de pousser jusqu'à 58 millions de personnes dans l'extrême pauvreté. Cependant, outre les Africains pauvres, la pandémie de Covid affecte également la classe moyenne africaine en pleine croissance, c'est-à-dire environ 170 millions sur les 1,3 milliard d'Africains actuellement classés dans la classe moyenne. Près de huit millions d'entre eux pourraient être plongés dans la pauvreté à cause du coronavirus et de ses conséquences économiques. Ce revers se fera sentir pendant des décennies. En outre, dans l'histoire récente de l'Afrique, d'autres maladies infectieuses comme la trypanosomiase du bassin du Congo de 1896 à 1906 avec un nombre des morts de plus de 500000 ainsi que l'épidémie de trypanosomose africaine en Ouganda de 1900 à 1920 avec 200000 à 300000 décès ont eu un impact négatif considérable sur les sociétés et économies africaines. En fait, d'autres pandémies, comme la fièvre jaune, le choléra, la méningite et la rougeole - sans parler du paludisme - ont contribué à des ralentissements économiques durables et affectent gravement le bienêtre social pendant des décennies.
\end{abstract}

Mots-clés: COVID-19, Corona, pandémies, Afrique subsaharienne, impact socioéconomique, migration, xénophobie, pauvreté, violence, éthique dans les épidémies

JEL-Code: D62, D63, D74, E24, E26, F15, F22, F24, F35, F52, F54, H12, H51, I14, I15, J46, N37, N97, O14, O17, O55, Z13

\footnotetext{
${ }^{1}$. Expert associé à l'Institut des affaires africaines, Institut allemand des études mondiales et regionales (GIGA), Hambourg.. Projet : 5 mai 2021.
} 


\section{Introduction}

Au cours de l'histoire, rien n'a tué plus d'êtres humains que les maladies infectieuses. Bien que les taux de mortalité dus aux pandémies aient chuté dans le monde d'environ 0,8\% par an, tout au long du XXe siècle, le nombre de nouvelles maladies infectieuses comme le $\underline{\text { Sars, }}$ le $\underline{\mathrm{VIH}}$ et le Covid-19 a presque quadruplé au cours du siècle dernier. En Afrique, on a signalé un total de 4522489 cas confirmés de COVID-19 et 119816 décès, au 23 avril 2021. La pandémie a eu de graves répercussions sur les secteurs économique et social dans presque tous les pays africains. Le colonialisme a contribué activement à la croissance et à l'impact accru des pandémies, comme le montrent les études de cas sur la Sénégambie. Les scientifiques français de l'époque considérait l'Afrique de l'Ouest par exemple comme un environnement pathologique et les Africains comme porteurs de transmetteurs infectieux. La perception du climat tropical chaud, combinée aux épidémies de maladies épidémiques et aux allergies saisonnières, a joué un rôle déterminant dans les processus de transformation urbaine grâce à des mesures d'hygiène telles que l'élimination des déchets, la fermeture des cimetières et l'imposition de nouveaux codes de construction. Cependant, la stigmatisation des Africains pauvres en tant que «indigènes dégoûtants » a également conduit à l'expulsion forcée des pauvres des villes - tout d'abord des centres-villes et plus tard à leur confinement dans des régions isolées (Ngalamulume, 2021). Aujourd'hui, la pandémie de COVID-19 menace de pousser jusqu'à 58 millions de personnes dans l'extrême pauvreté. Cependant, outre les Africains pauvres, la pandémie de Covid affecte également la classe moyenne africaine en pleine croissance, c'est-à-dire environ 170 millions sur les 1,3 milliard d'Africains actuellement classés dans la classe moyenne. Près de huit millions d'entre eux pourraient être plongés dans la pauvreté à cause du coronavirus et de ses conséquences économiques. Ce revers se fera sentir pendant des décennies.

En outre, dans l'histoire récente de l'Afrique, d'autres maladies infectieuses telles que la trypanosomiase du bassin du Congo de 1896 à 1906 avec un bilan de plus de 500000 morts ainsi que l'épidémie de trypanosomiase africaine en Ouganda de 1900 à 1920 avec 200000 à 300000 décès ont eu un impact négatif considérable sur les sociétés et économies africaines . En fait, d'autres pandémies, comme la fièvre jaune, le choléra, la méningite et la rougeole sans parler du paludisme - ont contribué à des ralentissements économiques durables et affectent gravement le bien-être social pendant des décennies.

\section{Des épidémies majeures et leur impact sur la société et l'économie africaines}

\subsection{COVID-19}

La pandémie de Corona a fait plus de 100000 morts en Afrique et près de 4 millions de cas ont été enregistrés à ce jour. Cependant, la pandémie de l'Afrique est une pandémie de 
nuances, et tous les pays ne sont pas touchés de la même manière. Seuls 10 pays représentent plus de $80 \%$ de tous les cas. Les pays insulaires souffrent d'impacts particuliers, la différenciation, rurale-urbaine est évidente, les implications socio-économiques révèlent des préjugés sexistes et la structure du commerce mondial sont importants (PNUD, 2021).

Un rapport récent du PNUD a analysé les impacts socio-économiques à long terme du COVID-19 dans divers contextes africains et a examiné l'effet que le COVID-19 aura sur le développement macro-économique dans 10 pays africains d'ici 2030 et 2050. Le document a mis en évidence les conséquences économiques et sociales multiformes de la pandémie du COVID-19 à travers l'Afrique, y compris sur les indicateurs de développement humain, l'interdépendance économique et les modèles de croissance et de résilience. L'évolution de la mortalité, de la croissance économique et des flux financiers internationaux en Angola, au Cap-Vert, au Tchad, en RDC, en Éthiopie, au Kenya, au Mali, à Maurice, au Nigéria et en Afrique du Sud sont analysée dans le document. Le rapport décrit explicitement les effets d'aujourd'hui sur la mortalité au niveau des pays, la croissance du produit intérieur brut (PIB) et les flux monétaires internationaux du commerce, de l'aide, des investissements directs étrangers (IDE) et des envois de fonds. Son impact global façonnera les schémas à long terme de mortalité, de croissance économique et de commerce international d'ici 2030 et 2050. En outre, le rapport révèle comment ces changements macroéconomiques affecteront les indicateurs socio-économiques et le développement humain en quantifiant les résultats de la mortalité infantile et de la pauvreté les décennies à venir (PNUD, 2021).

Figure 1: Développement de l'épidémie de COVID-19 dans différents pays africains de mars 2020 à avril 2021

The number of active cases by country. [22][23][24][25][26][27][28][29][30][31][32][33]

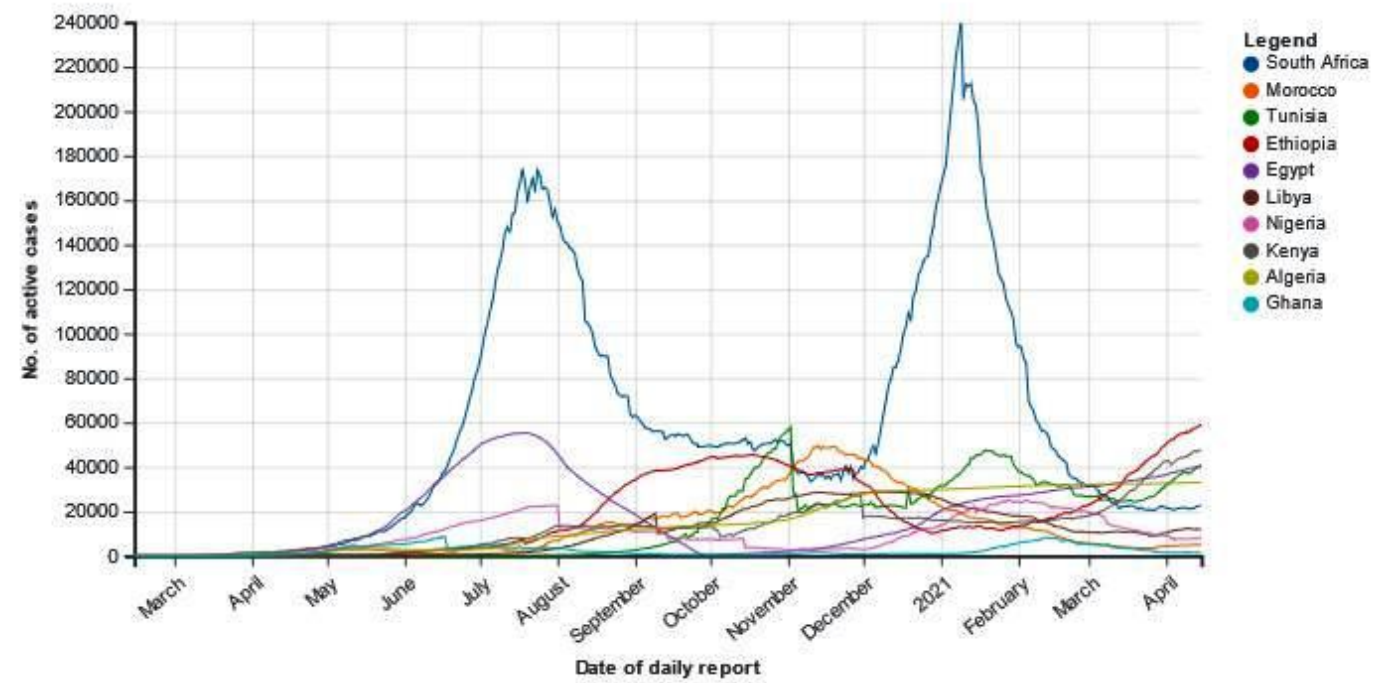

Source: COVID-19 pandemic in Africa (Wikipedia)

La propagation rapide du COVID-19 en Afrique a créé un sentiment d'urgence en Afrique et a suscité des appels à une réponse mondiale coordonnée pour arrêter la pandémie, atténuer ses effets dévastateurs, et ainsi jeter les bases d'un relèvement à long terme (Ozili, 2020 ). Les normes et valeurs socioculturelles qui sont au centre des sociétés africaines courent désormais un risque sérieux de disparaître dans l'oubli. La prolifération des espaces de médias sociaux et autres moyens de communication des sources professionnelles et non-professionnelles, a 
conduit à la mésinformation et à la désinformation délibérée avec des conséquences néfastes sur la lutte contre la pandémie.

Tous ces défis immédiats auront un impact durable qui s'étendra jusqu'à la période post-pandémique.

La pandémie a eu un impact sur le secteur informel et culturel dans son ensemble. Les mesures restrictives ont conduit à l'annulation de grands événements artistiques et culturels, y compris des festivals et des conférences à travers le continent. Elle a perturbé les affaires, en particulier des petite ou moyenne entreprise (PME) opérant dans le secteur informel et culturel, et a donc mis en danger les principales sources de revenus des jeunes entrepreneurs et des aspirants entrepreneurs. L'épidémie a non seulement révélé la fragilité des systèmes de santé dans toute l'Afrique, mais elle a également mis en évidence le besoin d'écosystèmes scientifiques, technologiques et d'innovation plus robustes et de haute capacité. L'indisponibilité des équipements de protection individuelle (EPI), la formation inadéquate des agents de santé, le manque d'installations adéquates pour le traitement des patients infectés, sont autant de facteurs qui ont contribué à saper l'image et les capacités de la communauté scientifique africaine. Les conséquences immédiates et à long terme des fermetures d'écoles sont susceptibles d'augmenter encore les inégalités en matière d'éducation.

En général, la maladie provoquée par le coronavirus (COVID-19) et les tentatives de limiter sa propagation ont eu des impacts économiques profonds et une contraction significative de l'économie mondiale. Une étude récente de la Banque mondiale (Josephson \& Kilic \& Michler, 2020) a fourni les premières preuves scientifiques sur les impacts socio-économiques et les réponses à la pandémie parmi les ménages et les individus dans quatre études de cas en Afrique subsaharienne, basées sur des données d'enquêtes auprès des ménages d'Éthiopie, Malawi, Nigéria et Ouganda. L'évaluation était basée sur des enquêtes en face-à-face sur les ménages pré-COVID-19 et sur de nouvelles enquêtes téléphoniques réalisées pendant la pandémie. Les principales constatations étaient quadruples. Premièrement, bien que les fausses croyances sur le virus COVID-19 et l'épidémie demeurent répandues, l'action du gouvernement pour limiter la propagation de la maladie a été associée à une meilleure connaissance individuelle de la maladie et à un recours accru aux mesures de précaution. Deuxièmement, on estime que 256 millions d'individus - $77 \%$ de la population des quatre pays - vivaient dans des ménages qui avaient perdu des revenus en raison de la pandémie. Troisièmement, les tentatives pour faire face à cette perte ont été exacerbées par l'incapacité d'accéder aux médicaments et aux aliments de base chez $20 \%$ à $25 \%$ des ménages de chaque pays. L'insécurité alimentaire a été supportée de manière disproportionnée par les Africains pauvres qui étaient déjà appauvris avant la pandémie. Quatrièmement, le contact élèveenseignant est passé d'un taux pré-COVID-19 de $96 \%$ à seulement $17 \%$ parmi les ménages avec enfants d'âge scolaire. Les résultats étaient destinés à éclairer les décisions des gouvernements et des organisations internationales sur les mesures visant à atténuer les effets de la pandémie de COVID-19 et ils révèlent la nécessité d'une surveillance continue (Josephson \& Kilic \& Michler, 2020).

À propos, les programmes de prévention et de vaccination contre le COVID-19 ont été évalués favorablement par rapport à des programmes similaires d'anciennes épidémies en Afrique. Malgré toutes les critiques justifiées concernant la prévention du Corona, en aucun temps avant, les autorités et la population n'auraient pu agir aussi minutieusement et rapidement. Des millions d'autres auraient été infectés et seraient morts sans la technologie de l'information et la médecine modernes. Dans le langage des experts du COVID-19, dans une certaine mesure, il était au moins possible « d'aplatir la courbe » (Malczycki, 2020). 
Après la décision des Etats-Unis et de plusieurs pays européens de suspendre l'utilisation du vaccin AstraZeneca en avril 2021 en raison du risque de caillots sanguins, les autorités ont préféré attendre les résultats des études menées par les agences de santé occidentales pour donner leur verte lumière. Les doses restituées devaient être redistribuées en mai 2021 à quatre pays : le Ghana, la République Centrafricaine, le Sénégal et le Togo (Caramel, 2021).

\subsection{Trypanosomaisis / maladie du sommeil}

Figure 2 : Répartition de la THA dans les pays d'endémie, 2017 et 2018
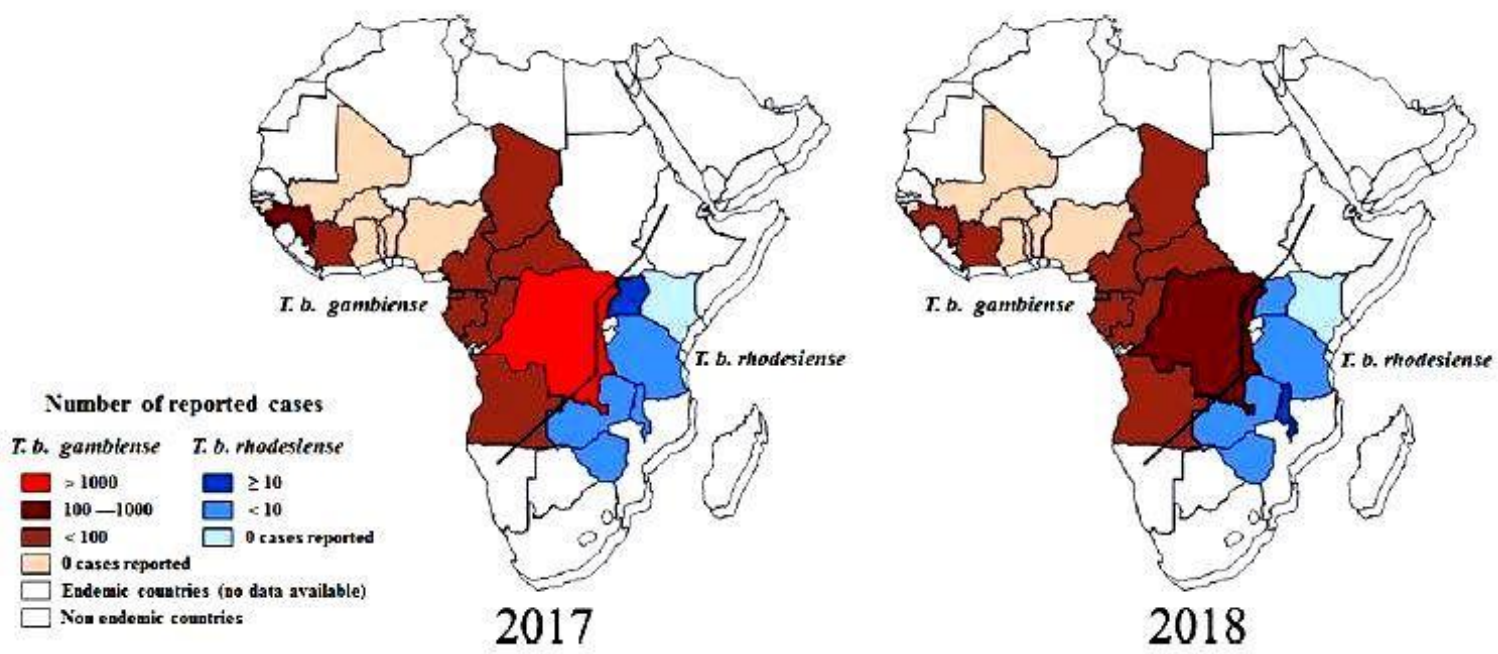

Source: Gaoe et al, 2020; $\underline{\text { WHO, } 2021}$

Figure 3: Décès pour 100000 habitants dus à la THA en 2002

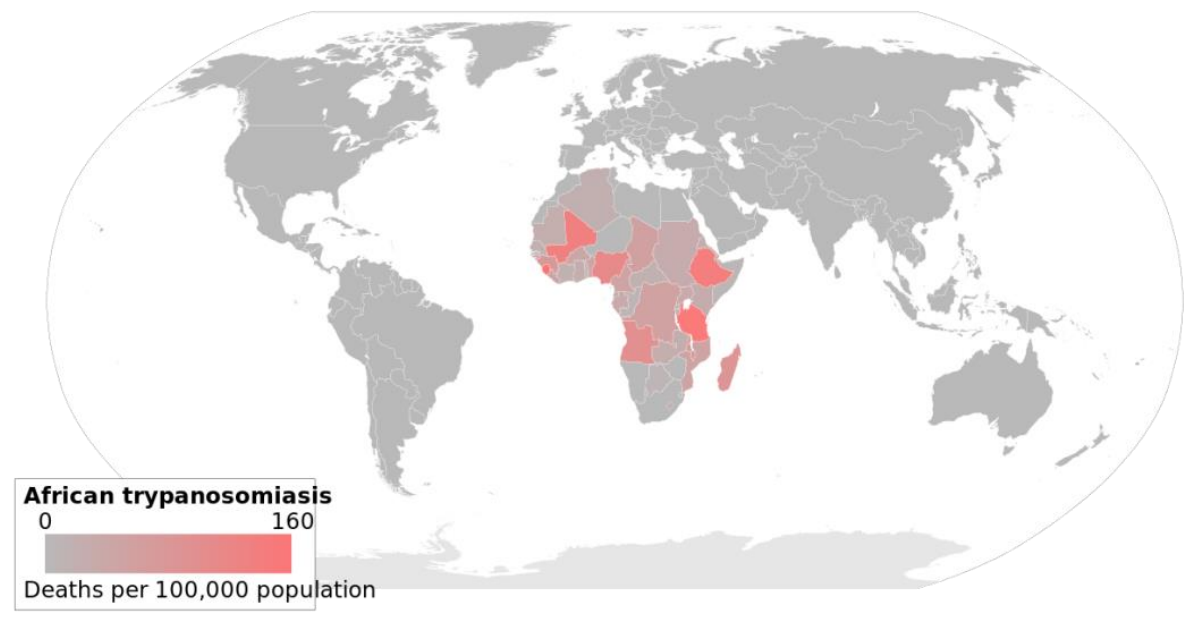

Source: Richard Wheeler (Zephyris), African trypanosomiasis, Wikipedia

L'apparition de la maladie du sommeil ou Trypanosomaisis humaine africaine (THA) correspond largement à l'aire de répartition de l'hôte intermédiaire du virus, la mouche tsé-tsé, soit la superficie de 8 millions de $\mathrm{km} 2$ entre 14 degrés Nord et 20 degrés Sud de latitude. L'espèce T. $b$. gambiense est responsable de la forme chronique de la maladie du sommeil en 
Afrique de l'Ouest et Centrale, tandis que $T$. $b$. rhodesiense donne naissance à la forme aiguë de la maladie en Afrique Orientale et Australe. En l'absence de traitement, les patients atteints de la maladie du sommeil meurent en quelques mois lorsqu'ils sont infectés par $T . b$. rhodesiense ou dans les années en cas d'infection par T. b. gambiense. En outre, les animaux sauvages et domestiques peuvent jouer un rôle majeur en tant que réservoirs de parasites pour les infections humaines par les trypanosomes (Steverding, 2008). L'histoire de la THA est étroitement liée à la traite des esclaves. La maladie du sommeil causant des pertes croissantes, les armateurs et les marchands d'esclaves ont pressé les médecins de leurs navires d'enquêter sur la maladie. Néanmoins, tout au long du 19ème siècle, les rapports sur la maladie du sommeil ont augmenté et la trypanosomiase humaine africaine est devenu une maladie bien reconnue, personne n'avait aucune idée réelle de la nature de la maladie ni de son traitement efficace.

Au tournant du 20e siècle, il y a eu trois épidémies graves de maladie du sommeil. La

$$
\text { Peinture : «La maladie du sommeil », par Gordon Ross (1873-1946) }{ }^{2}
$$

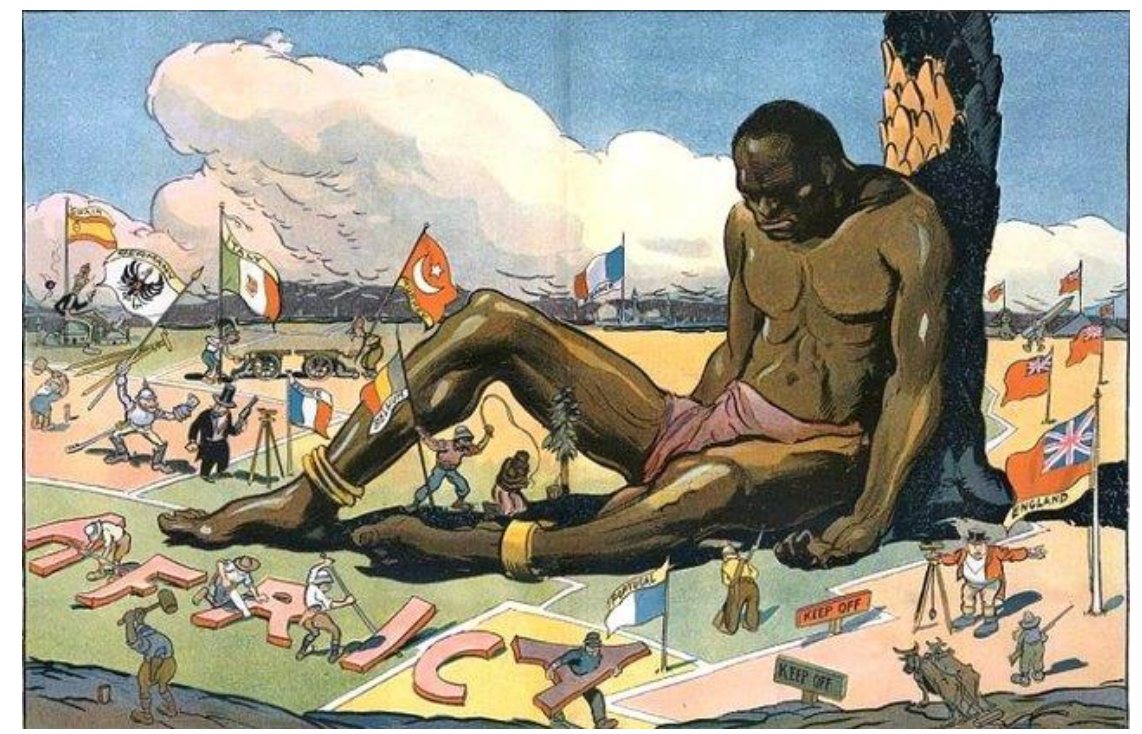

Source : Ross, Gordon, 1873-1946, artiste

N.Y. : Edité par Keppler \& Schwarzmann, Puck Building, 1911 October $25^{3}$.

première a commencé en 1896 et a duré jusqu'en 1906. Elle a touché principalement le bassin du Congo et l'Ouganda, avec respectivement 300000 et 500000 personnes décédées dans le bassin du Congo et le foyer de Busoga en Ouganda et au Kenya respectivement (Steverding, 2008). Les effets sanitaires et économiques désastreux de l'épidémie ont inquiété les administrations coloniales à tel point qu'elles ont envoyé des missions scientifiques pour enquêter sur la maladie et mettre au point un remède. Cependant, il s'est avéré difficile de trouver des médicaments efficaces (par exemple, Bayer-2005 et suramine) qui n'étaient disponibles qu'en 1916. Les deux médicaments ont aidé à lutter contre la deuxième grande épidémie de maladie du sommeil qui a commencé dans un certain nombre de pays africains en 1920 et s'est calmée à la fin année 1940. Une autre mesure importante pour contrôler

\footnotetext{
${ }^{2}$ L'allégorie de Gordon Ross sur l'impact du colonialisme en Afrique montre un grand homme africain enchaîné, affecté par la maladie du sommeil, assis, appuyé contre un arbre, endormi, tandis que plusieurs pays européens revendiquent des parties de l'Afrique. Ils plantent des drapeaux étiquetés Angleterre, Portugal, Belgique, Turquie, Italie, Allemagne, Espagne, et France tout autour de l'homme endormi.

${ }^{3}$ Noms des contributeurs : Ross, Gordon, 1873-1946, artiste. - N.Y. : Edité par Keppler \& Schwarzmann, Puck Building, 1911 October 25. - Source : Library of Congress Repository Library of Congress Prints and Photographs Division Washington, D.C.
} 
l'épidémie de maladie du sommeil des années 1920 a été l'introduction d'équipes mobiles pour suivre la propagation de la maladie. L'administration coloniale française a montré au Cameroun en 1926 l'efficacité de sa démarche. En 11 ans, les niveaux de prévalence de la maladie du sommeil sont passés de $60 \%$ en 1919 à 0,2-4,1\% en 1930. Par la suite, d'autres puissances coloniales ont introduit la méthode des équipes mobiles pour la $T$. b. gambiense lutte contre la maladie du sommeil. Une deuxième approche consistait en la lutte antivectorielle, comprenant l'utilisation de pièges de conception différente et le défrichage de brousse, ainsi que le contrôle du réservoir hôte et la destruction du gibier. Entre 1920 et 1940, le contrôle de l'hôte du réservoir et la destruction du gibier ont entraîné une réduction significative, mais jamais l'extermination, de la population de glossines. Avec la découverte de ses propriétés insecticides en 1939, le DDT a été utilisé en 1949 dans l'espoir de libérer de grandes parties des zones endémiques des glossines (Steverding, 2008).

Figure 4: La propagation de la maladie du sommeil en Afrique, 1939 - 2004

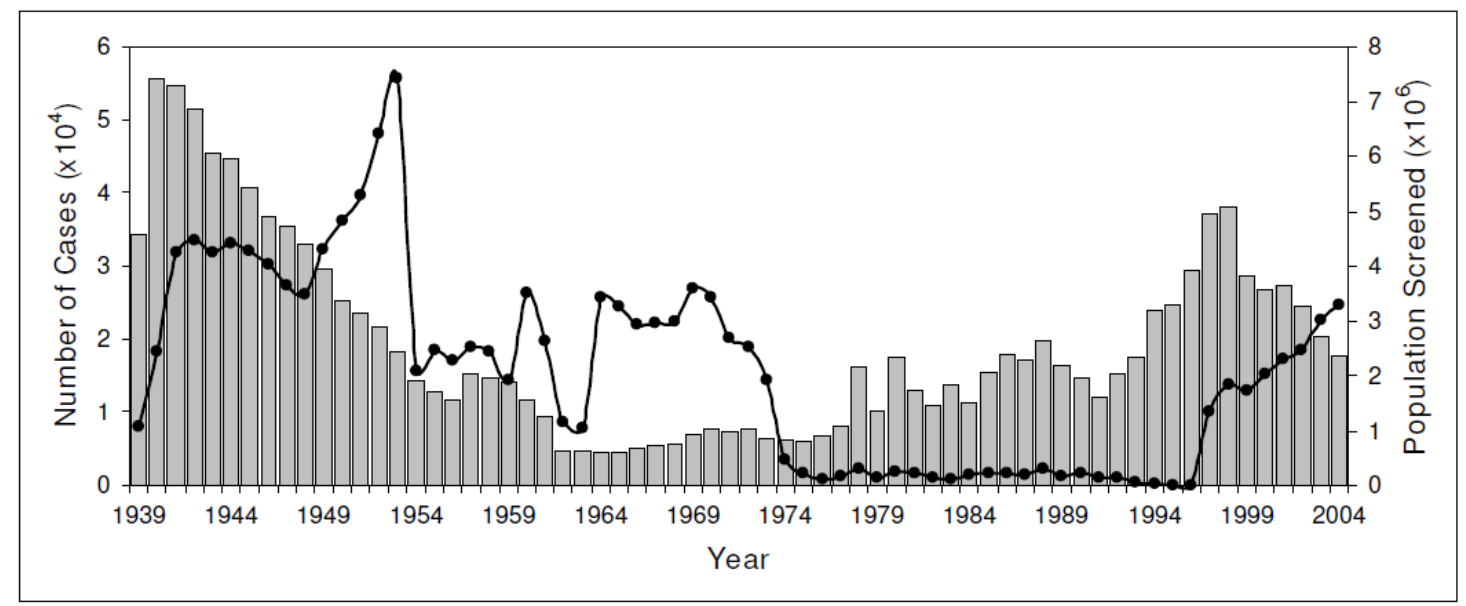

Nombre de cas déclarés de maladie du sommeil et population dépistée, 1939-2004. Colonnes grises, nombre de cas signalés ; cercles noirs, population examinée (Steverding, 2008).

Figure 5: Nombre de cas déclarés de gambiense-THA p.a. de 1990 à 2018 dans les pays d'endémie avec une ventilation pour chaque pays

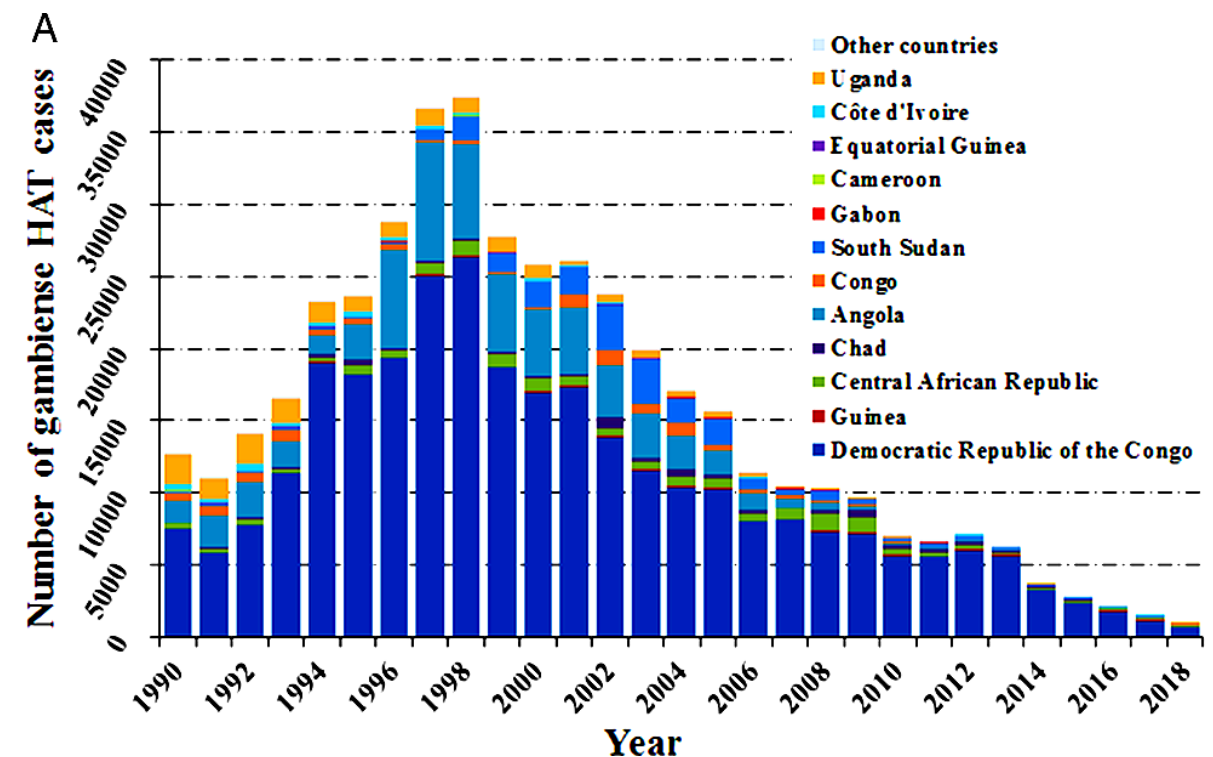

Source : Gao et al, 2018 ; Remarque : les données proviennent de l'Organisation mondiale de la santé 
Les conditions socio-économiques de la domination coloniale ont été un autre facteur majeur de la propagation de la maladie du sommeil en Afrique dans la première moitié du XXe siècle. Les médecins et l'administration coloniaux ont par exemple accusé la TAH de la digression démographique dans le district de l'Uele centre-nord de l'ex-Congo belge (Lyons, 1997). Les colonialistes Belges et britanniques qualifiaient généralement leur colonisation de « mission civilisatrice», et beaucoup considéraient l'introduction de la bio-médecine occidentale comme une caractéristique centrale de leur «cadeau » aux Africains. En 1930, cependant, il était clair que certaines caractéristiques de leur «mission civilisatrice » étaient en fait étroitement liées à la mauvaise santé de nombreux Congolais. Les Européens ont introduit un système politique sévère et répressif qui, associé à un système économique exploitant sans pitié, a conduit à l'introduction de nouvelles maladies alors que les maladies déjà existantes étaient exacerbées et se propageaient. Un grand nombre d'Africains ont été déplacés et beaucoup d'entre eux ont connu la famine. Cela a créé un environnement idéal pour propager la maladie et la maladie du sommeil est devenue de plus en plus enracinée et épidémique. De plus, de nombreux colonialistes pensaient qu'une grande partie de l'arriération qu'ils voyaient dans la société africaine était attribuable à des maladies endémiques, telles que la maladie du sommeil, qui pourraient aider à expliquer le manque d'utilisation de la roue et le besoin connexe de portage humain, ou des charrues, des moulins et autres à propulsion animale (Steverding, 2008). Les améliorations de la nutrition et de l'hygiène après la Première Guerre mondiale ont probablement autant à voir avec le déclin de la maladie du sommeil que les interventions médicales. Dans les années 1930, par exemple, de nombreux Africains du Congo belge ne souffraient plus de perturbations sociales et économiques intenses et apprenaient à mieux faire face aux règles et aux contrôles des puissances coloniales. Les Belges, quant à eux, ont progressivement cessé leur pratique d'ingénierie sociale consistant à déplacer brusquement des communautés entières.

Figure 6 : Zones de THA à forte prévalence en Afrique centrale, 2000-2009

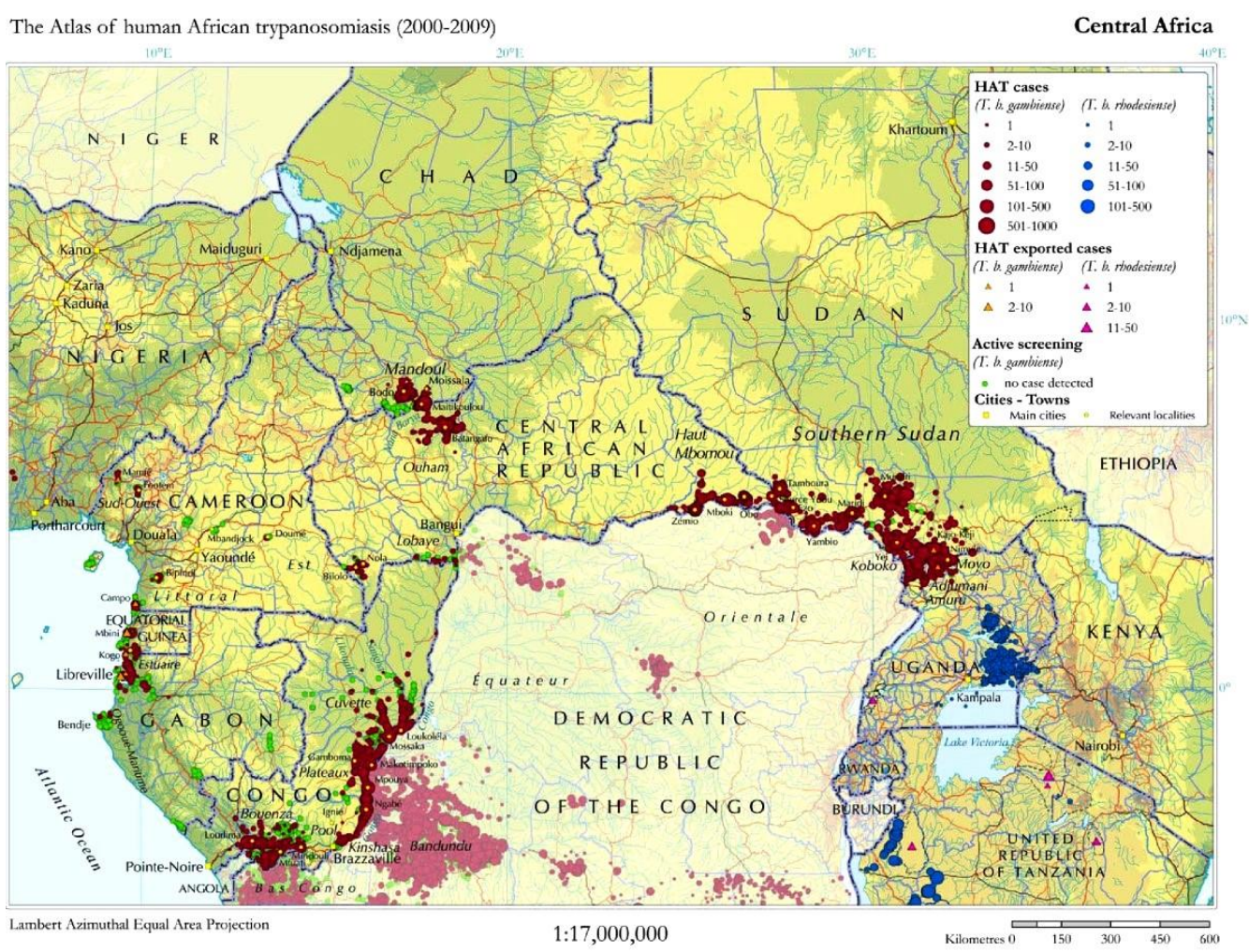

Source: Tong \& Valverde et al. (2011);

Reproduit sous l'attribution en libre accès à partir de Simarro PP et al. Int J Health Geogr 2010, 9:57 
La maladie du sommeil était également un problème majeur en Zambie depuis des siècles, notamment dans la province orientale (Machila, 2013). Pendant la domination coloniale britannique, l'administration coloniale a essayé de prendre des mesures appropriées pour contenir et empêcher la propagation des glossines et de la trypanosomiase avec des résultats mitigés, lorsque la British South African Company a découvert la maladie. L'impact de la Seconde Guerre mondiale a limité la disponibilité des ressources pour les programmes de lutte contre la mouche tsé-tsé et la trypanosomiase, ce qui a aggravé la situation. Ce n'est qu'à la fin de la guerre, en 1945, que l'administration coloniale s'est activement impliquée dans le contrôle de l'épidémie. Pendant ce temps, les populations indigènes de la province orientale ont continuellement développé et réadapté des stratégies de survie traditionnelles et des médicaments ethno-vétérinaires pour faire face à la maladie dans leurs communautés (Machila, 2013).

Cependant, depuis la décolonisation de la plupart des pays africains au début des années 1960, de nombreux États africains ont connu une instabilité politique et une ruine économique avec un effet désastreux sur les services de santé. Après une décennie de faible endémicité, la lutte contre la trypanosomiase n'était plus une priorité. En conséquence, les programmes de contrôle ont été arrêtés et le dépistage de la population a été réduit à un très petit nombre de personnes. En outre, les préoccupations concernant les effets environnementaux graves du DDT ont conduit à une interdiction de l'insecticide dans les années 1970. En conséquence, le nombre de cas déclarés de maladie du sommeil a augmenté régulièrement depuis les années 1970. C'était le début de la troisième et la plus récente épidémie de maladie du sommeil, touchant principalement l'Angola, le Congo, le Sud-Soudan et le district du Nil occidental en Ouganda. La situation est restée inchangée jusqu'en 1990. Au tournant du XXe siècle, la maladie du sommeil avait presque retrouvé le niveau des épidémies du début du siècle (Steverding, 2008). Heureusement, l'Organisation mondiale de la santé (OMS) a conclu un accord avec les sociétés pharmaceutiques Aventis (aujourd'hui Sanofi-Aventis) et Bayer AG en 2001 pour fournir gratuitement des médicaments contre la maladie du sommeil aux pays d'endémie. Médicins Sans Frontières a été chargé de la distribution des médicaments. En conséquence, le nombre de nouveaux cas a diminué régulièrement depuis 1998. À l'heure actuelle, le nombre estimé d'infectés est estimé entre 50000 et 70000.

Figure 7 : Défis spécifiques du contrôle de la THA dans les zones de conflit en $\underline{\text { RDC }}$

From: Challenges of controlling sleeping sickness in areas of violent conflict: experience in the Democratic Republic of Congo

\begin{tabular}{|l|}
\hline $\begin{array}{l}\text { - Conflict-afflicted areas are often already remote with minimal (if any) health infrastructures and limited numbers of trained medical staff, and their often precarious state is further } \\
\text { eroded by insecurity. }\end{array}$ \\
\hline - Insecurity often hinders active case-finding activities since mobile teams are often restricted in their travel. \\
\hline - Populations often move, hampering treatment provision and post-treatment monitoring and follow-up. \\
\hline - Population movements can also trigger new foci or reactivate old ones. \\
\hline - Community awareness and support are important factors for effective screening and treatment. Population displacement due to insecurity can rupture community networks. \\
\hline $\begin{array}{l}\text { - Direct attacks of treatment centres or transport trucks can lead to programme interruption or cessation, withdrawal of supporting international NGOs and key national staff, or } \\
\text { disruption of logistic support. }\end{array}$ \\
\hline - Difficult diagnosis, complex treatment, and long follow-up are especially challenging in conflict situations, because of the high technical skills and continuity of service required. \\
\hline
\end{tabular}

Source : Tong \& Valverde et al, 2011

En outre, l'Organisation de l'unité africaine (OUA) a lancé en 2001 la Campagne panafricaine d'éradication des glossines et de la trypanosomose (PATTEC) pour éliminer la mouche tsé-tsé d'Afrique. La technique des glossines mâles stériles a été utilisée avec succès dans l'éradication des glossines et par conséquent de la maladie du sommeil à Zanzibar en 1997. Cependant, contrairement à Zanzibar, infestée d'une seule espèce de glossine, l'initiative PATTEC a dû faire face à la une zone beaucoup plus grande de l'Afrique subsaharienne, habitée par au moins 7 espèces de glossines différentes reconnues comme vecteurs de 
transmission de la maladie du sommeil. Par conséquent, on peut douter du succès de l'approche PATTEC, car des campagnes d'éradication similaires ont échoué dans le passé parce que les zones infestées de glossines n'ont pas pu être isolées. Enfin, les coûts énormes associés au projet d'éradication étaient également préoccupants, car la plupart des pays concernés appartiennent aux pays pauvres les plus endettés du monde (Steverding, 2008).

Une étude de cas visant à évaluer l'impact économique et social de la THA dans les districts de Mambwe, Rufunsa, Mpika et Chama en Zambie a révélé divers effets à court et à long terme sur les moyens de subsistance et les stratégies d'adaptation des victimes de la maladie du sommeil, y compris les effets sur la santé physique et mentale, les deux sur les patients et les membres de la communauté affectés (Mwiinde et al, 2017). Les coûts étaient axés sur la recherche d'un traitement et l'hospitalisation. La moyenne des patients ayant dépensé de l'argent pour le traitement était inférieure à la moitié pour les patientes (84 USD) par rapport aux hommes (172 USD). L'argent a été utilisé pour acheter des médicaments pour l'automédication, pour rechercher un traitement auprès de guérisseurs traditionnels et pour rechercher un traitement dans des centres de santé privés. Les coûts de transport associés à la recherche de soins pour les patients atteints de THA étaient également élevés, un montant moyen de 99,3 USD devant être dépensé, ce qui a fortement dissuadé de rechercher des soins médicaux appropriés (Mwiinde et al, 2017).

Un autre objectif de l'étude était l'évaluation de l'impact des incapacités à long terme de la THA, qui étaient courantes. L'impact était significatif avec le nombre d'années de vie corrigées de l'incapacité (DALY), augmentant entre $44 \%$ et $50 \%$. Parmi les conséquences sociales de la THA figuraient l'incompréhension, la stigmatisation, l'abandon scolaire, la douleur, l'amnésie et le handicap. La déformation musculaire et nerveuse acquise avait un effet plus important sur les femmes qui perdaient souvent l'estime de soi. Tant au niveau communautaire que familial, la stigmatisation, la confusion mentale, les changements de personnalité et de comportement ont conduit à des abandons scolaires, à la mortalité, au divorce ou à la rupture des relations et ont abouti à un climat défavorable pour l'éducation des enfants. La confusion mentale a amené les victimes à ne pas s'associer à des amis, tandis que la douleur a obligé les victimes à rester à la maison, les privant de la vie sociale (Mwiinde et al, 2017).

Une deuxième étude de cas au Kenya et en Ouganda de 2004 à 2005 (districts de Busia, Teso et Bunqoma dans l'ouest du Kenya, et districts de Busia et Teso dans le sud-est de l'Ouganda entre janvier 2004 et juin 2005) a révélé que les comportements de recherche de santé perpétuaient l'impact de la THA sur les individus et les ménages affectés, que la THA a perturbé le fonctionnement social des ménages ainsi que la base économique des ménages affectés (Bukachi et al-2007). Un diagnostic tardif de la THA a entraîné de graves effets somatiques sur les patients. Les effets mentaux étaient prononcés chez les jeunes patients qui ont par la suite eu des difficultés à réintégrer la communauté. Les ménages ont souffert d'une charge financière en raison de la recherche d'un traitement auprès de différents prestataires de services de santé. La maladie était aussi parfois attribuée au VIH / sida ou à la sorcellerie. Ce dernier a conduit les victimes à être stigmatisées, à retarder la recherche d'un traitement ou à se faire soigner auprès de sources douteuses. De plus, la maladie a conduit à des conflits au 
sein des mariages, des familles et de la communauté, augmentant ainsi le fardeau des femmes et des enfants. Parmi les autres impacts économiques, citons le décrochage scolaire, l'absentéisme scolaire, la baisse de la productivité et l'augmentation des frais de funérailles et d'inhumation (Bukachi et al-2007; Pitlik, 2020). Enfin, des facteurs structurels tels que les intérêts politiques concurrents, les grèves des agents de santé, les allocations budgétaires inadéquates, les opportunités économiques, la marginalisation, l'analphabétisme, les normes et pratiques culturelles enracinées, le faible accès à l'eau, à l'assainissement et au logement, ont tous servi à propager la transmission (Ochola \& Karanja \& Elliott, 2021).

En outre, la THA a privé les victimes de possibilités d'améliorer leur qualité de vie (par exemple par l'éducation) et a entraîné une perte de revenus personnels et d'amis. Ces résultats correspondaient à ceux d'un rapport de l'OMS qui a révélé que les troubles mentaux et comportementaux représentent 17,6 \% de tous les handicaps en Afrique. Certains d'entre eux durent quelques semaines ou quelques mois, tandis que d'autres peuvent durer toute une vie. Enfin, la sensibilisation limitée des membres de la communauté et le manque de programmes de prévention se sont traduits par un fardeau élevé de la THA dans les communautés rurales. (Mwiinde et al. (2017) concluent que la THA est une maladie qui émerge de la pauvreté à la fois en termes de dynamique de transmission et de résultats cliniques, tout en perpétuant et en renforçant simultanément un état de pauvreté parmi les ménages touchés. La maladie affecte les ménages à plusieurs niveaux, y compris la création de revenus, l'agriculture et la sécurité alimentaire, l'éducation des enfants et la santé à long terme. Au niveau individuel, la maladie entraîne une perte d'estime de soi en raison de la stigmatisation en raison des incapacités physiques et mentales acquises à long terme.

\subsection{Fièvre jaune}

La fièvre jaune, qui est originaire d'Afrique et s'est propagée en Amérique du Sud au 17ème siècle avec l'importation d'esclaves africains par les marchands d'esclaves espagnols et portugais comme cargaison humaine ainsi que le moustique Aedes aegypti transporté dans les cales et les seaux des navires négriers venant d'Afrique au Nouveau Monde (Oldstone, 2009: 103). Plus tard, l'Aedes aegypti a également transmis d'autres virus comme le virus de la dengue, Zika et chikungunya. Aux XVIIIe et XIXe siècles, la fièvre jaune était considérée comme l'une des maladies infectieuses les plus dangereuses provoquant de nombreuses épidémies dans le monde. Jusqu'à aujourd'hui, il reste un problème majeur de santé publique en Afrique subsaharienne. Bien qu'un vaccin très efficace soit disponible depuis environ 60 ans, moins de $2 \%$ des gens sont vascinés, car la plupart des pauvres africains n'y ont pas accès.

Selon les estimations de l'OMS, environ 200000 victimes par an sont infectés dans le monde et 30000 meurent par an, mais plus de $90 \%$ des cas surviennent en Afrique. Au cours des 15 dernières années, la fièvre jaune a de nouveau considérablement augmenté, la plupart des cas étant observés en Afrique de l'Ouest.

Dans l'ensemble, il y a eu deux pics majeurs d'activité de la fièvre jaune en Afrique depuis 1948 : l'un entre 1960 et 1962, et l'autre entre 1985 et 1995. Le brochet au début des années 1960 était principalement dû à l'épidémie en Éthiopie et au point culminant en 1985-1995 
principalement en raison de flambées au Nigéria. En raison du retard dans la distribution du vaccin contre la fièvre jaune, le Nigéria est en fait sur le point de déclencher une épidémie au milieu de l'épidémie de COVID-19 (Çavdaroğlu et al, 2021). D'autres pays africains, comme le Ghana, l'Éthiopie, le Congo et la Guinée, peuvent souffrir d'une graisse similaire en raison des taux de migration élevés des personnes et de la population de la faune indigène. La pandémie Corona a provoqué une importante absence de soins médicaux, en outre, l'épidémie de COVID-19 a entraîné une augmentation significative de la charge de travail des membres du personnel hospitalier, affectant la gestion des patients (Çavdaroğlu et al, 2021).

Figure 8:

). Zones à risque de transmission du virus de la fièvre jaune en Afrique (2017)

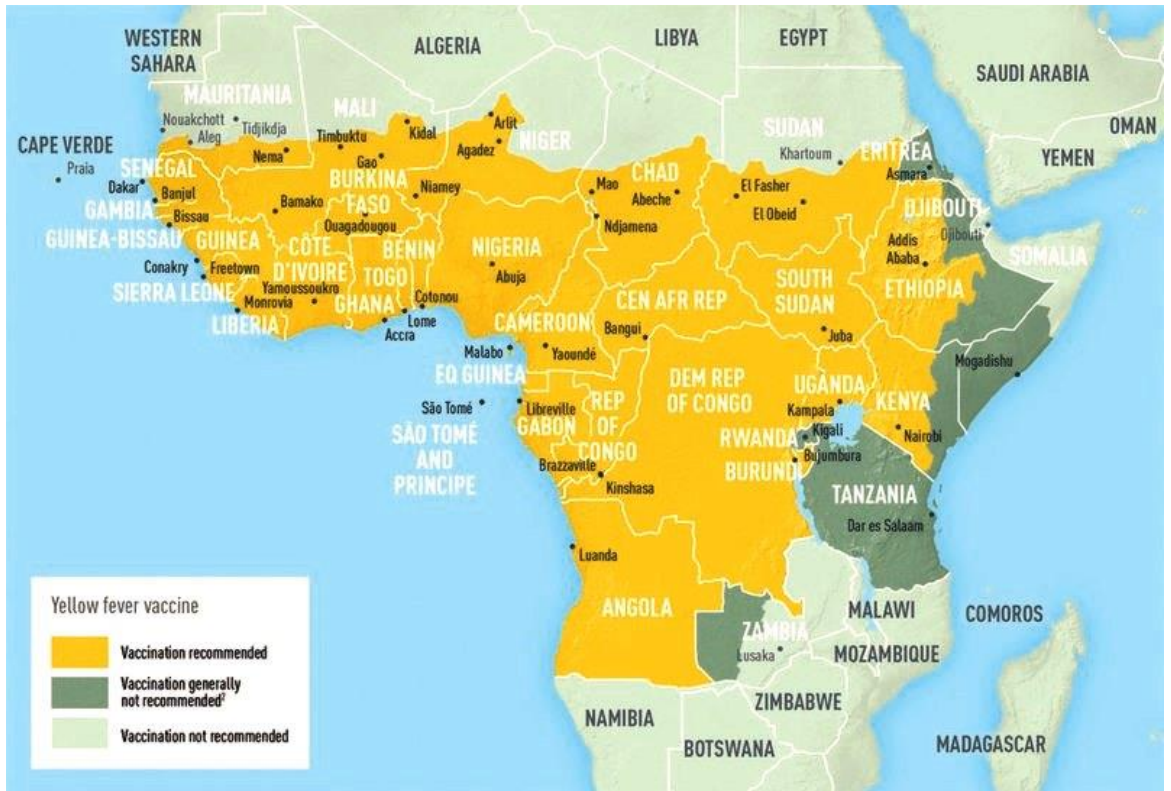

Source : Centres pour le Contrôle et la Prévention des maladies [U.S. CDC], Atlanta, Georgia

Dans l'ensemble, il y a eu deux pics majeurs d'activité de la fièvre jaune en Afrique depuis 1948 : l'un entre 1960 et 1962, et l'autre entre 1985 et 1995. Le brochet au début des années 1960 était principalement dû à l'épidémie en Éthiopie et au point culminant en 1985-1995 principalement en raison de flambées au Nigéria. En raison du retard dans la distribution du vaccin contre la fièvre jaune, le Nigéria est en fait sur le point de déclencher une épidémie au milieu de l'épidémie de COVID-19 (Çavdaroğlu et al, 2021). D'autres pays africains, comme le Ghana, l'Éthiopie, le Congo et la Guinée, peuvent souffrir d'une graisse similaire en raison des taux de migration élevés des personnes et de la population de la faune indigène. La pandémie Corona a provoqué une importante absence de soins médicaux, en outre, l'épidémie de COVID-19 a entraîné une augmentation significative de la charge de travail des membres du personnel hospitalier, affectant la gestion des patients (Çavdaroğlu et al, 2021).

L'énorme augmentation en Afrique depuis le début des années 1980 reflète une rupture majeure des mesures de lutte contre la fièvre jaune. Ce dernier est principalement dû à un échec des programmes de vaccination et de lutte contre les moustiques. Ainsi, dans la plupart des cas chez les enfants de moins de 15 ans, qui ont reçu des vaccinations de routine, les programmes ont été abandonnés (Mutebi \& Barrett, 2020). Au cours des trois dernières années, seulement dans cinq pays d'Afrique de l'Ouest (Nigéria, Côte d'Ivoire, Libéria, Sénégal et Guinée), un total de 840 cas, dont 216 décès, ont été signalés. De grandes épidémies de fièvre jaune, notamment en Afrique orientale et centrale, se sont produites

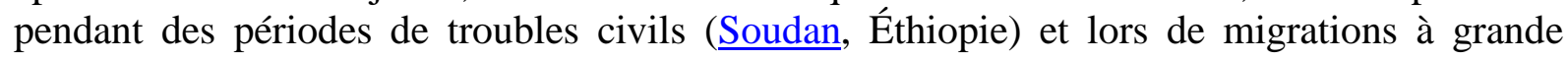


échelle vers des zones endémiques, par ex. à la recherche d'eau en période de sécheresse. En revanche, les épidémies en Afrique de l'Ouest se sont produites sans mouvement de masse similaire de personnes vers des zones hautement endémiques.

Figure 9 : Flambées et nombre de cas de fièvre jaune, HO 1996 - 2001

\begin{tabular}{|c|c|c|c|c|}
\hline Year & Country & Location & Cases & Deaths \\
\hline $1995-1996$ & Liberia & Buchanan & 359 & 9 \\
\hline 1996 & Benin & Atakora and Borgou & 86 & 65 \\
\hline 1996 & Ghana & Upper East Ghana & 27 & 5 \\
\hline 1997 & Liberia & Lofa County & 1 & 1 \\
\hline 1998 & Burkina Faso & Gaoua region & 2 & 1 \\
\hline 2000 & Nigeria & Kano State & 2 & \\
\hline 2000 & Liberia & Grand Cape Mount County & 102 & \\
\hline 2000 & Guinea & Northwest Guinea & 512 & 190 \\
\hline 2001 & Ivory Coast & & 203 & 21 \\
\hline 2001 & Guinea & & 18 & 2 \\
\hline 2001 & Liberia & & 3 & 3 \\
\hline Total & & & 1315 & 297 \\
\hline
\end{tabular}

Source: Mutebi \& Barrett, 2020, p.1460

La fièvre jaune donne un aperçu de l'évolution des interventions de santé publique. Les leçons apprises pour faire face à l'épidémie réelle de COVID-19 pourraient être tirées des implications de diplomatie sanitaire de la fièvre jaune sur la manière dont la santé mondiale et les relations internationales interagissent et s'influencent mutuellement. Dans le cadre du contrôle de la maladie, l'application précoce de la quarantaine s'est déplacée vers des approches plus coordonnées, qui incluent aujourd'hui les conditions d'admission des vaccins dans les pays. Les interventions de santé publique contre la fièvre jaune ont toujours été étroitement liées aux intérêts économiques et de la politique étrangère et ont souvent conduit à des tensions diplomatiques dans le passé, à commencer par les quarantaines (Vanderslott et Marks, 2020). Des études de cas en Ethiopie soulignent également le rôle que la lutte antivectorielle pourrait jouer dans l'atténuation de la transmission locale des maladies. L'étude met l'accent sur la nécessité urgente de renforcer les systèmes de surveillance des maladies et les capacités des laboratoires dans le pays pour faciliter des réponses plus rapides aux futures flambées de fièvre jaune et autres épidémies (Mulchandani, et al, 2019).

Figure 10 : Moustique Aedes aegypti - recherché pour la propagation du virus Zika «Tout d'abord, c'était la fièvre jaune, puis le paludisme. Zut médias de droite ! »

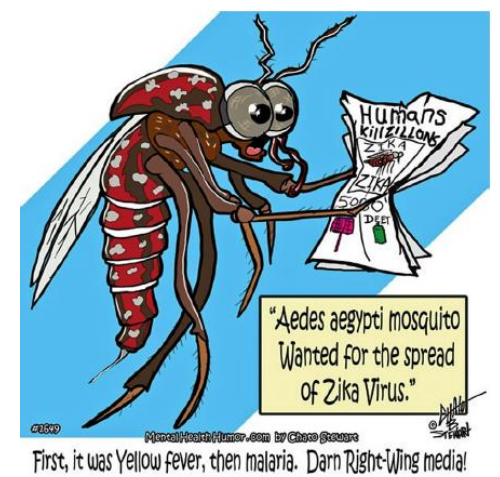

Source: Chato B. Stewart. L'histoire de Zika.

MentalHealthhumor.com, Saeed-2018, p. 147 


\section{$2.4 \mathrm{VIH} /$ sida}

Le virus de l'immunodéficience humaine $(\mathrm{VIH})$ ou le syndrome d'immunodéficience acquise (VIH / sida) a infecté plus de 60 millions de personnes au cours de la période de son plus grand viroulence (1983-2008) lorsque près de la moitié d'entre eux sont décédés (Oldstone, 2009: 252, chap.14 VIH ). On dit que l'origine du VIH est le contact étroit entre les humains et d'autres primates et / ou chauves-souris infectées à partir desquels la maladie a été transmise aux humains en Afrique de l'Ouest et centrale du début au milieu du 20e siècle (Sharp \& Hahn, 2011 ). Comme le VIH, qui s'est propagé aux humains à partir de singes, le coronavirus a sauté d'un animal, dans ce cas une chauve-souris. La théorie de travail est que Sars-Cov-2, le virus qui cause Covid-19, a probablement fait le saut aux gens via un mammifère, peut-être un pangolin abattu sur un marché humide de la ville chinoise de Wuhan (Pilling, 2020). Sont concernées non seulement les victimes directes, mais aussi leurs parents, amis et communautés qui doivent souffrir gravement.

L'épidémie de VIH / SIDA doit généralement être considérée comme un événement à longue vague par rapport aux autres épidémies. La plupart du temps, le véritable nombre de morts ne peut être estimé tant que l'impact n'a pas été pleinement constaté. Il peut s'écouler jusqu'à 20 ans avant que l'on puisse dire que l'épidémie mondiale a atteint un pic et / ou commencé à décliner (Whiteside, 2002). Comme pour la plupart des épidémies, le SIDA a le potentiel d'augmenter la pauvreté. La chaîne causale va des facteurs macro-économiques, qui aboutissent à la pauvreté à travers la communauté, le ménage et l'individu, jusqu'à la capacité du système immunitaire de l'individu. Autrement dit, la malnutrition protéino-énergétique, l'anémie ferriprive, la carence en vitamine A, toutes les conditions liées à la pauvreté, diminuent la résistance à la maladie. De plus, le comportement sexuel - l'un des principaux moteurs du VIH - est à son tour déterminé par des facteurs économiques, sociaux et culturels. Il existe de forts indicateurs que le SIDA a été à l'origine propagé par les chauffeurs de camion sur les principales routes à travers l'Afrique. Ils étaient généralement loin de chez eux pendant de longues périodes. Ils peuvent avoir des relations sexuelles avec une professionnelle du sexe parce qu'ils s'ennuient et sentent que leur travail est dangereux et qu'ils méritent donc une compensation. Les chauffeurs de camion sont souvent éloignés de leur femme et de leur famille, et ils peuvent subir la pression de leurs camarades pour qu'ils se livrent à des activités sexuelles, enfin, mais non des moindres, parce qu'ils ont l'argent nécessaire (Whiteside, 2002). Les professionnel(le)s du sexe, en revanche, étaient poussés par la pauvreté et le besoin de nourrir leur famille. De plus, une croissance économique rapide, la croissance concomitante de l'inégalité des revenus et la restructuration des secteurs économiques, avec une importance décroissante du secteur primaire (agriculture, sylviculture et minier) et plus de poids du secondaire (fabrication, électricité, gaz, eau et construction) et le secteur tertiaire (tous les services - banque, assurance, commerce et tourisme), accélèrent la propagation du sida par les perturbations, la privation, la maladie et la mort. Une croissance rapide a souvent perturbé les normes et les cultures traditionnelles parce que les gens ne peuvent pas s'adapter si vite aux changements (Whiteside, 2002). De ce fait, les personnes non qualifiées sont généralement les plus touchées. L'emploi formel diminue, le secteur informel augmente.

La pauvreté contribue à la propagation du VIH et le sida entraîne la pauvreté. En effet, l'épidémie est une crise de développement. Alors qu'un effort mondial est nécessaire pour faire progresser les apports techniques, comme les vaccins ou les traitements, pour aider à contrôler l'épidémie, il n'y a pas de réponse facile ou de solutions techniques et scientifiques 
simples pour faire face à sa propagation et à son impact. La réponse la plus efficace est un développement durable et équitable (Whiteside, 2002).

Figure 11 : Incidence du VIH en Afrique par pays, 2011
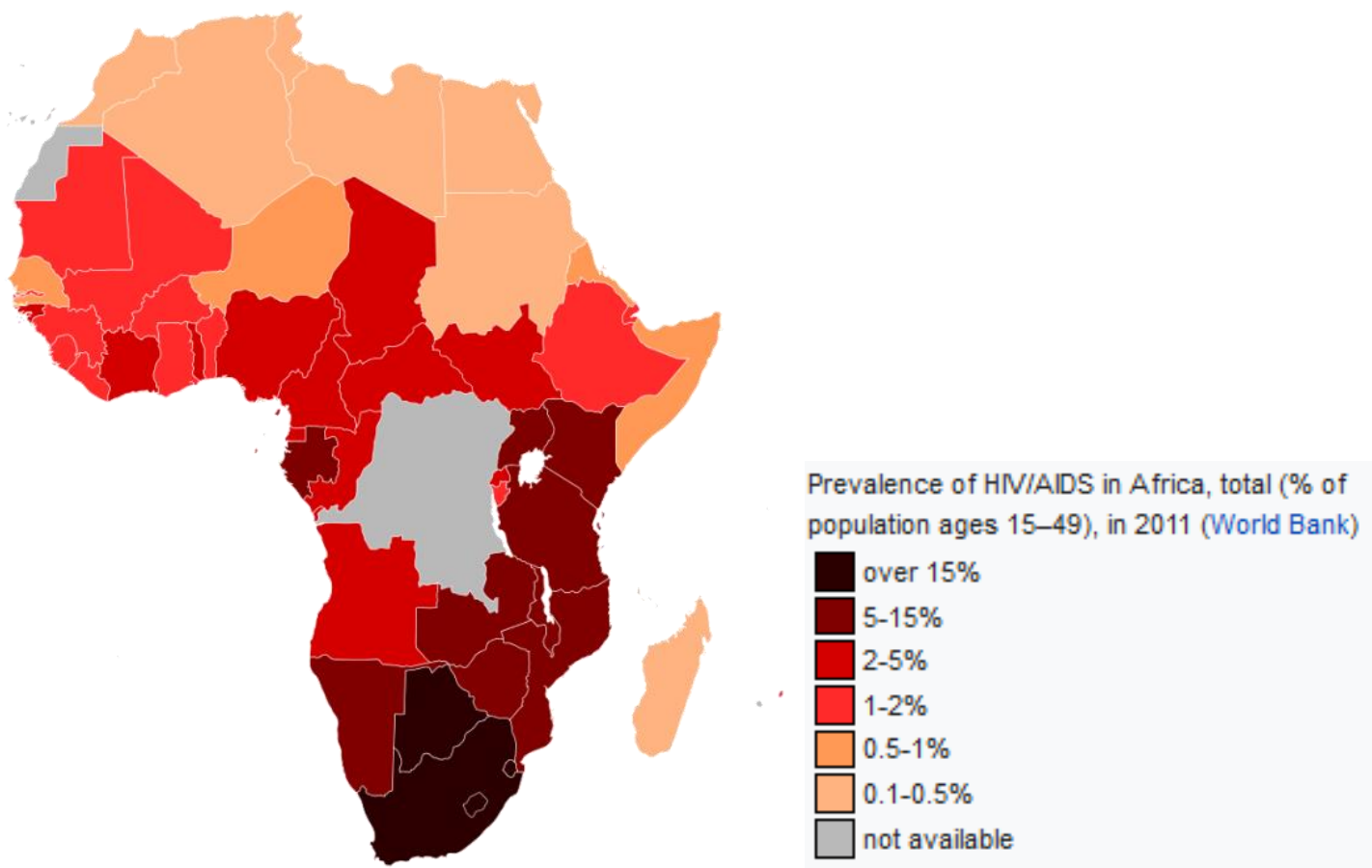

Données mises à jour. Banque mondiale VIH / sida en Afrique 2011 Source: HIV/AIDS in Africa, wikipedia

Pendant ce temps, la pharmacothérapie antivirus a réduit le taux de mortalité des deux tiers par rapport à celui des États-Unis dans les années 1990. La thérapie anti-VIH est un engagement à vie, le dernier, mais non le moindre, car il n'y a toujours pas de vaccin disponible. Selon les estimations des Nations Unies, actuellement plus de 34 millions d'humains sont infectés par le sida dans le monde, mais selon des estimations scientifiques bien informées, le nombre réel est probablement plus proche de 39 millions. Rien qu'en Afrique, le taux d'infection à VIH estimé est de $3 \%$ de la population adulte. Pour diverses raisons, les victimes ne demandent pas de soins médicaux pendant aussi longtemps que dix ans après l'infection initiale, alors qu'elles ont déjà un système immunitaire affaibli et sont gravement malades. En Afrique, plus d'une personne sur quarante, hommes et femmes, est infectée.

L'endiguement du sida dépend largement de la gouvernance; c'est-à-dire ce que les gouvernements font ou ne font pas pour leur peuple. Le bilan lamentable de l'Afrique du Sud dans la lutte contre le VIH dans les premiers stades de l'épidémie était largement dû à la négligence et au déni de tous les niveaux de gouvernement, y compris le président Jacob Zuma. Au contraire, d'autres gouvernements africains ont fourni au moins une éducation sur les comportements sexuels sans risque, le dépistage du VIH, l'utilisation de préservatifs et d'aiguilles stériles. Certains ont également fourni un traitement médicamenteux antirétroviral. Ces mesures ont considérablement inversé l'incidence et les décès dus au sida. 
Figure 12 : Prévalence du VIH dans le monde et en Afrique subsaharienne de 2001, 20082015 (15 à 49 ans).

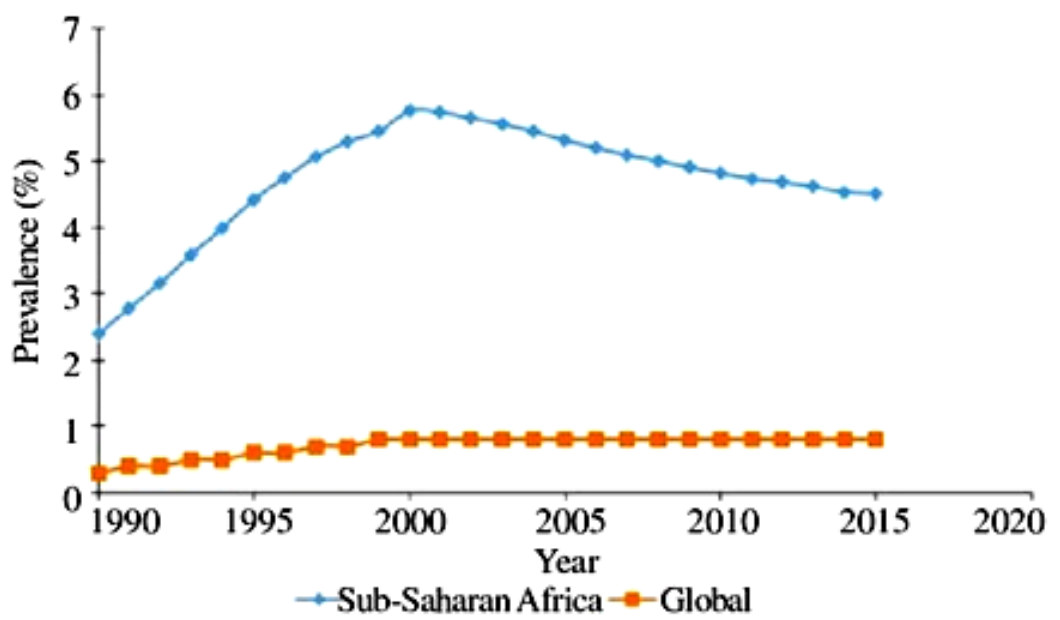

Source: Nweze \& Eke \& Nweze, 2017

Mais les normes culturelles coutumières sont difficiles à changer. La pratique d'avoir des relations sexuelles non protégées avec plusieurs partenaires persiste chez de nombreux Africains. Comme d'habitude, ce sont les pauvres et les vulnérables qui souffrent le plus. Les femmes africaines, par exemple, sont trois à quatre fois plus susceptibles que les hommes d'être infectées. La pauvreté et le manque d'installations de soins les obligent souvent à se prostituer pour survivre. De plus, les liens culturels traditionnels qui font que plusieurs femmes allaitent leurs nouveau-nés ainsi que les mutilations génitales féminines (MGF) sont durables. Les prestataires de soins de santé sont rares, avec environ un médecin pour près de 40000 personnes, contre un guérisseur traditionnel pour 400. Le manque de traitement et de médicaments adéquats pour la plupart des 15000 à 40000 enfants infectés au Cameroun, par exemple, a fait que seulement 400 ont reçu les médicaments dont ils avaient besoin en 2005 (Oldstone, 2009: 252, chap. $14 \mathrm{VIH}$ ).

Les ménages affectés par le sida avaient une charge de morbidité et de mortalité plus élevée. Les membres malades étaient moins susceptibles de récupérer ou d'effectuer des tâches quotidiennes. Au moins en Afrique du Sud, avec son secteur de la santé relativement avancé, l'utilisation des soins de santé publics pendant la maladie n'a apparemment pas imposé une charge financière directe majeure aux ménages (Booysen, 2002). Le coût du traitement et du transport liés à la recherche de soins de santé était relativement faible, ce qui prouvait que la gratuité des hôpitaux et des cliniques publiques, qui étaient les principaux piliers des soins de santé en Afrique du Sud, épargnait même les ménages les plus pauvres du coût direct majeur de la maladie. En revanche, les dépenses funéraires représentaient un fardeau substantiel avec une médiane de 4000 à 5000 rand dans la première vague de l'épidémie et de 3000 à 4000 rand dans la seconde. Les funérailles devaient généralement être financées par leurs propres revenus, soit de la famille élargie, soit des amis, et via une assurance obsèques usuelle. La maladie et la mort sont survenues principalement parmi les membres des ménages de la population économiquement active (âgés de 15 à 49 ans), ce qui souligne à nouveau l'effet néfaste de l'épidémie sur l'offre de main-d'œuvre dans les ménages touchés. 
Figure 13 : Caricature sur le déni du président de l'Afrique du Sud, Zuma, des dangers du VIH ${ }^{4}$

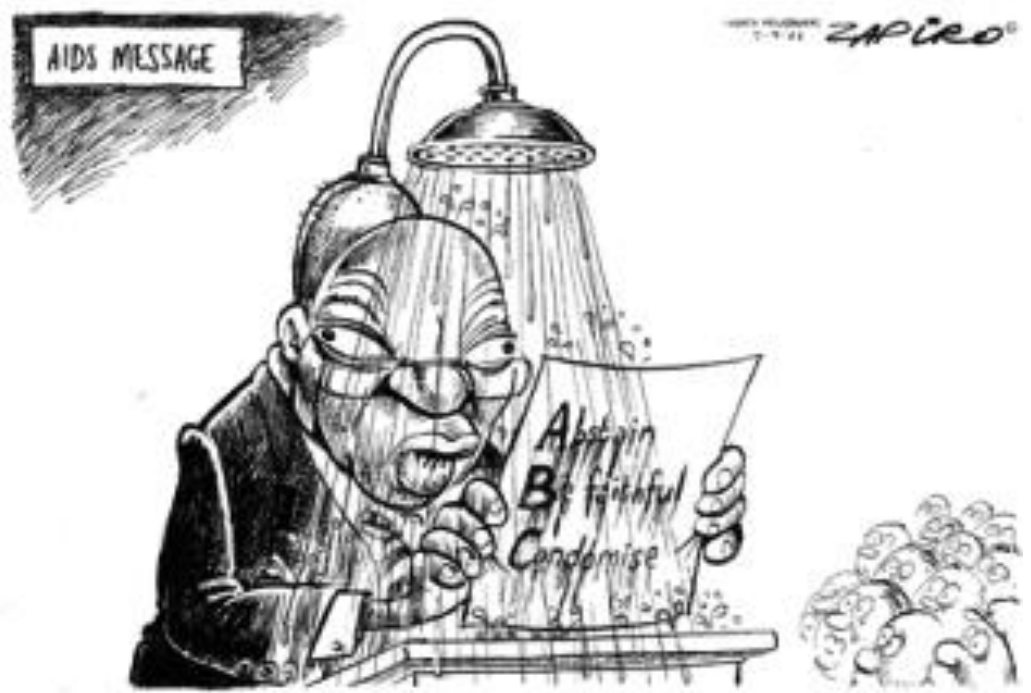

Source: Zapiro

La maladie et surtout la mortalité ont provoqué la migration principalement de personnes plus jeunes (c'est-à-dire des adolescents). Les personnes qui avaient quitté les ménages touchés étaient plus susceptibles de déménager dans des zones relativement proches de leur domicile, tandis que les personnes quittant les familles non touchées étaient plus susceptibles de déménager plus loin de leur domicile pour des raisons principalement liées à la migration normale dans le cas des ménages non affectés, à savoir emploi, changement de résidence, mariage ou éducation. Dans les ménages affectés, plus d'un tiers des membres ont déménagé pour des raisons de migration relativement rares, par ex. rester avec des parents, d'autres membres de la famille ou des amis, ou en raison d'une maladie ou d'un décès (Booysen, 2002). Le départ des personnes des ménages affectés représentait une perte relativement plus importante en termes de contributions monétaires abandonnées que dans le cas des ménages non affectés.

Les ménages touchés étaient plus pauvres que les familles non touchées, qu'ils soient mesurés en termes de revenu et de dépenses du ménage ou au niveau individuel. Les ménages touchés étaient également plus dépendants des sources de revenus non liées à l'emploi, qui consistaient principalement en des subventions publiques, mais incluaient également la valeur de leur propre production et consommation de subsistance, tandis qu'une plus petite proportion de leurs revenus était constituée de revenus d'emploi. Les ménages affectés dépensent également moins pour la nourriture que les ménages non affectés, à la fois en termes globaux et par habitant. À long terme, cela peut avoir contribué à la malnutrition parmi les membres du ménage. Les réponses les plus fréquentes des ménages aux crises financières semblent être l'emprunt, suivi de l'utilisation de l'épargne et de la vente d'actifs. Dans plus de

\footnotetext{
${ }^{4}$ La pomme de douche sur laquelle le président de la SA, Zuma, a été dépeinte par Zapiro pour illustrer la « réputation de Zuma en tant que démagogue déshonoré et chauvin qui ne peut pas contrôler ses besoins sexuels et pense qu'une douche protégerait contre le sida »-Zuma a été accusé de viol en 2005, ce qu'il était acquitté par la suite. Il a déclaré que les relations sexuelles étaient consensuelles et qu'il savait que les femmes avec lesquelles il avait eu la liaison étaient séropositives. Il a déclaré aux journalistes que pour minimiser le risque de sida, il avait pris une douche. Cela a provoqué une controverse généralisée alors que les défenseurs de la prévention du VIH se disputaient que le seul moyen d'éviter la propagation du VIH était l'abstinence et la pratique de rapports sexuels protégés et Zuma ne faisait pas la promotion de la vérité. (Yoo, Philemon (2015): Jacob Zuma Political Cartoons by Zapiro. Pyoo2, 29 janvier 2015) - Zapiro, dessinateur de renommée internationale, né sous le nom de Jonathan Shapiro au Cap en 1958. site web: http://www.zapiro.com/ about / About_Zapiro /, consulté le 29 avril 2021.
} 
$60 \%$ des cas, de l'argent a été emprunté à des parents et amis, tandis qu'à peine $20 \%$ des prêts ont été obtenus auprès de prêteurs ou de micro-prêteurs. L'argent emprunté était généralement utilisé pour acheter de la nourriture. Cependant, une plus grande proportion de familles touchées ont indiqué qu'elles l'utilisaient pour les funérailles et les frais médicaux, tandis que la majorité des familles non touchées ont indiqué qu'elles utilisaient l'argent pour payer les études, les vêtements et d'autres dépenses. Il en va de même pour les quantités considérables de désépargne. Les ménages touchés ont utilisé 21 (vague I) et 46 (vague II) mois d'épargne courante, tandis que les familles non touchées n'ont utilisé que 5 mois d'épargne courante. Faire face financièrement de cette manière était également plus probable dans les zones rurales que dans les zones urbaines, étant donné que les zones rurales sont généralement plus pauvres que les zones urbaines. Un décès impliquait une charge financière beaucoup plus lourde pour un ménage que la maladie. Dans le pire des cas, la charge pesant sur les ménages affectés représentait 3,4 à 4,3 fois le revenu mensuel moyen des ménages et 5,7 à 7,2 fois les dépenses mensuelles moyennes des ménages (Booysen, 2002).

Les résultats d'une autre étude de cas sur l'impact du VIH / SIDA sur les agricultrices et leurs ménages dans l'État d'Enugu (sud-est du Nigéria) ont également un impact socio-économique négatif significatif, en particulier sur les femmes et les plus vulnérables (Ugwu, 2009). Les principaux effets ont été la perte de main d'œuvre agricole féminine, la réduction de la production agricole et des revenus des ménages, l'augmentation du fardeau familial ainsi que la perte des biens familiaux et des droits des femmes. L'étude a souligné la nécessité d'un paradigme sexospécifique pour le développement agricole et rural étant donné que les femmes étaient au centre de l'épidémie de VIH / sida au Nigéria comme généralement en Afrique.

\subsection{Choléra}

Selon les estimations de l'OMS, il y a chaque année 1,3 à 4,0 millions de cas de choléra et 21 000 à 143000 décès dus au choléra dans le monde. Rien qu'en Afrique, 40 à 80 millions de personnes vivent dans des zones sensibles au choléra. Le changement climatique, l'urbanisation et la croissance démographique augmenteront probablement le risque de choléra dans les années à venir. Selon ONU Habitat, la part des Africains vivant dans les zones urbaines devrait passer de $36 \%$ en 2010 à $50 \%$ d'ici 2030. En conséquence, le nombre d'habitants de bidonvilles en Afrique subsaharienne augmentera avec la croissance dans la région. population urbaine. En 2010, déjà $60 \%$ de la population urbaine des villes subsahariennes vivait dans des bidonvilles. La pression sur les infrastructures va donc continuer à augmenter, ce qui risque d'aggraver l'accès à l'eau potable et à l'assainissement de base pour les populations les plus vulnérables. Par conséquent, une stratégie mondiale de lutte contre le choléra, «Ending Cholera: a global roadmap to 2030 » a été lancée en 2017 pour réduire les décès dus au choléra de 90 \% (OMS, 2021: Ending Cholera - A Global Roadmap to 2030. WHO, Global Task Force on Contrôle du choléra).

Il y a eu 499447 cas de choléra et 2990 décès en 2018, selon les rapports de 34 pays. Néanmoins, le nombre de cas de choléra a diminué de $60 \%$ dans le monde en 2018, et l'OMS a fait allusion à une tendance encourageante en matière de prévention et de contrôle du choléra dans les principaux points chauds de choléra du monde, notamment en Haïti, en Somalie et en République démocratique du Congo. Selon l'OMS, la diminution dans plusieurs grands pays où le choléra est endémique a démontrer l'engagement accru des pays dans les efforts mondiaux pour ralentir et prévenir les flambées de choléra. Cela a montré le rôle vital des campagnes de vaccination de masse contre le choléra. Cependant, la solution à long terme 
pour mettre fin au choléra consiste à améliorer l'accès à l'eau potable et à fournir un assainissement et une hygiène adéquats. Alors que les flambées sont toujours en cours dans divers pays, le nombre de cas représente une tendance à la baisse significative de la transmission du choléra qui s'est poursuivie en 2019 («Baisse des cas de choléra dans le monde, alors que les principaux pays d'endémie rapportent des progrès dans la lutte contre le choléra », OMS, 19 décembre 2019).

Néanmoins, le choléra reste un problème majeur de santé publique dans de nombreux pays africains. En Afrique subsaharienne, 190549 cas et 2231 décès ont été signalés en 2014 selon l'Organisation mondiale de la santé (OMS). D'autres estimations éclairées placent le nombre réel de décès significativement plus élevé jusqu'à 95000 par an (Bwire et al, 2017). Au cours des vingt dernières années, l'Afrique subsaharienne, et en particulier la région des Grands Lacs, a souffert de la charge de morbidité la plus élevée.

Les fortes demandes des services de santé africains, surchargés par la pandémie de VIH / SIDA, ont limité le financement de la lutte contre le choléra. En outre, le choléra n'est qu'une des nombreuses maladies diarrhéiques qui, en tant que groupe, restent la deuxième cause de mortalité et de morbidité infantile dans le monde en développement. Le biotype actuel du choléra, Vibrio cholerae El Tor, est établi en Afrique depuis 1972. Certaines des plus grandes épidémies se sont produites au Mozambique, avec des pics en 1993 et 1998.

Au-delà des risques inacceptables pour la vie et les moyens d'existence, ces menaces épidémiques sont des indicateurs d'autres problèmes de développement, c'est-à-dire de la relation étroite entre pauvreté et maladies infectieuses. Par conséquent, il est nécessaire de disposer d'évaluations et de réponses plus intégrées des risques de maladie qui pourraient faire face à des problèmes de sécurité sanitaire et de réduction de la pauvreté (Collins et al, 2006). Les gens sont vulnérables sur le plan socio-économique lorsqu'il n'y a pas de sécurité des moyens de subsistance, lorsque les droits sont refusés, à la suite d'un conflit et de catastrophes environnementales. Les grandes catastrophes humaines, en particulier les épidémies de maladies infectieuses à évolution rapide ou lente, ont un impact plus lourd sur les pauvres (Collins et al, 2006).

Le choléra diffère de nombreuses autres formes de diarrhée en ce qu'il peut provoquer un nombre élevé de cas et de décès sur une très courte période. Par exemple, des épidémies extrêmes de choléra ont eu lieu dans un camp de réfugiés rwandais à Goma en 1994 où, en l'espace de quelques semaines, il y avait 70000 cas de choléra et environ 12000 décès, soit un taux de mortalité de $17,1 \%$. En outre, si le choléra et les maladies diarrhéiques se développent dans des conditions de pauvreté, ils peuvent être encore accentués par des croyances, des attitudes et des pratiques d'hygiène propres à une région ou à une culture particulière. La reconnaissance des influences socio-économiques et comportementales ainsi que des risques pathogènes et environnementaux révèle des risques dont la nature varie d'un endroit à l'autre au fil du temps. Par conséquent, de nombreux indicateurs de gestion du risque de choléra sont également des indicateurs d'autres risques pour la santé (Collins et al, 2006). 
Figure 14 : Carte de l'épidémie de choléra de 2008-2009 en Afrique subsaharienne montrant les statistiques au 12 février 2009

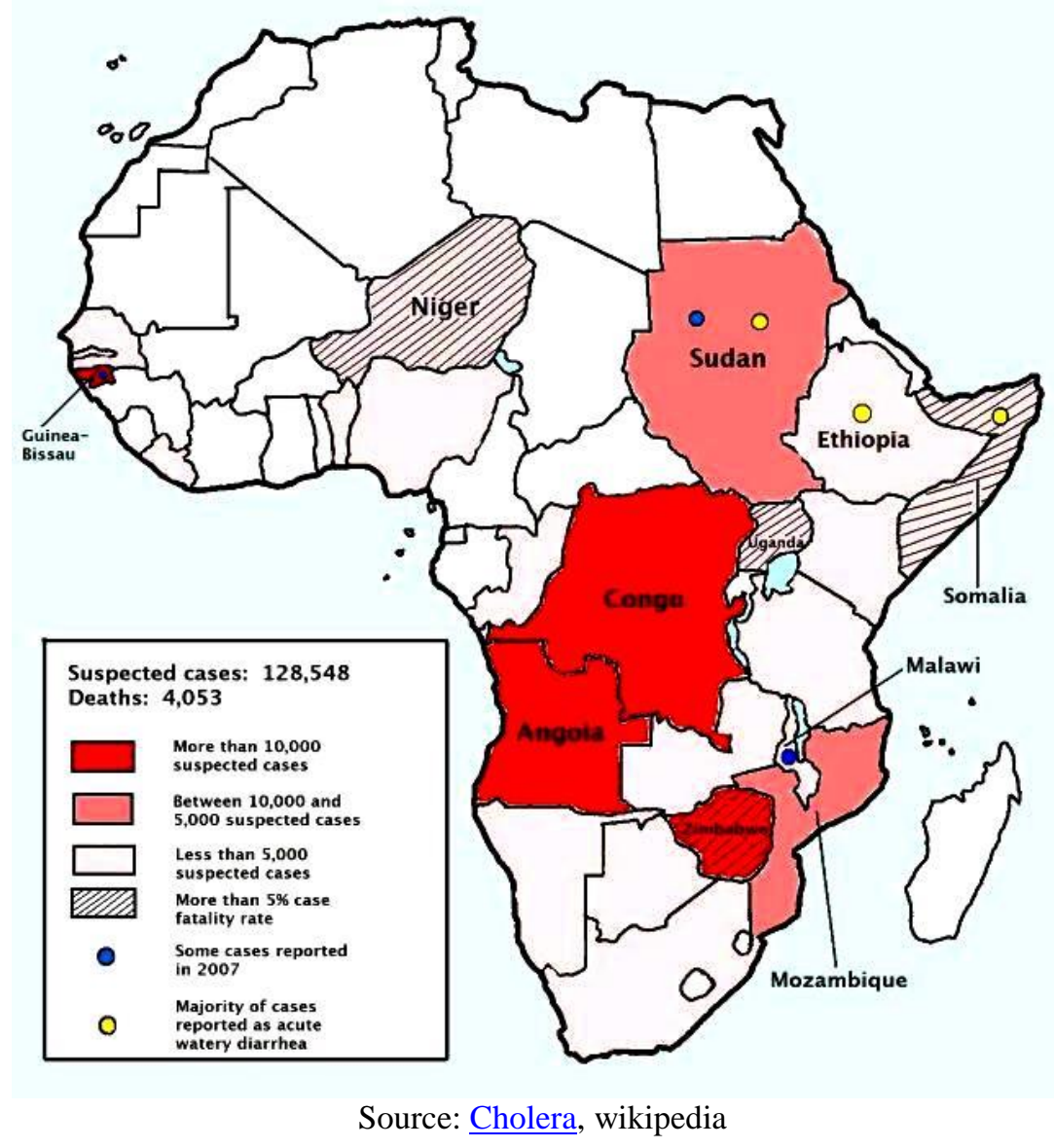

\subsection{1. Étude de cas sur l'impact socio-économique et la politique de l'épidémie de choléra de 2008/09 au Zimbabwe}

L'épidémie de coléra au Zimbabwe a commencé en août 2008. Elle a éclaté dans les communes pauvres et à forte densité de la région métropolitaine de Harare. L'épidémie s'est rapidement propagé à travers le pays et a finalement franchi les frontières des pays voisins. En moins de dix mois, il a contanimé plus de 100000 victimes, faisant près de 5000 morts. Elle est ainsi devenue l'épidémie de choléra la plus importante et la plus étendue de l'histoire africaine enregistrée (Chigudu, 2017).

La thèse de Chigudu «examine la politique de l'épidémie catastrophique de choléra au Zimbabwe en 2008/09, qui a causé un nombre sans précédent de 98000 cas et plus de 4000 décès. Sur le plan épidémiologique, l'épidémie peut s'expliquer par la panne des systèmes d'eau et d'assainissement du pays. Une telle lecture, cependant, dément les processus politiques, économiques et historiques byzantins qui ont précipité le dysfonctionnement des systèmes d'eau, qui délimitent le modèle socio-spatial de l'épidémie et qui expliquent la réponse fragmentée et inadéquate du système de santé national. Les facteurs causaux complexes et les conséquences profondes de l'épidémie indiquent que le choléra est un prisme unique à travers lequel on peut voir différents phénomènes politiques, y compris les dilemmes et les contradictions du changement politique, de l'ordre bureaucratique, de l'humanitarisme, de la crise et de la citoyenneté au Zimbabwe ». Sur la base de recherches approfondies sur le 
terrain, Chigudu affirme en premier, «que l'épidémie de choléra au Zimbabwe était une catastrophe «d'origine humaine ». C'était la dernière étape des processus à la fois dépendant du chemin et contingents enracinés dans des questions d'économie politique telles que l'effondrement des infrastructures de santé publique, l'échec des stratégies de subsistance et la répression violente. Deuxièmement, Chigudu soutient que «le choléra a reproduit et exacerbé une multiplicité des crises politiques liées à la légitimité de l'État zimbabwéen, la nature des inégalités structurelles dans la société zimbabwéenne et les failles fondamentales de la réponse humanitaire mondiale aux épidémies». Troisièmement, Chigudu examine «la myriade de significations, de souvenirs et de récits que l'épidémie a laissés dans son sillage dans les institutions publiques et dans la vie civique». Enfin, Chigudu soutient que «le choléra a été inscrit dans la mémoire historique comme une crise sanitaire, une crise politicoéconomique et une crise sociale ainsi qu'une crise des attentes, de l'histoire et de l'identité sociale » (Chigudu, 2017).

Figure 15 : « Je demand la permission d'arrêter tous les malades du choléra, Votre Excellence » 5

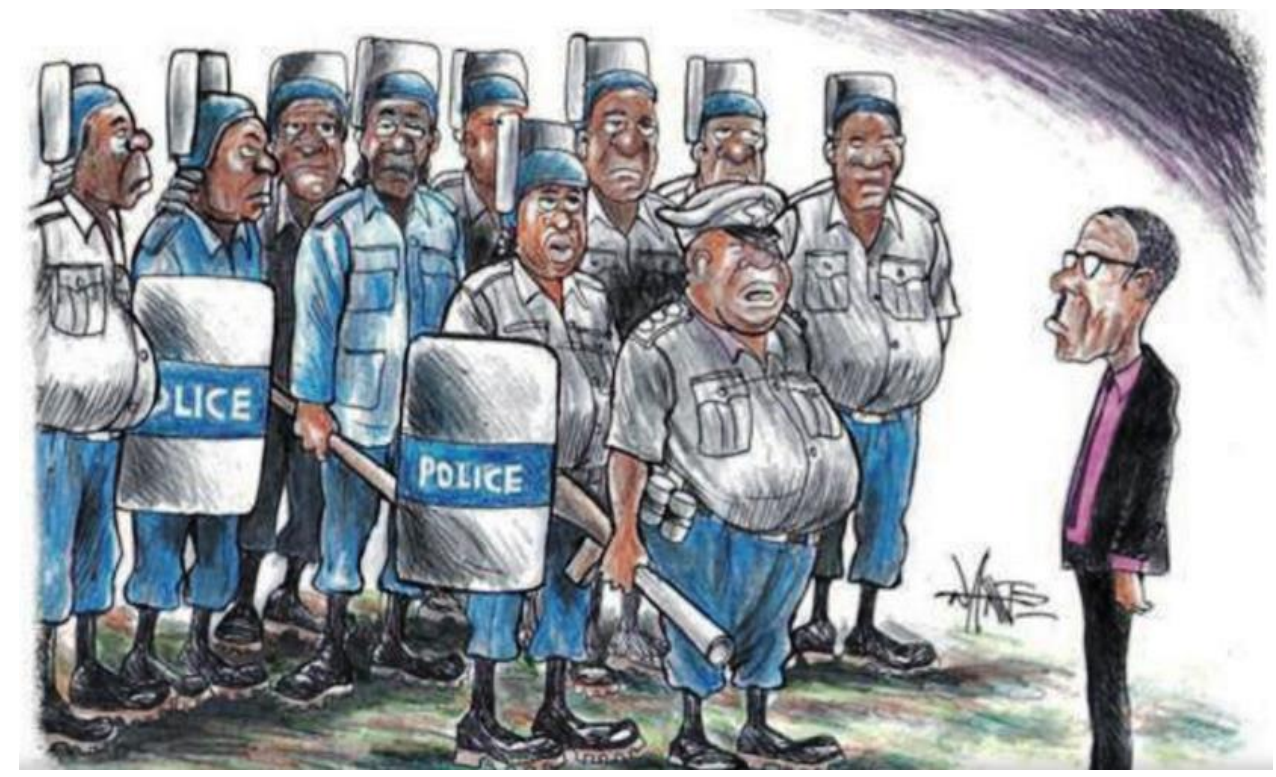

Source: Chigudu, S. (2017).

«État d'urgence »: la politique de l'épidémie de choléra au Zimbabwe, 2008/09

[Thèse de doctorat]. Université d'Oxford

\footnotetext{
${ }^{5}$ Tony Namates caricature satirique d'un commandant de police demandant la permission au président Robert Mugabe d'arrêter tous les malades du choléra. Son dessin animé a été initialement publié par le quotidien The Guardian, Harare, le 27 décembre 2008. - Tony Namate est un dessinateur zimbabwéen qui a acquis une reconnaissance internationale pour ses commentaires cinglants sur les questions sociopolitiques au Zimbabwe et au-delà (Tony Namate, wikipedia).
} 


\section{Leçons apprises}

1) Modèles d'alerte précoce et surveillance rapide et durable des pandémies et des points chauds potentiels, même en période postépidémique

2) Encourager l'auto-assistance ainsi que des stratégies de survie autochtones viables et des médicaments ethno-vétérinaires pour faire face à l'épidémie dans les communautés de victimes. Les Africains pauvres dépendent en grande partie de leur connaissance intime de l'environnement transmise de génération en génération pour lutter contre l'épidémie.

3) Diffuser des stratégies de survie modèle et des médicaments traditionnels qui se sont avérés efficaces dans le passé ou dans d'autres régions

4) Se concentrer sur :

(1) Des équipes mobiles pour lutter plus efficacement contre la pandémie dans ses hotspots

(2) Hotspots de pandémie dans les quartiers urbains des pauvres et des défavorisés (réfugiés, migrants, etc.) où de nombreuses victimes vivent à proximité les unes des autres, sans accès aux moyens de protection, aux médicaments et aux médicaments

(3) Renforcement des capacités du personnel de soins de santé primaires pour diagnostiquer et sensibiliser davantage à la maladie. De même, les personnes à risque devraient être habilitées à les aider à reconnaître tôt les symptômes de la maladie et à être réintégrées dans la communauté (Bukachi et al-2007).

(4) En tant que stratégie à long terme, l'amélioration de l'éducation et la réduction de la pauvreté devraient contribuer à la prévention, au contrôle et à l'élimination des épidémies (Bwire et al, 2017).

5) En effet, les épidémies sont le plus souvent une crise de développement. La réponse la plus efficace est un développement durable et équitable (Whiteside, 2002). 


\section{Appendice 1}

\section{(1) Les épidémies les plus graves d'Afrique}

\section{- $\quad$ Pandémie COVID-19 en Afrique}

- Il a été confirmé que la pandémie de COVID-19 s'était propagée à l'Afrique le 14 février 2020, le premier cas confirmé étant annoncé en Égypte. Le premier cas confirmé en Afrique subsaharienne a été annoncé au Nigéria fin février. En l'espace de trois mois, le virus s'était propagé sur tout le continent, car le Lesotho, dernier État souverain africain à être resté indemne du virus, a signalé un cas le 13 mai. Au 26 mai, il est apparu que la plupart des pays africains connaissaient une transmission communautaire, bien que la capacité de dépistage soit limitée. La plupart des cas importés identifiés sont arrivés d'Europe et des États-Unis plutôt que de Chine, pays d'origine du virus. On pense qu'il existe une sous-déclaration généralisée dans de nombreux pays africains dotés de systèmes de santé moins développés. De nouvelles souches du virus ont été découvertes en décembre 2020 en Afrique du Sud et au Nigéria, en plus de la variante de la lignée B.1.1.7 signalée au Royaume-Uni en septembre. Impact: les experts s'inquiètent de la propagation du COVID-19 en Afrique, car de nombreux systèmes de santé sur le continent sont inadéquats, rencontrant des problèmes tels que le manque d'équipement, le manque de financement, la formation insuffisante des travailleurs de la santé et la transmission de données inefficace. On craignait que la pandémie ne soit difficile à maîtriser en Afrique et qu'elle ne cause d'énormes problèmes économiques si elle se propageait largement. La pandémie a eu un impact économique sérieux dans les pays africains, endommageant la classe moyenne croissante du continent et menaçant d'augmenter les taux de pauvreté et d'extrême pauvreté. ( « Pandémie COVID-19 en Afrique », Wikipédia)

\section{- VIH / SIDA en Afrique:}

- Le VIH / SIDA est né en Afrique au début du XXe siècle et est un problème majeur de santé publique et une cause de décès dans de nombreux pays africains. Les taux de SIDA varient considérablement même si la majorité des cas sont concentrés en Afrique australe. Bien que le continent abrite environ 15,2\% de la population mondiale, plus des deux tiers du total des personnes infectées dans le monde - quelque 35 millions de personnes - étaient des Africains, dont 15 millions sont déjà décédés. L'Afrique subsaharienne représentait pour elle seule environ 69 \% de toutes les personnes vivant avec le VIH et $70 \%$ de tous les décès dus au sida en 2011 les âges de 20 et 49 ans environ vingt ans. En outre, l'espérance de vie dans de nombreuses régions d'Afrique est en baisse, en grande partie à cause de l'épidémie de VIH I sida, l'espérance de vie dans certains pays atteignant jusqu'à trente-quatre ans.

- Les pays d'Afrique du Nord et de la Corne de l'Afrique ont des taux de prévalence significativement plus faibles, car leurs populations sont généralement engagées dans moins de modèles culturels à haut risque qui favorisent la propagation du virus en Afrique subsaharienne. L'Afrique australe est la région la plus touchée du continent. En 2011, le VIH a infecté au moins 10 \% de la population au Bénin, au Botswana, au Lesotho, au Malawi, au Mozambique, en Namibie, en Afrique du Sud, à Eswatini, en Zambie et au Zimbabwe.

- En réponse, un certain nombre d'initiatives ont été lancées dans diverses régions du continent pour éduquer le public - notamment les jeunes - sur le VIH / SIDA. Parmi ceux-ci figurent des programmes de prévention combinée, considérés comme l'initiative la plus efficace, comme l'abstinence (qui s'est avérée difficile dans une société musulmane), être fidèle, utiliser une campagne de préservatifs et les programmes de sensibilisation de la Desmond Tutu HIV Foundation.

- Le nombre de personnes séropositives en Afrique recevant un traitement antirétroviral en 2012 était plus de sept fois le nombre de personnes recevant un traitement en 2005, avec près d'un million de plus l'année précédente: Le nombre de décès liés au sida en Afrique subsaharienne en 2011,33\% de moins que le nombre de 2005. Le nombre de nouvelles 
infections à VIH en Afrique subsaharienne en 2011 était de $25 \%$ inférieur à celui de 2001.

[ «VIH en Afrique », Wikipédia))

\section{- Ebola en Afrique de l'Ouest}

- La maladie a été identifiée pour la première fois en 1976, lors de deux flambées simultanées: l'une à Nzara (une ville du Soudan du Sud) et l'autre à Yambuku (République démocratique du Congo), un village près de la rivière Ebola d'où la maladie tire son nom. Les flambées de MVE se produisent par intermittence dans les régions tropicales de l'Afrique subsaharienne. De 1976 à 2012, l'Organisation mondiale de la santé rapporte 24 flambées impliquant 2387 cas et 1590 décès. La plus importante épidémie à ce jour a été l'épidémie en Guinée (Conacry) et dans d'autres régions d'Afrique de l'Ouest, qui s'est produite de décembre 2013 à janvier 2016, avec 28646 cas et 11323 décès. L'Afrique a commencé en République démocratique du Congo en mai 2017 et 2018. En juillet 2019, l'Organisation mondiale de la santé a déclaré que l'épidémie d'Ebola au Congo était une urgence sanitaire mondiale. ( « Ebola », Wikipedia)

\section{- $\quad$ Fièvre jaune}

- On estime que $90 \%$ des infections de fièvre jaune surviennent sur le continent africain. En 2016, une importante épidémie est apparue en Angola et s'est propagée aux pays voisins avant d'être contenue par une campagne de vaccination massive. En mars et avril 2016, 11 cas importés du génotype de l'Angola chez des ressortissants chinois non vaccinés ont été signalés en Chine, la première apparition de la maladie en Asie dans l'histoire enregistrée.

- L'analyse phylogénétique a identifié sept génotypes de virus de la fièvre jaune, et on suppose qu'ils sont différemment adaptés aux humains et au vecteur A. aegypti. Cinq génotypes (Angola, Afrique centrale / orientale, Afrique de l'Est, Afrique de l'Ouest I et Afrique de l'Ouest II) ne se trouvent qu'en Afrique. Le génotype I de l'Afrique de l'Ouest se trouve au Nigeria et dans la région environnante. Le génotype I de l'Afrique de l'Ouest semble être particulièrement infectieux, car il est souvent associé à des épidémies majeures. Les trois génotypes trouvés en dehors du Nigeria et de l'Angola se produisent dans des zones où les épidémies sont rares. Deux foyers, au Kenya (1992-1993) et au Soudan (2003 et 2005), impliquaient le génotype d'Afrique de l'Est, qui n'avait pas été détecté au cours des 40 années précédentes. («Fièvre jaune », Wikipedia)

\section{- Grippe espagnole}

- Deuxième vague meurtrière de la fin de 1918: la deuxième vague a commencé dans la deuxième quinzaine d'août, se propageant probablement à Boston et à Freetown, en Sierra Leone, par des navires de Brest, où elle était probablement arrivée avec des troupes américaines ou des recrues françaises pour l'entraînement naval. Du Boston Navy Yard et du Camp Devens (renommé plus tard Fort Devens), à environ 30 miles à l'ouest de Boston, d'autres sites militaires américains furent bientôt affligés, tout comme les troupes transportées en Europe. Aidé par les mouvements de troupes, il s'est répandu au cours des deux mois suivants dans toute l'Amérique du Nord, puis en Amérique centrale et du Sud, atteignant également le Brésil et les Carä̈bes à bord de navires. En juillet 1918, l'Empire ottoman a vu ses premiers cas chez certains soldats. De Freetown, la pandémie a continué de se propager à travers l'Afrique de l'Ouest le long de la côte, des rivières et des chemins de fer coloniaux, et des têtes de ligne vers les communautés plus éloignées, tandis que l'Afrique du Sud l'a reçue en septembre sur des navires ramenant les membres du South African Native Labour Corps. de France. De là, il s'est répandu autour de l'Afrique australe et au-delà du Zambèze, atteignant l'Éthiopie en novembre. (« Grippe espagnole », Wikipedia)

\section{- Plague / Peste Noire}

- La peste noire (également connue sous le nom de peste, de grande mortalité) était une pandémie de peste bubonique survenue en Afro-Eurasie de 1346 à 1353. C'est la pandémie la plus mortelle enregistrée dans l'histoire humaine, causant la mort de 75 à 200 millions de personnes en Eurasie et en Afrique du Nord, avec un pic en Europe de 1347 à 1351. La peste 
bubonique est causée par la bactérie Yersinia pestis, mais elle peut aussi provoquer des épidémies septicémiques ou pneumoniques. La peste noire a été le début de la deuxième pandémie de peste. La peste a créé des bouleversements religieux, sociaux et économiques, avec des effets profonds sur le cours de l'histoire européenne. De Crimée, il était très probablement transporté par des puces vivant sur les rats noirs qui voyageaient sur des navires négriers génois, se propageant à travers le bassin méditerranéen et atteignant l'Afrique (du Nord), l'Asie occidentale et le reste de l'Europe.

○ Troisième pandémie de peste 12-15 millions, 1855-1960, dans le monde (« Peste noire », Wikipédia)

\section{- Cholera}

- Cinquième pandémie de choléra, 1881-1896 Asie, Afrique, Europe, Amérique du Sud

- Sixième pandémie de choléra 1899-1923, Europe, Asie, Afrique, décès par choléra $800000+$

- 2001 Épidémie de choléra au Nigéria, 2001, Nigéria, Choléra, environ 400+ décès

- 2001 Épidémie de choléra en Afrique du Sud, 2001, Afrique du Sud, Choléra, 139 décès

- 2006 Épidémie de choléra à Luanda, 2006, Luanda, Angola, Choléra, 1200+

- 2007 Épidémie de choléra en Éthiopie, 2007, Éthiopie, Choléra, 684 décès

- Épidémie de choléra au Tchad en 2008, 2008, décès au Tchad 123

- Épidémie de choléra au Zimbabwe de 2008-09, 2008-2009, Zimbabwe, 4293 décès

\section{- Onchocercose, cécité des rivière}

- Onchocerca est originaire d'Afrique et a été exporté vers les Amériques par la traite des esclaves, dans le cadre de l'échange colombien qui a introduit d'autres maladies du vieux monde telles que la fièvre jaune dans le Nouveau Monde. Les résultats d'une étude phylogénétique au milieu des années 1990 concordent avec une introduction au Nouveau Monde de cette manière. Les souches américaines d'ADN sont identiques aux souches de savane en Afrique de l'Ouest.

- Environ 15,5 millions de personnes sont infectées par la cécité des rivières. Environ 0,8 million ont une certaine perte de vision à cause de l'infection. La plupart des infections surviennent en Afrique subsaharienne. En 1915, le médecin Rodolfo Robles a d'abord lié le ver à une maladie oculaire. Elle est répertoriée par l'Organisation mondiale de la santé (OMS) comme une maladie tropicale négligée. (Wikipédia).

- Différents programmes de lutte visent à empêcher l'onchocercose d'être un problème de santé publique. Le premier était le Programme de lutte contre l'onchocercose (OCP), qui a été lancé en 1974 et, à son apogée, couvrait 30 millions de personnes dans 11 pays. Grâce à l'utilisation de pulvérisations larvicides sur les rivières à débit rapide pour contrôler les populations de mouches noires et, à partir de 1988, à l'utilisation de l'ivermectine pour traiter les personnes infectées, l'OCP a éliminé l'onchocercose en tant que problème de santé publique. Aucun vaccin pour prévenir l'onchocercose chez l'homme n'est disponible.

- Aucun pays africain n'a jusqu'à présent vérifié l'élimination de l'onchocercose, mais le traitement a été arrêté dans certaines régions (par exemple au Nigéria), à la suite d'évaluations épidémiologiques et entomologiques indiquant qu'aucune transmission en cours n'a pu être détectée. En 2015, l'OMS a facilité le lancement d'un programme d'élimination au Yémen qui a ensuite été suspendu en raison du conflit.

- Le gouvernement ougandais, travaillant avec le programme de cécité des rivières du Centre Carter depuis 1996, a changé de stratégie pour la distribution de Mectizan, le principal médicament pour le traitement de la cécité des rivières. Le système de distribution des volontaires, dominé par les hommes, n'a pas réussi à tirer parti des structures et des rôles de parenté traditionnels. Le programme est passé en 2014 d'équipes de santé villageoises à des distributeurs communautaires, sélectionnant principalement des femmes dans le but de s'assurer que tous les membres du cercle de leur famille et de leurs amis reçoivent des 
informations sur la cécité des rivières et le Mectizan. ( Onchocercose, cécité des rivières », wikipedia)

- L'élimination de l'onchocercose humaine apporterait une contribution significative à l'objectif de développement durable (ODD) 3.3, qui comprend un appel à mettre fin à l'épidémie de maladies tropicales négligées (MTN) d'ici 2030 (Élimination de l'onchocercose humaine: rapport d'étape, 2019-2020, OMS , 2020).

\section{- Poliomyélite}

- Afrique: vaccination contre la poliomyélite en Egypte

- En 2003, dans le nord du Nigéria - un pays qui à l'époque était considéré comme provisoirement exempt de polio - une fatwa a été émise déclarant que le vaccin antipoliomyélitique était conçu pour rendre les enfants stériles. Par la suite, la poliomyélite est réapparue au Nigéria et s'est propagée de là à plusieurs autres pays. En 2013, neuf agents de santé administrant le vaccin antipoliomyélitique ont été pris pour cible et tués par des hommes armés à moto à Kano, mais c'était la seule attaque. Les chefs traditionnels et religieux locaux et les survivants de la polio ont travaillé pour relancer la campagne, et le Nigéria a été retiré de la liste d'endémie de poliomyélite en septembre 2015 après plus d'un an sans aucun cas, seulement pour être rétabli sur la liste en 2016 lorsque deux cas ont été détectés.

- En 2013, le Center for Disease Control a reçu des rapports de 183 cas de poliomyélite en Somalie, 14 au Kenya et 8 cas dans la région somalienne de l'Éthiopie, mais l'Afrique n'a eu aucun cas confirmé de poliovirus sauvage (PVS) depuis 2016. Des cas de poliovirus circulant de type 2 dérivé d'un vaccin continuent d'apparaître dans plusieurs pays.]

- Le 25 août 2020, la Commission régionale africaine de certification a déclaré l'Afrique indemne de poliomyélite sauvage. («Poliomyélite », Wikipedia)

\section{Appendice 2}

(2) Chronique des épidémies en Afrique («Liste des épidémies», Wikipedia)

- 1896-1906 Épidémie de trypanosomiase africaine du bassin du Congo, 1896-1906, bassin du Congo, trypanosomiase africaine, 500000 décès

- 1900-1920 Ouganda Épidémie de trypanosomiase africaine, 1900-1920, Ouganda, trypanosomiase africaine, 200 000-300 000 décès

- 1996 Épidémie de méningite en Afrique de l'Ouest, 1996, Afrique de l'Ouest, méningite, 10000 décès

- 2002-04 épidémie de SRAS, 2002-2004, dans le monde, syndrome respiratoire aigu sévère / SRAS, 774 décès

- Épidémie de peste en Algérie en 2003, Algérie en 2003, peste bubonique, 1 (18 cas)

- 2003-2019 Asie et Égypte Épidémie de grippe aviaire, 2003-2019, Asie du Sud-Est et Égypte, virus de la grippe A sous-type H5N1, 455 décès

- 2006 Épidémie de peste dans la province de l'Ituri, 2006, province de l'Ituri, République démocratique du Congo, peste bubonique, 61 morts

- 2006-07 Épidémie de fièvre de la vallée du Rift en Afrique de l'Est, 2006-2007, fièvre de la vallée du Rift en Afrique de l'Est, 394 décès

- Épidémie d'Ebola de Mweka, 2007, République démocratique du Congo, 187 décès

- Épidémie d'Ebola en Ouganda en 2007, 2007, Ouganda, Ebola, 37 décès 
- Epidémie de peste à Madagascar en 2008, 2008, Madagascar, peste bubonique, 18+

- 2009-2010 Épidémie de méningite en Afrique de l'Ouest 2009-2010, Afrique de l'Ouest, 1100 décès de méningite

- Pandémie de grippe porcine de 2009, 2009-2010, dans le monde, virus de la grippe A sous-type H1N1, décès confirmés en laboratoire: 18449 (signalés à l'OMS), nombre estimé de décès: 284000 (plage possible 151 700-575 400)

- Épidémie de fièvre jaune 2012 au Darfour, Soudan, 2012, Darfour, Soudan, fièvre jaune 171 décès

- Épidémie de coronavirus du syndrome respiratoire du Moyen-Orient en 2012, 2012, Syndrome respiratoire du Moyen-Orient / MERS-CoV dans le monde, 936 décès (au 1er février 2021)

- Épidémie de virus Ebola en Afrique de l'Ouest, 2013-2016, dans le monde, principalement concentrée en Guinée, au Libéria, en Sierra Leone, virion du virus Ebola Ebola, 11323 + décès

- Épidémie de peste à Madagascar en 2014, 2014-2017, Madagascar, peste bubonique, 292 décès

- Épidémie de virus Zika en 2015-2016, 2015-2016, dans le monde entier, virus Zika, 53 décès

- Épidémie de fièvre jaune en Angola et en RD du Congo en 2016, 2016, en Angola et en RD du Congo Fièvre jaune, 498 (377 en Angola, 121 au Congo)

- Épidémie de choléra au Yémen 2016-2021, 2016-présent, Yémen, choléra, 3886 (au 30 novembre 2019)

- Épidémie d'Ebola au Kivu 2018-2020, République démocratique du Congo et Ouganda Ebola 2280 décès

- Épidémie de rougeole de 2019 en République démocratique du Congo, 2019-2020, République démocratique du Congo, rougeole, 7 018+ décès

- Épidémie de fièvre de Lassa au Nigeria 2019-présent, fièvre de Lassa au Nigeria 246 (à partir de janvier 2021)

- Épidémie d'Ebola en République démocratique du Congo 2020, 2020, République démocratique du Congo Ebola 55 décès

- Épidémie de fièvre jaune au Nigéria 2020 - présent, Nigéria, fièvre jaune, 296 (au 31 décembre 2020). 


\section{Bibliographie annotée}

Afolabi, Muhammed O. et al (2020): Lessons from the Ebola epidemics and their applications for COVID-19 pandemic response in sub-Saharan Africa. Bioethics, Volume21, Issue1, March 2021, Pages 25-30 -------- Résumé: Le COVID - 19, causé par un nouveau coronavirus nommé SARS - CoV - 2, a été identifié en décembre 2019, à Wuhan, en Chine. Elle a été confirmée pour la première fois en Afrique subsaharienne au Nigéria le 27 février 2020 et s'est depuis propagée rapidement à tous les pays d'Afrique subsaharienne, causant plus de 111309 cas confirmés et 2498 décès au 3 juin 2020. Les leçons apprises lors de la récente crise d'Ebola Les flambées de maladie à virus (MVE) dans certains pays d'Afrique subsaharienne devraient façonner et influencer les réponses de la région à la pandémie du COVID-19. Cependant, certains des défis associés à la gestion des flambées de MVE persistent et créent des obstacles à la gestion efficace de la pandémie de COVID-19. Cet article décrit les points communs entre les épidémies de MVE et la pandémie de COVID-19, en vue de tirer les leçons apprises pour lutter efficacement contre la pandémie en cours. Les principaux succès, échecs et leçons tirées des précédentes flambées de MVE sont discutés. Des recommandations sur la manière dont ces leçons peuvent être traduites pour renforcer la réponse au COVID-19 en Afrique subsaharienne sont fournies.

Arthi, Vellore \& John Parman (2021): Disease, downturns, and wellbeing: Economic history and the long-run impacts of COVID-19. Explorations in Economic History, Volume 79, January 2021, 101381. ----- Comment le COVID-19 pourrait-il affecter le capital humain et le bien-être à long terme? La pandémie de COVID-19 a déjà imposé un coût humain lourd - pris ensemble, cette crise de santé publique et le ralentissement économique qui l'accompagne semblent prêts à éclipser la portée, l'ampleur et la perturbation de la plupart des pandémies modernes. Les preuves que nous avons des autres pandémies modernes se limitent en grande partie aux impacts à court terme. Par conséquent, l'expérience récente ne peut guère nous aider à anticiper et à répondre à l'impact potentiel à long terme du COVID-19 sur les individus sur des décennies, voire des générations. L'histoire offre cependant une solution. Les crises historiques offrent des analogues plus proches du COVID-19 dans chacune de ses dimensions clés - en tant que pandémie mondiale, en tant que récession mondiale - et offrent la piste nécessaire pour étudier le parcours de vie et les résultats intergénérationnels. Dans cet article, nous passons en revue les preuves des effets à long terme sur la santé, le travail et le capital humain des pandémies historiques (avec un accent sur la pandémie de grippe de 1918) et des récessions historiques (avec un accent sur la Grande Dépression). Nous concluons en discutant de la manière dont les crises passées peuvent éclairer notre approche du COVID-19 - en nous aidant à nous dire ce qu'il faut rechercher, à quoi se préparer et quelles données nous devons collecter maintenant.

Babaniyi, Peter Mwaba et al (2015): Risk Assessment for Yellow Fever in Western and North-Western Provinces of Zambia. J Glob Infect Dis. 2015 Jan-Mar; 7(1): 11-17. doi: 10.4103/0974-777X.150884: 10.4103/0974-777X.150884 ----- Les provinces du nord-ouest et de l'ouest de la Zambie ont été reclassées comme zones à faible risque de fièvre jaune (FJ). Cependant, le potentiel actuel de transmission de la fièvre jaune dans ces zones n'est pas clair. Une étude transversale a été menée dans les provinces du nord-ouest et de l'ouest de la Zambie. Sur les 3625 répondants qui ont participé à l'enquête, 46,7 \% étaient des hommes et 9,4\% étaient âgés de moins de 5 ans. Dans l'ensemble, 58,1 \% des participants ont dormi sous une moustiquaire imprégnée d'insecticide et 20,6\% ont signalé une pulvérisation d'insecticides à effet rémanent à l'intérieur. Un total de $616(17,0 \%)$ échantillons étaient présumés positifs pour la fièvre jaune. La prévalence de la fièvre jaune était de 0,3\% pour une infection à long terme et de $0,2 \%$ pour une infection récente par la fièvre jaune. Aucun des cas confirmés de fièvre jaune n'avait reçu le vaccin contre la fièvre jaune. Les taux de prévalence des autres flavivirus étaient de 149 (4,1\%) pour la dengue, $370(10,2 \%)$ pour le Nil occidental et $217(6,0 \%)$ pour le virus Zika. Il existe des preuves d'infection passée et récente par la fièvre jaune dans les deux provinces. Par conséquent, ils courent un faible risque d'infection par la fièvre jaune. La vaccination contre la fièvre jaune devrait être incluse dans le programme PEV dans les deux provinces et renforcer la surveillance avec confirmation par le laboratoire.

BBC news Afrique (n.A.) (2020b): Coronavirus: cinq épidémies qui ont contribué à changer le cours de l'histoire. 28 mars 2020 (no author given, in French) ----------- L'épidémie de coronavirus est en train de changer radicalement la façon dont des millions de personnes dans le monde vivent. Nombre de ces changements seront temporaires. Mais les maladies ont eu, tout au long de l'histoire, d'énormes effets à long terme : de la chute des dynasties, à la montée du colonialisme et même au refroidissement du climat. (1) La peste noire du 14e siècle et l'essor de l'Europe occidentale. (2) Décès dus à la variole en Amérique et changement climatique. (3) Fièvre jaune et révolte d'Haïti contre la France. (4) Peste bovine africaine et expansion coloniale en Afrique. 
Beach, Brian \& Karen Clay \& Martin H. Saavedra (2020): The 1918 Influenza Pandemic and its Lessons for COVID-19. Working Paper 27673, NBER, Nat. Bureau of Economic Research, Cambridge, MA, August 2020 ------ La pandémie de grippe de 1918 et ses leçons pour le COVID-19 Brian Beach, Karen Clay et Martin H. avec un accent particulier sur les sujets qui ont connu un regain d'intérêt en raison du COVID-19. Nous commençons par donner un aperçu des principaux détails contextuels et épidémiologiques ainsi que des données disponibles pour les chercheurs. Nous examinons ensuite les effets sur la mortalité, la fécondité et l'économie à court et moyen terme. Le rôle des interventions non pharmaceutiques dans l'élaboration de ces résultats est discuté tout au long. Nous examinons ensuite les conséquences sanitaires à plus long terme et leur impact sur l'accumulation du capital humain et le statut socio-économique. Tout au long du document, nous mettons en évidence des domaines importants pour les travaux futurs

Blanton, R. E. et al (2020): African Resources and the Promise of Resilience against COVID-19. Am J Trop Med Hyg. 2020 Aug; 103(2): 539-541. -------- La pandémie du COVID-19 a mis du temps à arriver dans les pays les plus pauvres du monde, en particulier en Afrique. Il y a de bonnes raisons de croire que les conséquences pour le continent pourraient être pires que partout ailleurs. Les faiblesses de certains gouvernements, systèmes de santé et économies, ainsi que les conflits armés, sont des facteurs que le virus peut et va exploiter. Un article récent de la British Broadcasting Corporation a noté qu'il y a 10 pays africains qui n'ont pas de ventilateurs, neuf ont pour 1 million d'habitants et la plupart des autres en ont trop peu pour desservir leur population dans une épidémie aux proportions américaines mais ne sont pas tous impuissants. Cependant, pour prévisualiser correctement l'impact du COVID-19 sur le continent, il faut tenir compte à la fois des faiblesses et des forces. L'Afrique de 2020 n'est pas l'Afrique de 1960 ni même de 2014. L'Afrique est un continent de 54 pays, avec une gamme de conditions climatiques, culturelles, démographiques et économiques qui les opposent aux régions plus développées et entre elles (tableau 1). Les effets du COVID-19 d'un pays à l'autre pourraient être très différents, et il existe des ressources qui peuvent aider à produire des résultats meilleurs que prévu. ... Le Bénin, le Burkina Faso, le Cameroun, le Ghana, le Nigéria, le Sénégal et le Togo ont obtenu des prêts importants de la Banque mondiale pour mettre en place le projet des centres d'excellence africains. Certains de ces centres ont été à l'avant-garde de la réponse gouvernementale à des flambées telles que Fièvre de Lassa, monkeypox, fièvre jaune et, actuellement, COVID-19.

Booysen, F. le R. et al (2002): The Socio-Economic Impact of HIV/AIDS on Households in South Africa: Pilot Study in Welkom and Qwaqwa, Free State Province. University of the Free State Centre for Health Systems Research \& Development, May 2002 ---- La pauvreté associée à l'épidémie de VIH / SIDA semble représenter une menace majeure pour les moyens de subsistance des ménages. Il a été démontré que les ménages affectés sont plus pauvres que les ménages non affectés, la pauvreté étant relativement plus endémique parmi les ménages affectés. Le facteur prédictif le plus important de l'état de pauvreté est le manque d'accès à l'aide médicale. En outre, certains éléments indiquent que les ménages touchés par la mort et / ou la maladie étaient plus susceptibles d'être pauvres, tout comme les ménages qui partagent moins d'années de scolarité entre leurs membres, ceux qui ont un plus petit nombre de membres employés, qui sont plus petits, qui sont dirigés par des femmes, qui résident dans les zones rurales, et qui sont dans le groupe affecté par opposition au groupe non affecté.

Bukachi, Salome A (2007): Socio-economic and cultural impacts of human African trypanosomiasis and coping strategies of households in the Busoga Focus (Kenya). Univ. of Nairobi Research Archiv --------- Cette étude a été conçue pour étudier les impacts socioéconomiques et culturels de la trypanosimose humaine africaine (THA) et les stratégies d'adaptation des ménages dans le foyer de Busoga. Le travail de terrain de l'étude a été mené dans les districts de Busia, Teso et Bunqoma dans l'ouest du Kenya, et dans les districts de Busia et Teso dans le sud-est de l'Ouganda entre janvier 2004 et juin 2005. Les principales hypothèses qui ont guidé l'étude étaient les suivantes: les impacts de la THA sur les personnes et les ménages touchés; La THA perturbe le fonctionnement social des ménages; et la THA affecte la base économique des ménages touchés. Les données ont été obtenues grâce à: l'examen des dossiers hospitaliers; entretiens structurés; entrevues avec des informateurs clés; des entretiens approfondis et des groupes de discussion dlscusslona.L'échantillonnage proposé a été utilisé -; pour obtenir la taille de l'échantillon de 481 auprès des répondants b0tt\}., HAT et non HAT. Les données quantitatives obtenues grâce à des entretiens structurés ont été analysées à l'aide de statistiques descriptives et Xlll présentées sous forme de tableaux de fréquence et de pourcentages. D'autre part, les données qualitatives, obtenues par examen des dossiers hospitaliers, entretiens avec des informateurs clés, entretiens approfondis et des discussions de groupe, a été analysé selon des thèmes émergents en utilisant une approche théorique fondée et présenté sous forme d'études de cas, d'extraits et de citations. Les résultats révèlent également que les effets mentaux de la THA sont prononcés chez les jeunes patients qui rencontrent par la suite des difficultés à réintégrer la communauté. Les ménages affectés par la THA subissent une charge financière accrue en raison de la recherche d'un traitement auprès de prestataires de services de santé très différents. Durée médiane le délai de mise en route du traitement contre la THA était de trois à 
quatre mois et une grande partie de ce délai est attribuable à l'échec du fournisseur de services de santé à diagnostiquer la THA. La maladie a également été parfois attribuée à tort au VIH / sida ou à la sorcellerie, ce qui a amené les patients à être stigmatisés, à retarder la recherche d'un traitement ou à se faire soigner auprès de sources erronées. Les résultats montrent également que la THA perturbe le fonctionnement normal des ménages affectés. Cela se manifeste par des conflits au sein des mariages, des familles et de la communauté et par l'inversion des rôles, ce qui augmente le fardeau et les responsabilités des femmes et des enfants. Sur le plan socio-économique, l'étude révèle que la THA appauvrit les ménages en réaffectant les ressources des ménages pour faire face à l'augmentation des dépenses financières liées à la recherche d'un traitement et de soins. D'autres impacts économiques, ont été l'abandon scolaire, l'absentéisme scolaire, une baisse de la productivité et une augmentation des frais de funérailles et d'inhumation. Cette étude recommande donc l'insti, jutinq 'de mesures inter-frontalières continues et concertées. réduire l'incidence de la THA. Dans cette optique, il est nécessaire de mettre en place des stratégies permettant de détecter efficacement les cas de THA à un stade précoce de la THA. Cela peut être réalisé en renforçant la capacité du personnel de soins de santé primaires à diagnostiquer la THA et à accroître . leur prise de conscience de la même chose. De même, les personnes à risque de THA devraient être habilitées à disposer d'informations pertinentes pour les aider à reconnaître les symptômes de la maladie à un stade précoce. Enfin, l'étude I recommande la mise en place de stratégies qui aideraient les patients atteints de THA à s'intégrer Cette étude fournit des informations riches sur les impacts socio-économiques et culturels de la THA qui peuvent être utilisées par les décideurs et les exécutants de programmes pour prendre des décisions éclairées qui $l$ aider à atténuer les effets de la THA et à lui accorder l'attention et la priorité qu'elle mérite, considérant qu'il s'agit d'une des maladies négligées. De plus, cette étude révèle que les maladies comme la THA sont une chaîne importante dans le cycle de la pauvreté.

Burke, J. (1971): Historique de la lutte contre la maladie du sommeil au Congo. Ann Soc Belg Méd Trop, 1971,51,4-5,465-477 ------- 1885-1904. L'histoire obscure: A la fin du lge siècle et même au cours des premières découvertes du 20e siècle, nous ne possédons que relativement peu de renseignements sur l'évolution de la maladie du sommeil en Afrique en général et au Congo en particulier. C'est la période que Buxton intimé «histoire obscure» de la trypanosomiase. Et pourtant, c'est au cours de cette période que se situe l'extension géographique de la maladie, qui débuta probablement vers 1885 par une première épidémie qui fut suivie par une seconde vers 1920 et qui ne se stabilisera qu'en 1940 lorsque tout l'ouest et le centre de l'Afrique seront envahis. L'origine de la première épidémie se situe probablement quelque part au confluent du fleuve Congo et de l'Ubangi, d'où elle s'étend rapidement vers le Nord en suivant la rivière Sanga et vers l'Ouest envahissant l'actuelle République populaire du Congo, l'ancien royaume de Loango et le Bas-Congo. En 1887, la maladie est endémique sur le Stanley Pool. Ensuite, l'épidémie s'étend vers le Nord-Est en suivant les eaux du fleuve Congo, de l'Ubangi et du Bomu, pour atteindre le lac Albert en 1888. Peu de détails sont connus sur ce qui se passe à l' intérieur du bassin du Congo. On peut raisonnablement admettre que la maladie ait suivi le cours des innombrables rivières pour faire son apparition ou sa réapparition un peu partout. En 1889 éclate en Ouganda autour de Busoga la plus terrible épidémie de trypanosomiase dont on a fait état. Il est parfois admis avec Scott que cette première épidémie pourrait bien avoir trouvé son origine dans les caravanes de Stanley qui, en 1887, quitta les rives du Lualaba pour voler au secours d'Emin Pacha. Ses soldats et porteurs s'établirent en effet avec femme et enfants dans la région de Busoga.

Bwire, Godfrey et al (2017): Epidemiology of cholera outbreaks and socio-economic characteristics of the communities in the fishing villages of Uganda: 2011-2015. PLOS, Published online: March 13, 2017 ----- Les communautés des villages de pêcheurs de la région des Grands Lacs en Afrique et en particulier en Ouganda connaissent des épidémies récurrentes de choléra qui entraînent une mortalité et une morbidité considérables. Nous avons évalué l'épidémiologie du choléra et les caractéristiques de la population dans les villages de pêcheurs de l'Ouganda pour mieux cibler les interventions de prévention et de contrôle du choléra et contribuer à son élimination de ces communautés. Nous avons mené une étude prospective entre 2011 et 2015 dans des villages de pêcheurs en Ouganda. Nous avons collecté, examiné et documenté des données épidémiologiques et socio-économiques pour 10 flambées de choléra survenues dans des communautés de pêcheurs situées le long des Grands Lacs africains et du Nil en Ouganda. Ces flambées ont provoqué 1827 cas suspects de choléra et 43 décès, avec un taux de létalité (TFC) de 2,4\%. Bien que les communautés des villages de pêcheurs ne représentent que 5 à $10 \%$ de la population ougandaise, elles supportent le plus gros fardeau du choléra, contribuant à $58 \%$ et $55 \%$ de tous les cas et décès signalés en Ouganda au cours de la période d'étude. Le CFR était significativement plus élevé chez les hommes que chez les femmes (3,2\% contre 1,3\%, $p=0,02)$. Les éclosions étaient saisonnières, la plupart des cas se produisant au cours des mois d'avril à mai. Les garçons de moins de 5 ans et de 5 à 9 ans présentaient un risque accru. Le choléra était endémique dans certains villages avec des «points chauds» bien définis. Les pratiques prédisposant les communautés aux épidémies de choléra comprenaient: l'utilisation de l'eau contaminée du lac, un assainissement et une hygiène médiocres. D'autres facteurs étaient: l'ignorance, l'analphabétisme et la pauvreté. Les épidémies de choléra étaient une cause majeure de morbidité et de mortalité parmi les communautés de pêcheurs en Ouganda. Outre les améliorations en 
matière d'eau, d'assainissement et d'hygiène, les vaccins oraux contre le choléra pourraient jouer un rôle important dans la prévention et le contrôle de ces flambées, en particulier lorsqu'ils sont ciblés sur les zones et les populations à haut risque. La promotion et la facilitation de l'accès aux services sociaux, y compris l'éducation et la réduction de la pauvreté, devraient contribuer à la prévention, au contrôle et à l'élimination du choléra dans ces communautés. - Le choléra, bien que maladie évitable et traitable, reste une cause majeure de morbidité et de mortalité dans la région des Grands Lacs en Afrique, y compris en Ouganda. Les communautés des villages de pêcheurs représentent 5 à $10 \%$ de la population totale ougandaise. La plupart des villages de pêcheurs sont situés le long des lacs Victoria, Albert et Edward et du Nil. Au cours de la période d'étude, 2011-2015, ces villages étaient responsables de plus de 50\% des cas annuels de choléra et des décès signalés en Ouganda. Le CFR était significativement plus élevé chez les hommes que chez les femmes $(3,2 \%$ contre $1,3 \%, p=0,02)$. Notre étude est la première à décrire systématiquement l'épidémiologie de ces flambées et les caractéristiques socio-économiques des communautés des villages de pêcheurs en Ouganda. Notre étude a révélé que les habitants des villages de pêcheurs couraient un risque accru d'épidémies de choléra en raison d'un accès limité à l'eau potable, à l'assainissement et à l'hygiène. En outre, les villages avaient des caractéristiques démographiques similaires telles que l'analphabétisme, l'ignorance concernant la transmission du choléra, la pauvreté et la migration constante de la population. Outre les améliorations en matière d'eau, d'assainissement et d'hygiène, l'utilisation complémentaire des vaccins oraux contre le choléra pourrait jouer un rôle important, en particulier lorsqu'elle est ciblée sur les zones et les populations à haut risque. En tant que stratégie à long terme, l'amélioration de l'éducation et la réduction de la pauvreté devraient contribuer à la prévention, au contrôle et à l'élimination du choléra dans les villages de pêcheurs et en Ouganda dans son ensemble.

Caramel, Laurence (2021): L'Afrique face au Covid-19 - la peur du scénario indien. Le Monde (Paris), 30 May 2021 --- La présidence de l'Union africaine réunira les ministres de la santé samedi 8 mai afin de sonner l'alerte. Il s'agit d'appeler à la mobilisation pour mettre le continent à l'abri d'un scénario à l'indienne. "Nous regardons avec stupéfaction ce qui est en train de se passer en Inde. Cela peut arriver n'importe où. Nous devons nous préparer et surtout ne pas baisser la garde ", a averti jeudi 29 avril le docteur John Nkengasong, directeur du Centre africain de prévention et de contrôle des maladies (Africa $C D C$ ). Les difficultés indiennes ont par ailleurs des répercussions importantes sur les campagnes de vaccination puisque le Serum Institute of India, qui fabrique les vaccins AstraZeneca pour l'initiative de solidarité internationale Covax, a cessé d'exporter depuis plusieurs semaines afin de répondre à la demande domestique. Or, presque tous les pays africains comptent sur Covax pour commencer à immuniser leur population. Avec les autres vaccins - Sinopharm, Spoutnik V et Johnson \& Johnson - 17 millions de doses seulement ont jusqu'à présent été administrées en Afrique, dont 8,9 millions au Maroc. Face aux difficultés logistiques dans un pays aussi grand que l'Europe de l'Ouest et à la réticence des populations, le gouvernement a fait le constat qu'il ne parviendrait pas à administrer ces doses avant leur date d'expiration mi-juin. Les doses restituées vont être redistribuées dans les prochaines semaines à quatre pays : le Ghana, la République centrafricaine, le Sénégal et le Togo.

Çavdaroğlu, Sude et al (2021): The spread of . Yellow fever amidst the COVID-19 pandemic in Africa and the ongoing efforts to mitigate it. J Med Virol, . 2021 Apr 19. ------------ Aucun résumé disponible

Chauhan, Ravendra P. et al (2020): Systematic Review of Important Viral Diseases in Africa in Light of the 'One Health' Concept. Pathogens, 2020, 9(4), 301; , Published: 20 April 2020 --------- Les maladies virales émergentes et réémergentes sont un grand problème de santé publique. L'émergence récente du coronavirus lié au syndrome respiratoire aigu sévère (SRAS) (SRAS-CoV2) en décembre 2019 en Chine, qui cause la maladie COVID-19 chez l'homme, et sa propagation actuelle dans plusieurs pays, conduisant à la première pandémie de l'histoire être causée par un coronavirus, souligne l'importance des maladies virales zoonotiques. La fièvre de la vallée du Rift, la rage, le Nil occidental, le chikungunya, la dengue, la fièvre jaune, la fièvre hémorragique de Crimée-Congo, le virus Ebola et la grippe parmi de nombreux autres virus ont été signalés dans différents pays africains. Le manque d'informations, le manque de connaissances, les ressources limitées et le changement climatique, associés aux traditions culturelles, font du continent africain un point chaud pour les maladies virales à transmission vectorielle et zoonotiques, qui peuvent se propager à l'échelle mondiale. Actuellement, aucune information n'est disponible sur l'état des maladies virales en Afrique. Cette revue systématique met en évidence les informations disponibles sur les maladies virales, y compris les maladies zoonotiques et à transmission vectorielle, signalées en Afrique. Les résultats nous aideront à comprendre la tendance des maladies virales émergentes et réémergentes sur le continent africain. Les résultats recommandent une surveillance active des maladies virales et une mise en cuvre stricte des mesures One Health en Afrique pour améliorer la santé publique humaine et réduire la possibilité de pandémies potentielles dues aux virus zoonotiques. - Mots clés: Afrique; émergent; réémerger; maladies infectieuses; pandémie; SRAS-CoV-2; COVID-19 [FEMININE; virus; zoonose; à transmission vectorielle; la grippe aviaire; virus de la grippe A; coronavirus; monkeypox; 
immunodéficience simienne; rage; la dengue; fièvre hémorragique; Virus de la fièvre de la vallée du Rift; Virus du Nil occidental; Ebola; une santé; épidémiologie.

Chippaux, J.P. \& A. Chippaux (2018): Yellow fever in Africa and the Americas: a historical and epidemiological perspective. J Venom Anim Toxins Incl Trop Dis 24, 20 (2018). --------- La fièvre jaune a été transportée pendant la traite des esclaves aux XVe et XVIe siècles de l'Afrique aux Amériques où le virus a rencontré des conditions écologiques favorables qui ont permis la création d'un cycle sylvatique durable. Malgré des programmes efficaces de lutte antivectorielle et de vaccination pendant près d'un siècle, des épidémies de fièvre jaune ont réapparu dans de nombreux pays d'Amérique latine, en particulier au Brésil. L'émergence ou la réémergence de maladies à transmission vectorielle englobe de nombreux facteurs complexes. Des flambées de fièvre jaune surviennent si au moins trois conditions sont remplies: l'introduction du virus dans une communauté humaine non immunisée, la présence de vecteurs compétents et anthropophiles et l'insuffisance de la prévention et / ou de la gestion adéquate de l'épidémie croissante. D'autre part, deux armes sont disponibles pour lutter contre la fièvre jaune: la lutte antivectorielle et la vaccination. En revanche, la fièvre jaune est absente d'Asie et du Pacifique malgré la présence du vecteur et la sensibilité des populations humaines au virus. Sur la base d'un examen de l'histoire mondiale de la fièvre jaune et de son épidémiologie, les auteurs émettent quelques recommandations pour améliorer la prévention des épidémies.

Chitsamatanga, Bellita Banda \& Wayne Malinga (2021): 'A tale of two paradoxes in response to COVID-19': Public health system and socio-economic implications of the pandemic in South Africa and Zimbabwe. Cogent Social Sciences, 2021 ---------- La réponse de l'Afrique à l'épidémie de maladies infectieuses a fait l'objet d'un examen minutieux au fil des ans et l'épidémie de COVID-19 a aggravé la situation. La propagation rapide de ce virus provoque le chaos et la panique dans le domaine mondial qui remet en question la préparation des systèmes de santé publique à faire face à une pandémie de cette ampleur. Cela a sans aucun doute catapulté le mot «COVID-19» comme un nouveau mot à la mode. C'est dans ce contexte que le document utilise la recherche documentaire pour approfondir la compréhension des réponses de l'Afrique du Sud et du Zimbabwe à l'épidémie de COVID-19. Ce faisant, la principale impulsion du document est d'interroger le système de santé publique et les implications socio-économiques de cette pandémie sur les deux pays. Dans le cadre de ses conclusions, le document note que les deux pays sont l'histoire de deux paradoxes: l'un avec un statut de revenu intermédiaire et l'autre un statut de faible revenu; un facteur clé pour déterminer le niveau et l'efficacité des stratégies de réponse à cette crise sanitaire alarmante. Cependant, malgré ces disparités économiques et ces différences de statut de revenu, cette pandémie a révélé que les deux pays ont des problèmes similaires profondément enracinés dans leurs systèmes de santé publique déjà surchargés. En outre, la situation est encore catapultée et exacerbée par des facteurs socio-économiques sous-jacents tels que la pauvreté, le chômage, les inégalités, le ralentissement du développement économique, l'insuffisance de l'eau et de l'assainissement et l'insécurité alimentaire qui ont fait de la lutte contre cette pandémie un défi de taille. Le document conclut que la réponse et les tentatives de lutte contre le COVID-19 par l'Afrique du Sud et le Zimbabwe dépendent fortement de leur capacité sanitaire et de conditions socio-économiques favorables.

Collins, A.E. \& M.E. Lucas \& M.S. Islam \& L.E. Williams (2007): Socio-economic and environmental origins of cholera epidemics in Mozambique: guidelines for tackling uncertainty in infectious disease prevention and control. Pages 537-549 ---- Les origines de l'incidence du choléra en Afrique sont socio-économiques et environnementales. De plus, la nature de la transmission et de la survie de Vibrio cholerae présente un risque persistant de choléra. Le programme de gestion des risques de maladies infectieuses (IDRM) au Mozambique a fait face à cela dans l'un des endroits les plus récents au monde où le choléra est le plus répandu. La première phase du programme suggère que la reconnaissance de la complexité du choléra est cruciale pour sa gestion efficace. Les impacts potentiels d'une évaluation intégrée et surveillée localement des risques de choléra sont une réduction de l'incertitude quant aux origines des épidémies, une meilleure lutte contre les maladies diarrhéiques et la sécurité sanitaire.

Davies, Nicholas et al. (2020): The impact of Coronavirus disease 2019 (COVID-19) on health systems and household resources in Africa and South Asia. MedRxiv., The Preprint Server for Health Science, BMJ Yale, ----------- Contexte: Les épidémies de maladie à coronavirus 2019 (COVID-19) mettent à rude épreuve les systèmes de santé et les ménages. Les systèmes de santé en Afrique et en Asie du Sud peuvent être particulièrement à risque en raison de la prévalence potentielle élevée des facteurs de risque de maladie grave, de la taille importante des ménages et de la capacité de santé limitée. Méthodes: Nous avons étudié l'impact d'une épidémie non atténuée de COVID-19 sur les ressources et les coûts du système de santé, et les coûts des ménages, à Karachi, Delhi, Nairobi, Addis-Abeba et Johannesburg. Nous avons adapté un modèle dynamique de transmission et de maladie du SRAS-CoV-2 pour capturer la démographie et les modèles de contact spécifiques au pays. Le modèle épidémiologique a ensuite été intégré dans un cadre économique qui a capturé les systèmes de santé propres aux villes et l'utilisation 
des ressources des ménages. Résultats: Les villes manquent cruellement de lits de soins intensifs, de personnel de santé et de ressources financières pour répondre à la demande lors d'une épidémie de COVID19 non atténuée. Une épidémie de COVID-19 fortement atténuée, selon des hypothèses optimistes, peut éviter une capacité de lit d'hôpital écrasante dans certaines villes, mais pas la capacité de soins intensifs.

Interprétation: Des stratégies d'atténuation viables englobant une combinaison de réponses doivent être établies pour étendre la capacité des soins de santé, réduire la demande de pointe en ressources de santé, minimiser la progression vers les soins intensifs et protéger les personnes les plus exposées au risque de maladie grave. Financement: Fondation Bill \& Melinda Gates, Commission européenne, Institut national de recherche en santé, Département du développement international, Wellcome Trust, Royal Society, Research Councils UK. Preuve avant cette étude: Nous avons mené une recherche PubMed le 5 mai 2020, sans restriction de langue, pour les études publiées depuis le début, combinant les termes («coût»OU «économique») ET «covid». Notre recherche a donné 331 articles, dont seulement deux rapportaient des estimations des coûts du système de santé du COVID-19. La première étude a estimé l'utilisation des ressources et les coûts médicaux du COVID-19 aux États-Unis en utilisant un modèle statique du COVID 19. La deuxième étude a estimé les coûts des tests de réaction en chaîne par polymérase aux États-Unis. Nous n'avons trouvé aucune étude examinant les implications économiques du COVID-19 dans les milieux à revenu faible ou intermédiaire. Valeur ajoutée de cette étude: Il s'agit de la première étude à utiliser des données collectées localement dans cinq villes (Karachi, Delhi, Nairobi, Addis-Abeba et Johannesburg) pour projeter les ressources de santé et les implications économiques pour la santé d'une épidémie non atténuée de COVID-19. Outre l'utilisation de données locales, notre étude va au-delà des travaux existants pour (i) examiner la capacité des systèmes de santé dans les villes clés à faire face à cette demande, (ii) prendre en compte les ressources en personnel de santé nécessaires, car celles-ci sont en deçà de la demande par des marges plus importantes que les lits d'hôpitaux, et (iii) tenir compte des coûts économiques pour les services de santé et les ménages. Implications de toutes les preuves: la demande de lits en USI et de personnel de santé dépassera la capacité actuelle de plusieurs ordres de grandeur, mais l'écart de capacité pour les lits d'hôpitaux généraux est plus étroit. Avec des hypothèses optimistes sur la gravité de la maladie, l'écart entre la demande et la capacité de lits d'hôpitaux généraux peut être comblé dans certaines villes, mais pas dans toutes. Des efforts sont nécessaires pour alléger le fardeau économique de la maladie sur les ménages.

Dubbink, Jan H. (2020): COVID-19 treatment in sub-Saharan Africa: If the best is not available, the available becomes the best. Travel Med Infect Dis. 2020, September-October; 37: 101878. ------- La transmission communautaire du COVID-19 est en cours dans la majorité des pays d'Afrique subsaharienne (ASS), menaçant, comme ailleurs, la capacité des systèmes nationaux de santé (HCS) dans les pays à revenu faible et intermédiaire (PRFI). Le plus grand souci est le manque d'agents de santé (TS) et d'infrastructures de soins de santé Si les pays les plus riches luttent, que peut-on faire si les PRFI, comme la Sierra Leone, qui sert d'exemple dans ce qui suit, sont durement augmentation exponentielle des cas?

Folayan, Coker M. et al (2020): Things must not fall apart: the ripple effects of the COVID-19 pandemic on children in sub-Saharan Africa. Pediatr Res. 2020 Sep 24. --------------- Les enfants de zéro à 19 ans en Afrique subsaharienne supportent une proportion disproportionnée du fardeau mondial des maladies transmissibles et non transmissibles. Des progrès significatifs en matière de santé publique ont été réalisés dans la lutte contre ces maladies, mais des facteurs tels que le sous-équipement des systèmes de santé, les flambées de maladies, les conflits et l'instabilité politique continuent de remettre en question la prévention et le contrôle. La pandémie de la maladie du nouveau coronavirus (COVID-19) causée par le coronavirus 2 du syndrome respiratoire aigu sévère (SRAS-CoV-2) introduit de nouveaux défis pour les programmes de santé publique en Afrique subsaharienne. Les programmes ciblant les principales maladies chez les enfants, comme la dénutrition, la pneumonie et la diarrhée évitables par la vaccination, le paludisme, la tuberculose, le VIH et la drépanocytose, sont particulièrement préoccupants. Cet article se concentre sur l'impact de la pandémie de COVID-19 sur la santé des enfants en Afrique subsaharienne. Nous passons en revue l'épidémiologie des principales maladies pédiatriques et, en faisant référence aux projections de modélisation, discutons de l'impact à court et à long terme de la pandémie sur la lutte contre les principales maladies. Nous délibérons sur les complications potentielles des co-infections / comorbidités SRAS-CoV-2 et identifions les problèmes sociaux et éthiques critiques. En outre, nous soulignons la rareté des données COVID-19 et des essais cliniques dans cette région et le manque d'enfants participants dans les études en cours. Enfin, les approches et les interventions visant à atténuer l'impact de la pandémie sur les résultats de santé des enfants sont discutées. IMPACT: Les enfants d'Afrique subsaharienne portent un fardeau disproportionné de maladies transmissibles et non transmissibles dans le monde; cela reste vrai même si la pandémie COVID-19 persiste. Au milieu de la littérature COVID-19 en rapide expansion, il y a peu de couverture complète de l'impact indirect de la pandémie sur la santé des enfants en Afrique subsaharienne. Cet article décrit de manière exhaustive la menace que représente la pandémie pour la prévention et le contrôle des principales maladies chez les enfants en Afrique subsaharienne. Il discute de l'impact potentiel des co-infections / comorbidités SRAS-CoV-2, met en évidence les lacunes de la recherche et plaide pour des données et des mesures pour atténuer les effets d'entraînement de la pandémie sur cette population.. 
Gao, J., et al. (2020). Human African trypanosomiasis: The current situation in endemic regions and the risks for non-endemic regions from imported cases. Parasitology, 147(9), 922-931. doi:10.1017/S0031182020000645 ---- La trypanosomiase humaine africaine (THA) est causée par Trypanosoma brucei gambiense et Trypanosoma brucei rhodesiense et a provoqué des épidémies dévastatrices au cours du 20e siècle. Grâce aux programmes de contrôle efficaces mis en ouvre au cours des deux dernières décennies, le nombre de cas signalés est tombé à un niveau historiquement bas. Bien que moins de 977 cas aient été signalés en 2018 dans les pays d'endémie, la THA reste un problème de santé publique dans les régions d'endémie jusqu'à ce qu'elle soit complètement éliminée. En outre, près de 150 cas confirmés de THA ont été signalés dans des pays non endémiques au cours des trois dernières décennies. La majorité des cas de THA non endémiques ont été signalés en Europe, aux États-Unis et en Afrique du Sud, en raison d'alliances historiques, de liens économiques ou de la proximité géographique de pays d'endémie. En outre, avec la mise en æuvre du projet «Belt and Road», des cas sporadiques de THA importés ont été signalés en Chine comme un signe d'alerte à la prévention des maladies tropicales. Dans cet article, nous explorons et interprétons les données sur l'incidence de la THA et ne trouvons aucune corrélation positive entre le nombre de cas de THA dans les pays endémiques et non endémiques. Ces données fourniront des informations utiles pour mieux comprendre les cas importés de THA dans le monde dans la phase postélimination.

Gillespie, Stuart (2008): Poverty, Food Insecurity, HIV Vulnerability and the Impacts of AIDS in sub-Saharan Africa. IDS-Bulletin, volume 39, issue 5 (2008), DOI: 10.1111/j.1759-5436.2008.tb00490.x ------.Tout au long de cette décennie, le discours dominant sur les liens entre le statut socio-économique et le VIH montre que les personnes et les ménages pauvres sont plus vulnérables à l'infection par le VIH, 1 et les moins capables de faire face aux conséquences de la maladie et des décès liés au sida. Alors que les premiers stades de l'épidémie dans les années 80 et au début des années 90 ont été motivés par des «hommes mobilisés avec de l'argent», le sida est désormais considéré comme une maladie de la pauvreté. Mais est-ce trop simpliste? Ce bref aperçu vise à passer en revue les données actuelles sur les liens en amont et en aval entre la pauvreté, l'insécurité alimentaire, la vulnérabilité au VIH et les impacts du SIDA. La première section se concentre sur l'amont - c'est-à-dire si, et par quelles voies, la pauvreté expose les gens à un plus grand risque d'être exposés au virus. Ceci est suivi d'un examen de ce que l'on sait sur le côté aval (ou post-infection) - comment les maladies liées au sida et la mortalité prématurée exacerbent ou précipitent la pauvreté.

Hagan, John Elvis et al (2020): Africa's COVID-19 Situation in Focusand Recent Happenings: A MiniReview. Front. Public Health, 17 December 2020 -------- Étant donné que le COVID-19 (SRAS-CoV-2) s'est infiltré en Afrique, une menace majeure de crise de santé publique persiste sur le continent. De nombreux gouvernements locaux et diverses parties prenantes ont intensifié leurs efforts pour la détection précoce et la gestion du COVID-19. Cette mini revue met en évidence la tendance actuelle en Afrique, l'histoire et les informations épidémiologiques générales sur le virus. Les efforts en cours (par exemple, améliorer la capacité de test) et certains moyens efficaces (par exemple, surveillance intensifiée, détection rapide, recherche des contacts, mesures d'isolement [par exemple, quarantaine] et éloignement social) de prévention et de gestion du COVID-19 en Afrique sont décrits. L'examen se termine en soulignant la nécessité de développer l'infrastructure de santé publique (par exemple, les laboratoires, les centres de maladies infectieuses, les hôpitaux régionaux) et le renforcement des capacités humaines pour lutter contre le COVID-19 et les épidémies futures potentielles. En outre, des campagnes régulières d'éducation sur la santé publique sont nécessaires de toute urgence. Des études épidémiologiques futures pour déterminer les tendances en matière de létalité et de mortalité à travers le continent sont nécessaires.

Josephson, Anna \& Kilic, Talip \& Michler, Jeffrey D. (2020): Socioeconomic Impacts of COVID-19 in Four African Countries. Policy Research Working Paper;No. 9466. World Bank, Washington, DC. (C) World Bank. ----- La maladie à coronavirus 2019 (COVID-19) et les tentatives pour limiter sa propagation ont eu de profonds impacts économiques, et une contraction significative de l'économie mondiale est attendue. Ce document fournit quelques-unes des premières preuves sur les impacts socio-économiques et les réponses à la pandémie parmi les ménages et les individus en Afrique subsaharienne. Pour ce faire, des méthodes économétriques de forme réduite sont appliquées aux données d'enquêtes longitudinales sur les ménages en Éthiopie, au Malawi, au Nigéria et en Ouganda provenant des enquêtes en face-à-face des ménages pré-COVID-19 et des nouvelles enquêtes téléphoniques qui sont mise en cuvre pendant la pandémie. Les principaux résultats sont au nombre de quatre. Premièrement, bien que les fausses croyances au sujet du COVID-19 restent répandues, l'action du gouvernement pour limiter la propagation de la maladie est associée à une meilleure connaissance individuelle de la maladie et à un recours accru aux mesures de précaution. Deuxièmement, on estime que 256 millions d'individus - 77 pour cent de la population des quatre pays - vivent dans des ménages qui ont perdu des revenus en raison de la pandémie. Troisièmement, les tentatives pour faire face à cette perte sont 
exacerbées par l'incapacité d'accéder aux médicaments et aux aliments de base chez 20 à 25 pour cent des ménages de chaque pays, et l'insécurité alimentaire est supportée de manière disproportionnée par les ménages qui étaient déjà appauvris avant la pandémie. Quatrièmement, le contact élève-enseignant est passé d'un taux pré-COVID-19 de 96 pour cent à seulement 17 pour cent parmi les ménages avec enfants d'âge scolaire. Ces résultats peuvent aider à éclairer les décisions des gouvernements et des organisations internationales sur les mesures visant à atténuer les effets de la pandémie de COVID-19 et à révéler la nécessité d'une surveillance continue.

Krawczyk-2020: How nonprofits (NGOs) have been affected during pandemic. Auburn University, Office of Communications \& Marketing Expert Answers, 2020 May De nombreuses organisations à but non lucratif se sont lancées dans cette situation d'urgence sans disposer de fonds de réserve importants. Et maintenant, la pandémie de coronavirus a rendu leur situation financière encore plus désastreuse. Les activités de financement ont été annulées ou reportées et les ventes de billets ont disparu. Les donateurs s'inquiètent pour l'économie et, dans certains cas, ont renoncé à donner. Les fondations ont subi d'énormes pertes de dotations. Ainsi, les organisations à but non lucratif ont actuellement du mal à survivre financièrement. Pourtant, en même temps, les besoins de ceux qu'ils servent sont plus grands que jamais.

Leach, M. \& H. Mac Gregor \& I. Scoones, A. Wilkinson (2021): Post-pandemic transformations: How and why COVID-19 requires us to rethink development. World Development, Volume 138, February 2021, 105233 ---- Le COVID-19 s'avère être le «grand» tant attendu: une pandémie capable de mettre les sociétés et les économies à genoux. Il est urgent d'examiner comment le COVID-19 - en tant que crise de santé et de développement - s'est déroulé comme il l'a fait et d'envisager les possibilités de transformations post-pandémiques et de repenser le développement plus largement. S'appuyant sur plus d'une décennie de recherche sur les épidémies, nous soutenons que les origines, le déroulement et les effets de la pandémie de COVID-19 nécessitent une analyse qui aborde à la fois les conditions politicoéconomiques structurelles et des processus beaucoup moins ordonnés et "indisciplinés " reflétant la complexité, l'incertitude et la contingence. et la spécificité du contexte. Cette dualité structurelleindisciplinée dans les conditions et les processus d'émergence, de progression et d'impact d'une pandémie fournit une perspective pour voir trois domaines de défi clés. Le premier est la manière dont les avis et les preuves scientifiques sont utilisés dans les politiques, lorsque les conditions sont strictement «verrouillées» dans des relations de pouvoir établies et pourtant si incertaines. Deuxièmement, le fonctionnement des économies, la crise du COVID-19 ayant révélé les limites d'un modèle conventionnel de croissance économique. Le troisième concerne la manière dont de nouvelles formes de politique peuvent devenir la base de relations remodelées entre les citoyens et les États face à une pandémie, comme celles qui concernent la solidarité et la prise en charge mutuelles. Le COVID-19 démontre que nous sommes confrontés à un avenir incertain, où l'anticipation et la résilience aux chocs majeurs doivent devenir la problématique centrale des études et de la pratique du développement. Là où les approches traditionnelles du développement ont été descendantes, rigides et orientées vers des objectifs économiques étroitement définis, le développement postCOVID-19 doit avoir une connaissance et une politique radicalement transformatrices, égalitaires et inclusives en son cœur.

Lyons, Maryinez (1992): The Colonial Disease: A Social History of Sleeping Sickness in Northern Zaire, 1900-1940. Cambridge History of Medicine. New York: Cambridge University Press ------ Les Belges qualifiaient généralement leur colonisation du Congo de «mission civilisatrice» et beaucoup considéraient l'introduction de la bio-médecine occidentale comme une caractéristique centrale de leur «cadeau» aux Africains. En 1930, cependant, il était clair que certaines caractéristiques de leur «mission civilisatrice» étaient en fait étroitement liées à la mauvaise santé de nombreux Congolais. Les Européens avaient en effet apporté la recherche scientifique et la bio-médecine occidentale; mais ils avaient également introduit un système politique sévère et répressif qui, associé à un système économique impitoyablement exploiteur, conduisait à l'introduction de nouvelles maladies tandis que les maladies déjà existantes étaient exacerbées et se propageaient. La médecine tropicale, ou «coloniale», était un nouveau domaine au tournant du siècle, étroitement lié à la fois à l'expansionnisme européen et à la trypanosomiase humaine, ou maladie du sommeil. En 1901, une épidémie dévastatrice a éclaté en Ouganda, tuant bien plus de 250000 personnes.

Machila, Nisbert (2013): Trypanosomiasis, the State and Livelihoods in Eastern Province of Zambia, 1908-1964. researchgate.net ---------.La trypanosomiase était un problème majeur en Zambie, en particulier dans la province orientale pendant la période coloniale. Pendant des siècles, les habitants de la province orientale de la Zambie ont été victimes de trypanosomiase. Cette thèse examine la trypanosomiase dans la province orientale de la Zambie de 1908 à 1964. La thèse soutient que lors de la découverte de la maladie, la British South African Company a exprimé sa peur et une grande panique et que des mesures ont dû être prises rapidement. Il démontre également que, par l'intermédiaire du Département vétérinaire, B.S.A.Co a pris des mesures appropriées destinées à contenir et à prévenir la propagation des glossines et de 
la trypanosomiase. L'étude fait également valoir que l'éclatement de la Seconde Guerre mondiale en 1939 a limité la disponibilité des fonds pour les programmes de lutte contre la mouche tsé-tsé et la trypanosomiase. Cela a aggravé la situation. Ce n'est qu'à la fin de la Seconde Guerre mondiale en 1945 que l'administration coloniale s'est activement impliquée dans le contrôle de la maladie. Cette étude démontre également que les habitants de la province orientale de la Zambie ont développé des stratégies de survie traditionnelles et des médicaments ethno-vétérinaires pour faire face à la trypanosomiase dans leurs communautés. Les Africains dépendaient largement de leur connaissance de l'environnement pour lutter contre la trypanosomiase. L'étude explore divers mécanismes utilisés par les habitants de la province orientale de la Zambie pour survivre pendant les épidémies de la maladie. L'intervention coloniale par le biais des services vétérinaires et de lutte contre les glossines est également devenue une source majeure de médecine ethno-vétérinaire.

Malczycki, Matt (2020): COVID-19-compared to other pandemics-is historic because of world response. Auburn University, Published: May 26, 2020 --------- Ce qui rend le COVID-19 historique jusqu'à présent, c'est la vitesse à laquelle le monde a agi pour arrêter la propagation de la maladie. Oui, les quarantaines et les fermetures auraient pu sauver des vies si elles s'étaient produites plus tôt, mais, dans le grand schéma de l'histoire humaine, la réponse mondiale au COVID-19 a établi des records de vitesse. À n'importe quel autre moment, nous n'aurions pas été en mesure d'agir aussi minutieusement que nous l'avons fait aussi rapidement que nous l'avons fait. Des millions d'autres auraient été infectés et seraient morts sans la technologie de l'information et la médecine modernes. Dans le langage de notre époque, dans une certaine mesure, nous avons «aplati la courbe» et nous l'avons fait mieux que jamais.

Mwiinde, A.M. \& Simuunza, M. \& Namangala, B. et al. (2017): Estimating the economic and social consequences for patients diagnosed with human African trypanosomiasis in Muchinga, Lusaka and Eastern Provinces of Zambia (2004-2014). Infect Dis Poverty 6, 150 (2017). https://doi.org/10.1186/s40249-017-0363-6 ------.La trypanosomose humaine africaine aiguë (rHAT) causée par Trypanosoma brucei rhodesiense est associée à une mortalité élevée et est mortelle si elle n'est pas traitée. Seules quelques études ont examiné les impacts psychologiques, sociaux et économiques de la rHAT. Dans cette étude, des méthodes de recherche mixtes qualitatives et quantitatives ont été utilisées pour évaluer les impacts socio-économiques de la rHAT dans les districts de Mambwe, Rufunsa, Mpika et Chama en Zambi.

Montes, Jose et al (2020): How much will poverty rise in Sub-Saharan Africa in 2020 ?. World Bank, Poverty \& Equity Notes, No. 20, May 2020 --------- La pandémie de coronavirus en cours devrait ralentir considérablement la croissance du PIB par habitant en 2020 en Afrique subsaharienne (ASS) d'environ 5 points de pourcentage par rapport aux prévisions pré-pandémique. Cette note présente les résultats d'une analyse d'une base de données complète d'enquêtes menées dans 45 des 48 pays d'Afrique subsaharienne pour examiner les effets de la baisse de croissance du projet sur la pauvreté dans la région. 26 millions de personnes supplémentaires en ASS, et jusqu'à 58 millions, pourraient tomber dans l'extrême pauvreté définie par le seuil de pauvreté international de 1,90 USD par jour dans le PPP de 2011. Le taux de pauvreté en Afrique subsaharienne augmentera probablement de plus de deux points de pourcentage, ce qui ramènera la réduction de la pauvreté dans la région d'environ 5 ans.

Mulchandani, Ranya et al (2019): A community-level investigation followinga yellow fever virus outbreak in South OmoZone, South-West Ethiopia. Peer J., February 20, 2019 -----Malgré la disponibilité d'un vaccin hautement efficace, le virus de la fièvre jaune (YFV) reste un problème de santé publique important en Afrique et en Amérique du Sud en raison de son taux élevé de létalité. Cette étude a examiné l'épidémiologie historique et les déterminants entomologiques et sociaux contemporains d'une flambée de fièvre aphteuse dans la zone sud de l'Omo (SOZ), en Éthiopie. Les résultats de l'étude mettent en évidence le rôle potentiel que la lutte antivectorielle pourrait jouer dans l'atténuation de la transmission locale des maladies et soulignent le besoin urgent de renforcer les systèmes de surveillance des maladies et les capacités des laboratoires nationaux pour faciliter des réponses plus rapides aux futures flambées de fièvre jaune.

Musambachime, M. C. (1981). The Social and Economic Effects of Sleeping Sickness in Mweru-Luapula 1906-1922. African Economic History, (10), 151. doi:10.2307/3601298 --La trypanosomiase humaine africaine (THA), une maladie causée par des parasites protozoaires transmis par les glossines, est une importante maladie tropicale négligée endémique dans les régions reculées de l'Afrique subsaharienne. Bien que la détermination du fardeau de la THA ait été fondée sur les taux d'incidence, de mortalité et de morbidité, le véritable fardeau de la THA va au-delà de ces paramètres. Cette étude visait à établir le fardeau socio-économique auquel étaient confrontés les ménages atteints de THA et les stratégies d'adaptation qu'ils utilisaient pour faire face à l'augmentation du fardeau. 
Mutebi, John-Paul \& Alan D.T. Barrett (2020) The epidemiology of yellow fever in Africa (Review). Microbes and Infection, Volume 4, Issue 14, November 2002, pp 1459-1468 ------- La fièvre jaune (FJ) reste un problème majeur de santé publique, en particulier en Afrique, malgré la disponibilité d'un vaccin très efficace. L'Organisation mondiale de la santé estime qu'il y a 200000 cas de fièvre jaune par an, dont 30000 décès, dont plus de $90 \%$ surviennent en Afrique. Au cours des 15 dernières années, le nombre de cas de fièvre jaune a considérablement augmenté, la majeure partie de l'activité de fièvre jaune étant en Afrique de l'Ouest. Cette augmentation de l'activité de la fièvre jaune est en partie due à une rupture des programmes de vaccination contre la fièvre jaune et de lutte contre les moustiques. Cinq génotypes du virus $Y F$ ont été trouvés en Afrique et chaque génotype circule dans une région géographique distincte. Le génotype I de l'Afrique de l'Ouest, trouvé au Nigeria et dans les régions environnantes, est associé à des épidémies fréquentes, alors que les trois génotypes en Afrique de l'Est et centrale se trouvent dans des régions où les flambées de fièvre jaune sont rares. On pense également que d'autres facteurs, y compris la variation génétique et comportementale entre les espèces de vecteurs, jouent un rôle dans l'épidémiologie de la fièvre jaune en Afrique.

Nattrass, Nicoli (2003): The Moral Economy of AIDS in South Africa. Cambridge University Press ------Relativement peu de personnes ont accès aux traitements antirétroviraux en Afrique du Sud. Le gouvernement justifie cela par des raisons de prix abordable. Nicoli Nattrass soutient que le point de vue du gouvernement isole la politique de lutte contre le sida de la discussion sociale et des efforts pour financer des interventions à grande échelle. Nattrass aborde la politique controversée de l'Afrique du Sud contre le SIDA d'un point de vue à la fois économique et éthique, présentant: * une histoire de la politique de lutte contre le SIDA en Afrique du Sud * une analyse experte de l'impact macroéconomique du SIDA * une délimitation de la relation entre le SIDA et la pauvreté et ses défis pose pour le développement, les inégalités et la solidarité sociale * une enquête sur la façon dont un programme de prévention de la transmission mère-enfant serait moins coûteux que de devoir traiter des enfants atteints de maladies liées au SIDA * une exploration de la relation entre le traitement du SIDA et les comportements sexuels à risque * un argument économique et social pour une intervention élargie de prévention et de traitement du SIDA. Ce travail pertinent et accessible est une ressource précieuse pour les lecteurs intéressés par la politique de lutte contre le sida et les implications sociales et économiques de la pandémie.

Ndongko,T. M. (1996): A preliminary study of the socio-economic impact of HIV/AIDS in Africa. Africa Development / Afrique et Développement, CODESRIA, Dakar, Vol. 21, No. 1 (1996), pp. 39-55 ---- L'article présente une étude préliminaire de l'impact socio-économique du Sida/VIH en Afrique. Examinant l"évolution générale de la propagation de la pandémie et son impact sur les différents aspects de la vie économique et sociale, l'auteur démontre que les résponses nationales et locales au niveau des pays africains, bien qu'elles constituent un début, n'en demandent pas moins beaucoup d'attention et de moyens. L'auteur termine son article en suggérant ce qu'il est possible de faire à tous niveaux pour la prise en charge de la pandémie.

Nweze, J. A. \& I. Eke \& E.I. Nweze (2017): HIV/AIDS in sub-Saharan Africa: Current status, challenges and prospects. Asian Pacific Journal of Tropical Disease 7(4):239-256; DOI:10.12980/apjtd.7.2017D6-366 -----Le problème du VIH / SIDA était en quelque sorte un conte de fées et une simple information jusqu'à ce que le trouble immunologique soit scientifiquement confirmé. Aujourd'hui, le VIH / sida continue d'être un grave problème de santé international et l'Afrique subsaharienne reste la région la plus touchée. Plus de 25,6 millions de personnes vivent actuellement avec le VIH en Afrique subsaharienne. Cela représente les deux tiers des récentes infections à VIH dans le monde et plus de 70 pour cent de tous les décès liés au sida. En 2015, l'Afrique orientale et australe affichait un taux de prévalence du VIH chez les adultes d'environ 7,1\% (environ 19 millions de patients séropositifs), tandis que l'Afrique occidentale et centrale représentait environ 2,2\% (environ 6,5 millions de patients séropositifs). Rares sont les pays qui affichent actuellement de nombreux signes de déclin graduel à modéré de la prévalence du VIH. Cependant, le taux de prévalence du VIH a continué d'augmenter dans des pays comme le Lesotho (22,7\%), le Botswana (22,2\%) et l'Afrique du Sud (19,2\%). La nature, la procédure et le résultat du fléau dans cette région ont été façonnés par une interaction ahurissante de facteurs traditionnels, comportementaux, sociaux et matériels. Même s'il existe des programmes de prévention, de traitement et de soins particulièrement solides, trop de partenaires sexuels se livrent à des pratiques sexuelles à risque. Le but de cet article est de discuter des tendances actuelles du VIH / SIDA en Afrique subsaharienne, des facteurs qui auraient pu contribuer à la forte prévalence du virus dans la région, des effets du fléau du VIH / SIDA, des programmes de prévention et la voie à suivre.

Ngalamulume, Kalala (2021): 'Pestilential Emanations', Medical Knowledge, and Stigmatisation in Saint-Louis, Senegal, 1854-1920. eTropic: electronic journal of studies in the Tropics, Vol. 20 No. 1 (2021): Special Issue: Pandemic, Plague, Pestilence and the Tropics ------ Cet article montre comment des médecins français basés à Saint-Louis-du-Sénégal, la capitale du Sénégal colonial, ont conceptualisé la région sénégambienne comme un environnement malade et les Africains comme porteurs 
d'agents infectieux. Il explique comment les perceptions du climat tropical chaud, associées aux épidémies de maladies épidémiques et aux allergies saisonnières, ont joué un rôle déterminant dans les processus de transformation urbaine grâce à des mesures d'hygiène telles que l'élimination des déchets, la fermeture des cimetières et l'imposition de nouveaux codes de construction. L'article montre également comment la stigmatisation des Africains a été impliquée dans l'éloignement forcé des citadins pauvres - d'abord du centre-ville, puis de toute l'île-ville. Les connaissances médicales coloniales au Sénégal étaient initialement basées sur la théorie des miasmes, cependant, la théorie des germes a été adoptée à la suite de l'épidémie de fièvre jaune de 1900. Les deux théories, en relation avec le racisme, ont eu un impact sur le paysage urbain de Saint-Louis, au Sénégal.

Ochola, Elizabeth A. \& Diana M. S. Karanja \& Susan J. Elliott (2021): The impact of Neglected Tropical Diseases (NTDs) on health and wellbeing in sub-Saharan Africa (SSA): A case study of Kenya. PLOS Neglected tropical diseases.15(2): e0009131 ----- Les maladies tropicales négligées (MTN) restent endémiques dans de nombreuses régions de l'Afrique subsaharienne (ASS) laissées pour compte par le progrès socio-économique. En tant que telles, ces maladies sont des marqueurs de l'extrême pauvreté et des inégalités qui sont propagées par les systèmes politiques, économiques, sociaux et culturels qui affectent la santé et le bien-être. Alors que les pays adoptent et s'efforcent d'atteindre les objectifs de développement durable (ODD), les besoins de ces populations vulnérables doivent être pris en compte dans les arènes locales et mondiales. La recherche utilise des données qualitatives primaires collectées dans cinq comtés d'endémie MTN du Kenya: entretiens des informateurs clés $(n=21)$ impliqués dans les programmes de mise en ouvre des MTN et des groupes de discussion $(n=5)$ d'individus affectés. Informée par les théories de l'écologie politique de la santé, la recherche se concentre sur le Kenya post-décentralisation et identifie les facteurs politiques, économiques, sociaux et culturels qui propagent les MTN et leurs effets sur la santé et le bien-être. Nos résultats indiquent que les facteurs structurels tels que les intérêts politiques concurrents, les grèves des agents de santé, les allocations budgétaires inadéquates, les opportunités économiques, la marginalisation, l'analphabétisme, les normes et pratiques culturelles enracinées, le faible accès à l'eau, à l'assainissement et au logement, servent tous à propager la transmission des MTN et par la suite. affectent la santé et le bien-être des populations. En tant que tel, nous recommandons que le Kenya post-décentralisation veille à ce que les structures politiques, économiques et socioculturelles locales soient équitables, sensibles et sensibles aux besoins de tous. Nous proposons également la réduction de la pauvreté par le renforcement des capacités et l'autonomisation comme moyen de lutter contre les MTN pour des opportunités économiques et une productivité durables aux niveaux local et national.

Olago, Daniel \& Michael Marshall \& Shem O. Wandiga (2007): Climatic, Socio-Economic, and Health Factors Affecting Human Vulnerability to Cholera in the Lake Victoria Basin, East Africa. Ambio, Vol. 36, No. 4 (Jun., 2007), pp. 350-358 --- Les épidémies de choléra ont une histoire enregistrée dans la région de l'Afrique de l'Est datant de 1836. Le choléra est maintenant endémique dans le bassin du lac Victoria, une région avec l'une des populations les plus pauvres et à la croissance la plus rapide au monde. Les analyses des précipitations, des températures et des caractéristiques hydrologiques de certaines stations du bassin du lac Victoria montrent que les épidémies de choléra sont étroitement associées aux années El Niño. De même, des températures soutenues supérieures à la normale (Tmax) pendant deux saisons consécutives, suivies d'un léger refroidissement pendant la deuxième saison, déclenchent une épidémie de choléra. Les systèmes sanitaires et socio-économiques sur lesquels reposent les communautés du bassin du lac ne sont pas suffisamment robustes pour faire face aux épidémies de choléra, ce qui les rend vulnérables à l'impact de la variabilité et du changement climatiques. Collectivement, ce rapport fait valoir que les communautés vivant autour du bassin du lac Victoria sont vulnérables au choléra induit par le climat qui est aggravé par le faible statut socio-économique et l'absence d'un système de santé adéquat. En évaluant la capacité d'adaptation des communautés, le rapport conclut que les niveaux persistants de pauvreté ont rendu ces communautés vulnérables aux épidémies de choléra.

Oldstone, Michael (2009). Viruses, Plagues, and History: Past, Present and Future. Oxford University Press. ---- Les virus, les fléaux et l'histoire nous montrent non seulement ce que sont les virus et comment ils fonctionnent, mais aussi ce que les plus récents comme Ebola et le VIH pourraient signifier pour notre avenir. Encore plus effrayant, Oldstone discute du virus de la grippe de 1918 à 1919 - qui a peutêtre tué jusqu'à 50 millions de personnes dans le monde et a certainement aidé l'Angleterre, la France et les États-Unis à vaincre l'Allemagne pendant la Première Guerre mondiale - et se demande si cela est dû. une visite de retour. Certes, un livre avec un chapitre intitulé "La maladie de la vache folle et les Anglais: encéphalopathies spongiformes - maladie à virus ou à prions?" n'est pas pour tout le monde, mais c'est fascinant pour quiconque s'intéresse à la santé et au bien-être et à l'avenir médical de notre planète.

Ozbay, Gulcin et al (2020): A comparative evaluation between the impact of previous outbreaks and COVID-19 on the tourism industry. International Hospitality Review, Article publication date: 25 January 2021 ------- L'objectif principal de cette étude est de faire une 
évaluation comparative des impacts des épidémies précédentes et de la maladie à coronavirus 2019 (COVID-19) sur l'industrie du tourisme. Le COVID-19 semble avoir perturbé toutes les mémorisations sur les épidémies jamais vues. Personne n'a prévu que l'épidémie de fin décembre se propagerait rapidement à travers le monde, serait fatale et bouleverserait l'économie mondiale. Le syndrome respiratoire aigu sévère, Ebola, le syndrome respiratoire du Moyen-Orient et d'autres ont causé des pertes limitées dans une géographie limitée, donc des comportements similaires étaient attendus dans un premier temps dans COVID19. Mais ce n'était pas le cas. Aujourd'hui, les gens continuent de perdre la vie et de connaître des difficultés économiques. L'une des industries les plus en difficulté est sans aucun doute le tourisme.

Ozili, Peterson K (2020): COVID-19 in Africa: socioeconomic impact, policy response and opportunities. MPRA-WP: 103316 ----La pandémie de COVID-19 ou coronavirus qui a affecté l'économie mondiale a également affecté l'économie africaine par des retombées sur les pays africains. De nombreux pays africains ont pris des mesures audacieuses de quarantaine et de verrouillage pour contrôler la propagation du COVID-19, bien que cela ait eu un coût tel que l'effondrement des systèmes de santé et une crise économique douloureuse ou une récession. Une réponse coordonnée et audacieuse des autorités africaines est nécessaire. Premièrement, des fonds publics devraient être fournis pour améliorer la capacité des systèmes de santé dans les pays africains. Deuxièmement, un soutien financier devrait être fourni aux particuliers, aux entrepreneurs et aux entreprises pour les aider à faire face aux effets néfastes de la crise des coronavirus. Troisièmement, les employeurs devraient être incités à préserver l'emploi pendant la crise afin d'éviter le licenciement massif de travailleurs. Enfin, la banque centrale des pays africains devrait fournir des liquidités et un soutien au crédit ainsi que des programmes d'achat d'actifs pour éviter le resserrement du crédit et des liquidités sur les marchés financiers nationaux.

Paintsil, Elijah (2020): COVID-19 threatens health systems in sub-Saharan Africa: the eye of the crocodile. J Clin Invest. 2020;130(6):2741-2744, ------ La menace de la maladie à coronavirus 2019 (COVID-19) pour les systèmes de santé en Afrique subsaharienne (ASS) peut être comparée métaphoriquement à un lac en Afrique infesté d'une nuée de crocodiles et du dicton «l'oil du crocodile». Dans le lac, seuls les yeux du crocodile apparaissent à la surface tandis que le reste du corps est immergé dans l'eau. Dans ce point de vue, les yeux et le corps du crocodile représentent respectivement la préparation en matière de santé publique et les systèmes de santé en ASS. L'Afrique subsaharienne a connu de multiples épidémies, y compris, au cours des 3 dernières décennies, le VIH et le virus Ebola. Fait intéressant, le VIH, le virus Ebola et le SRAS-CoV-2 sont tous d'origine zoonotique. Le VIH résulte du transfert inter-espèces du virus de l'immunodéficience simienne des chimpanzés, trouvés en Afrique orientale et centrale, à l'homme (1). Le virus Ebola a été découvert chez l'homme lors d'épidémies concomitantes en République démocratique du Congo et au Soudan en 1976 (2, 3). On pense que les chauves-souris sont les hôtes naturels du virus Ebola. Le SRAS-CoV-2 provenait également de chauves-souris trouvées dans des grottes en Chine. Bien que le VIH et Ebola soient originaires d'Afrique, le SRAS-CoV-2 a été importé de Chine. Ce point de vue discute de l'impact potentiel de l'épidémie de COVID-19 sur les systèmes de santé déjà fragiles en ASS et prévoit les leçons susceptibles d'être tirées du COVID-19 en ASS.

Parman, John (2021): Disease, downturns, and wellbeing: Economic history and the long-run impacts of COVID-19. Explorations in Economic History, Volume 79, January 2021, 101381 -------- Comment le COVID-19 pourrait-il affecter le capital humain et le bien-être à long terme? La pandémie de COVID-19 a déjà imposé un coût humain lourd - pris ensemble, cette crise de santé publique et le ralentissement économique qui l'accompagne semblent prêts à éclipser la portée, l'ampleur et la perturbation de la plupart des pandémies modernes. Les preuves que nous avons des autres pandémies modernes se limitent en grande partie aux impacts à court terme. Par conséquent, l'expérience récente ne peut guère nous aider à anticiper et à répondre à l'impact potentiel à long terme du COVID-19 sur les individus sur des décennies, voire des générations. L'histoire offre cependant une solution. Les crises historiques offrent des analogues plus proches du COVID-19 dans chacune de ses dimensions clés - en tant que pandémie mondiale, en tant que récession mondiale - et offrent la piste nécessaire pour étudier le parcours de vie et les résultats intergénérationnels. Dans cet article, nous passons en revue les preuves des effets à long terme sur la santé, le travail et le capital humain des pandémies historiques (avec un accent sur la pandémie de grippe de 1918) et des récessions historiques (avec un accent sur la Grande Dépression). Nous concluons en discutant de la manière dont les crises passées peuvent éclairer notre approche du COVID-19 - en nous aidant à nous dire ce qu'il faut rechercher, à quoi se préparer et quelles données nous devons collecter maintenant.

Pilling, David (2020): How Africa fought the pandemic,and what coronavirus has taught the world. Financial Times (London), October 23, 2020 ------ Des flambées futures similaires peuvent-elles être évitées? Les leçons essentielles de Covid-19 peuvent être tirées de la réponse puissante des pays africains. Veuillez utiliser les outils de partage disponibles via le bouton de partage en haut ou à côté des articles. Copier des articles à partager avec d'autres constitue une violation des CGU et de la politique 
de copyright de FT.com. Envoyez un e-mail à licensing@ft.com pour acheter des droits supplémentaires. Les abonnés peuvent partager jusqu'à 10 ou 20 articles par mois en utilisant le service d'articles cadeaux.

L'analyse génomique révélera plus tard que presque toutes les infections introduites en Afrique ne venaient pas de Chine mais d'Europe, ce que M. Nkengasong appelle une «attaque amphibie». C'est un renversement des schémas normaux de maladies infectieuses dont l'Afrique est si souvent l'épicentre. Cette fois, la menace venait du nord. Hormis une poignée de pays, comme l'Afrique du Sud et l'Égypte, il n'y avait pratiquement pas d'unités de soins intensifs sur un continent de 1,3 milliard d'habitants, même si des équipements sophistiqués ne seraient pas la clé de la gestion de la pandémie, même dans les pays riches. Le VIH a depuis infecté 75 millions de personnes dans le monde et en a tué 32 millions, la majorité en Afrique. Comme le VIH, qui s'est propagé aux humains à partir de singes, le coronavirus a sauté d'un animal, dans ce cas une chauve-souris. La théorie de travail est que Sars-Cov-2, le virus qui cause Covid-19, a probablement fait le saut aux gens via un mammifère, peut-être un pangolin abattu sur un marché humide de la ville chinoise de Wuhan. À presque tous les égards, l'Afrique est désavantagée par rapport aux continents plus riches. À part un. Les Africains en savent trop sur les maladies infectieuses. Alors que le virus a paniqué les Européens et les Américains, de nombreux Africains ont haussé les épaules. Ce sont des vétérans de batailles acharnées contre des maladies endémiques telles que le paludisme, la tuberculose et le choléra, et plus récemment émergentes telles que la fièvre de Lassa et le VIH / Sida. Inévitablement, le virus a percé les défenses érigées à la hâte en Afrique, se propageant à près de 40 pays le 20 mars. Mais les chiffres étaient relativement faibles et de nombreux pays ont déployé des efforts agressifs pour étouffer les nouvelles infections. Le Rwanda était l'un des plus agressifs. Le 31 janvier 2020, il a annulé des vols en provenance de Chine. Une semaine après que le premier cas ait échappé au filet en mars, il a complètement suspendu les vols internationaux, fermé ses frontières et dit aux gens de rester à l'intérieur. L'Afrique du Sud a également pris des mesures audacieuses. Le 23 mars 2020, avant un seul décès de Covid-19, le président Ramaphosa a annoncé un verrouillage de trois semaines, l'un des plus stricts au monde. Tous les travailleurs, sauf les travailleurs essentiels, ont reçu l'ordre de rester à la maison et la vente d'alcool a été interdite. Tous les pays africains ne peuvent pas faire de même. En fait, il y avait un argument selon lequel les verrouillages de type occidental pourraient faire plus de mal que de bien. Les pauvres devaient manger. Et insister sur le fait qu'ils restent dans des établissements informels surpeuplés n'était guère une recette de distanciation sociale. Certains ont averti que les verrouillages étaient une réaction excessive. Après tout, l'Afrique a une population très jeune, avec un âge médian de 19,4 ans, soit environ la moitié de celle de l'Europe. Il y a peu d'obésité. Si les sociétés ferment, alors les programmes vitaux, y compris les campagnes de vaccination et les soins maternels, pourraient s'arrêter, causant plus de dégâts que Covid-19 lui-même.

Pitlik, Silvio Daniel (2020): COVID-19 Compared to Other Pandemic Diseases. Rambam Maimonides Med J., 2020 Jul; 11(3): e0027. online 2020 Jul 31. --------- Pandémies provenant principalement des zones tropicales. Les épidémies de fièvre jaune surviennent principalement en Afrique et en Amérique du Sud. La maladie est transmise par plusieurs espèces de moustiques, principalement par Aedes aegypti. Le cycle de vie de la maladie a deux scénarios possibles: (1) le cycle sylvatique, où les hôtes sont différents types d'animaux, principalement des singes; et (2) le cycle urbain, où le réservoir, ce sont les êtres humains. Les flambées se produisent principalement pendant la saison des pluies. L'accumulation d'eau, sur terre ou dans divers objets, facilite le développement des moustiques vecteurs. D'autres virus transmis par Aedes aegypti comprennent le virus de la dengue, le virus Zika et le virus chikungunya. - Depuis près d'un demi-siècle, plusieurs flambées de virus Ebola se sont produites en Afrique de l'Ouest et centrale. Le réservoir à long terme de ce virus est une espèce de chauve-souris. En raison de la déforestation massive, il y a eu des épisodes de retombées virales sur les humains et les animaux, y compris les gorilles et les chimpanzés. Par la suite, une transmission interhumaine s'est produite à la suite d'un contact étroit avec des patients ou des corps lors des cérémonies d'enterrement, et certains patients en convalescence ont continué à transmettre le virus pendant un certain temps après leur guérison. En raison de la forte contagiosité d'Ebola, de nombreux agents de santé ont également été infectés. Actuellement, il existe un vaccin efficace pour prévenir Ebola (tableau 5) ainsi qu'un médicament composé de trois types d'anticorps (tableau 6).

Rutto, Jane J. et al (2013): Socio-Economic and Cultural Determinants of Human African Trypanosomiasis at the Kenya - Uganda Transboundary. PubMed / PLoS Neglected Tropical Diseases 7(4):e2186 / Researchgate, April 2013 ----- Le Kenya et l'Ouganda ont signalé différentes incidences de trypanosomiase humaine africaine au cours des trois dernières décennies, cette dernière enregistrant plus de cas. Cette étude transversale a évalué les caractéristiques démographiques, les pratiques de lutte contre les glossines et la trypanosomose, les facteurs de risque socio-économiques et culturels influençant l'infection à Trypanosoma brucei rhodesiense (T.b.r.) dans les districts de Teso et Busia, dans l'ouest du Kenya et dans les districts de Tororo et Busia, dans le sud-est de l'Ouganda. Un cadre conceptuel a été postulé pour expliquer les interactions de divers facteurs socio-économiques, culturels et de lutte contre les glossines qui prédisposent les individus et les populations à la THA. Méthodes: Une enquête transversale sur les ménages a été menée entre avril et octobre 2008. Quatre districts administratifs déclarant T.b.r et situés à côté l'un de l'autre à la frontière internationale du Kenya et de l'Ouganda ont été 
délibérément sélectionnés. La collecte de données sur les ménages a été effectuée dans deux villages qui avaient connu la THA et un autre village qui n'avait pas signalé de cas de THA de 1977 à 2008 dans chaque district. Un questionnaire structuré a été administré à 384 chefs de ménage sélectionnés au hasard ou à leurs représentants dans chaque pays. Le pourcentage de répondants ayant donné une réponse précise a été indiqué. Des données secondaires ont également été obtenues sur les questions socio-économiques et politiques dans les deux pays. Résultats: Des connaissances insuffisantes sur le cycle de la maladie et les mesures d'intervention ont contribué de manière considérable à la THA, et plus encore en Ouganda qu'au Kenya. Les pratiques socioculturelles liées au genre prédisposaient grandement les individus à la THA. Les cultures à base de pesticides dans les années 1970 auraient réduit la population de vecteurs tandis que la végétation du café et de la banane et l'élevage du bétail augmentaient directement l'occurrence de la THA. Les pratiques d'élevage dans les villages étaient de puissants prédicteurs de l'incidence de la THA. Les résidents du Kenya (6,7\%) ont appliqué la chimioprophylaxie et les contrôles chimiothérapeutiques contre la trypanosomiase dans une plus large mesure que l'Ouganda $(2,1 \%)$. Conclusion: Les connaissances sur les glossines et ses méthodes de lutte, la culture, les pratiques d'élevage, les variables démographiques et socioéconomiques expliquent mieux l'occurrence de la THA que les caractéristiques du paysage.

Saeed, Omar et al (2018): Chapter 12 - Psychological and Social Aspects of Zika Virus Disease. In: The Zika Virus Disease - From Origin To Outbreak. 2018, pp. 143-153. .La maladie à virus Zika est généralement une maladie bénigne chez les adultes qui provoque une fièvre légère, une éruption cutanée, une conjonctivite (yeux rouges), des douleurs musculaires ou articulaires et un malaise général qui commence 2 à 7 jours après la piqûre d'un moustique infecté. Seulement $20 \%$ des personnes infectées développent des symptômes de la maladie. Cependant, on soupçonne fortement que le virus Zika est lié à la microcéphalie congénitale, une maladie rare dans laquelle un bébé a une tête inhabituellement petite et aura plus tard des problèmes de développement en vieillissant. Comme la maladie à virus Zika affecte principalement les femmes enceintes, elle a créé un niveau élevé de stress psychologique parmi cette population. Il est tout à fait compréhensible que même l'idée de donner naissance à un enfant atteint d'une malformation, que la malformation ait été ou non causée par la maladie à virus Zika, soit certainement un événement stressant pour une famille.

Sardon, Jean-Paul (2020): De la longue histoire des épidémies au Covid-19. Les Analyses de Population \& Avenir, 2020, 10.3917 ------ L'histoire humaine est marquée par des maladies épidémiques. Ils ont toujours suivi des mouvemens, liés au commerce ou aux guerres. Ces épidémies, définies comme des fléaux avant les temps modernes, pourraient être causées par différentes maladies (typhoüde, variole, peste bubonique ou pulmonaire, fièvre jaune). La récente accélération des voyages, ainsi que le développement du transport aérien, ont accéléré la propagation de nouvelles épidémies. Cependant, les progrès de la détection des cas et la rapidité avec laquelle les traitements ont été le plus souvent mis en ouvre ont permis de limiter leurs conséquences sanitaires. Des fléaux de l'Antiquité à l'actuelle pandémie Covid-19, en passant par la peste noire et la grippe espagnole, les grandes épidémies passées sont passées en revue, ainsi que le nombre de leurs victimes.

Sharp, Paul M. \& and Beatrice H. Hahn (2011): Origins of HIV and the AIDS Pandemic. Cold Spring Harb Perspect Med., 2011 Sep; 1(1) ----.Le syndrome d'immunodéficience acquise (SIDA) des humains est causé par deux lentivirus, les virus de l'immunodéficience humaine de types 1 et 2 (VIH-1 et VIH-2). Nous décrivons ici les origines et l'évolution de ces virus, ainsi que les circonstances qui ont conduit à la pandémie du SIDA. Les deux VIH sont le résultat de multiples transmissions interspécifiques de virus de l'immunodéficience simienne (SIV) infectant naturellement les primates africains. La plupart de ces transferts ont abouti à des virus qui ne se propagent chez l'homme que dans une mesure limitée. Cependant, un événement de transmission, impliquant SIVcpz de chimpanzés dans le sud-est du Cameroun, a donné naissance au groupe M du VIH-1 - la principale cause de la pandémie de SIDA. Nous discutons de la manière dont les facteurs de restriction de l'hôte ont façonné l'émergence de nouvelles zoonoses SIV en imposant des obstacles adaptatifs à la transmission inter-espèces et / ou à la propagation secondaire. Nous montrons également que le SIDA a probablement touché les chimpanzés bien avant l'émergence du VIH. Le suivi des changements génétiques qui se sont produits lors du passage des SIV des singes aux singes et des singes aux humains fournit un nouveau cadre pour examiner les exigences de changements d'hôte réussis et pour évaluer le risque zoonotique futur.

Steverding, D. (2008): The history of African trypanosomiasis. Parasites Vectors 1, 3 (2008). ----- La préhistoire de la trypanosomiase africaine indique que la maladie peut avoir été un facteur sélectif important dans l'évolution des hominidés. L'histoire ancienne et l'histoire médiévale révèlent que la trypanosomiase africaine a affecté la vie des personnes vivant en Afrique subsaharienne à tout moment. L'histoire moderne de la trypanosomiase africaine tourne autour de l'identification des agents responsables et du mode de transmission de l'infection, et du développement de médicaments pour le traitement et de méthodes de contrôle de la maladie. De l'histoire récente de la maladie du sommeil, nous pouvons apprendre que la maladie peut être contrôlée mais probablement pas éradiquée. L'histoire actuelle de la 
trypanosomiase humaine africaine a montré que la production de médicaments contre la maladie du sommeil n'est pas toujours garantie et que, par conséquent, de nouveaux médicaments, meilleurs et moins chers, sont nécessaires d'urgence.

Tangwa, Godfrey B. \& Nchangwi Syntia Munung (2020): COVID-19: Africa's relation with epidemics and some imperative ethics considerations of the moment. First Published June 27, 2020 -----.COVID-19 est une pandémie très complexe. Elle a affecté des individus, différents pays et régions du monde de la même manière dans certains sens et différemment dans d'autres sens. Alors que l'Afrique subsaharienne a résisté à une série d'épidémies de maladies infectieuses émergentes et réémergentes, la manière dont la pandémie de COVID-19 a évolué nécessite quelques observations, remarques et conclusions de notre propre point d'observation situé. Par rapport aux épidémies / pandémies précédentes, de nombreux pays africains ont fait preuve d'un sentiment de solidarité face au COVID-19 qui démontre de manière convaincante qu'une éthique Ubuntu est viable et mondialisable. Le continent africain semble, enfin, avoir réalisé que le dumping éthique doit être évité et a fait des progrès dans la définition de son programme de recherche sur le COVID-19 et le renforcement de sa réponse à l'épidémie pour la santé publique et la recherche en santé. Il faut faire plus en termes d'engagement public, de financement et de soutien technique pour la recherche sur les thérapies potentielles / vaccins candidats qui sont le produit d'études scientifiques sur le continent.

Tilley, Helen (2016): Medicine, Empires, and Ethics in Colonial Africa. AMA J Ethics. 2016;18(7):743-753 ------- Cet essai examine l'histoire de la construction de l'empire européen et du travail de santé en Afrique subsaharienne, en se concentrant sur quatre modèles qui éclairent l'éthique des interventions extérieures: (1) les dommages épidémiologiques et corporels causés par la conquête et le développement économique; (2) les infrastructures sanitaires inégales et inadéquates mises en place à l'époque coloniale, y compris certaines conséquences iatrogènes; (3) les ambiguïtés éthiques et les transgressions des campagnes de recherche et de traitement coloniales; et (4) les efforts concertés et involontaires pour saper les pratiques de guérison africaines, qui n'étaient pas toujours à la mesure des techniques médicales introduites. Ce type d'analyse historique nous aide à nous concentrer sur différents types de problèmes éthiques qui sont nés des asymétries de pouvoir du passé - entre les personnes, les professions, les États et les institutions - qui façonnent la nature des systèmes de santé internationaux à ce jour. Qu'apprend-on sur l'éthique et les systèmes de santé internationaux quand on regarde vers le passé? Cet essai examine cette question en examinant l'histoire du colonialisme en Afrique subsaharienne, en se concentrant sur les méfaits de la conquête et sur les campagnes de traitement et de recherche parrainées par les services médicaux naissants. Avec plus de 11 millions de kilomètres carrés, l'Afrique est le deuxième plus grand continent (après l'Asie) et a été la dernière région massive du monde que les Européens ont colonisée (entre 1880 et 1910). Le moment et l'ampleur de la colonisation européenne comptent. C'était une période où les théories germinales de la maladie ont commencé à prédominer dans de nombreuses régions du monde et les traitements pharmaceutiques et les campagnes de vaccination étaient en augmentation [1,2]. C'était aussi une époque où les régimes d'hygiène dans les villes devenaient plus uniformes [3]. Ces nouvelles idées et techniques ont accru la conviction des gens que les maladies pouvaient être maîtrisées et que les vies humaines pouvaient être prolongées, si seulement les nouvelles connaissances étaient appliquées. En explorant les dimensions éthiques de la médecine en Afrique coloniale, nous pouvons commencer à apprécier la complexité morale non seulement des interventions passées mais aussi des systèmes de santé internationaux d'aujourd'hui, étant donné leurs racines dans la dynamique impériale. En effet, l'analyse historique des préjudices involontaires - et délibérés - produits pendant la période coloniale met en lumière diverses leçons pour le présent, car ces schémas persistent et continuent d'affecter les perceptions et les pratiques des gens.

UNDP (2021): Long-Term Socio-Economic Impacts of COVID-19 in African Contexts. UNDP, March 11, 2021 --- La pandémie du COVID-19 a fait plus de 100000 morts en Afrique et près de 4 millions de cas ont été enregistrés à ce jour. L'histoire du COVID-19 en Afrique est faite de nuances. Seuls 10 pays représentent plus de $80 \%$ de tous les cas, les pays insulaires subissent des impacts particuliers, la différenciation rurale-urbaine est évidente, les implications socio-économiques révèlent des préjugés sexistes et les modèles commerciaux sont importants. Il n'y a pas d'histoire unique de COVID-19 en Afrique. S'attaquer au COVID-19 en Afrique et concevoir des stratégies correctives appropriées nécessite une compréhension approfondie des divers contextes africains et une appréciation du rôle de l'intégration régionale dans la définition de solutions.

UNESCO (2020): Socio-economic and cultural impacts of COVID-19 on Africa. United Nations Educational, Scientific and Cultural Organization ----- L'épidémie de COVID-19 est une crise de santé publique mondiale. Elle résonne profondément aussi au cœur de la mission de l'UNESCO. COVID-19 nous dit que la coopération scientifique est essentielle pour traiter un problème de santé publique mondial. Cela nous dit que l'éducation continue doit être assurée alors que tant d'enfants aujourd'hui ne peuvent pas aller à l'école. C'est un rappel brutal de l'importance d'une information fiable et de qualité, à un 
moment où les rumeurs fleurissent. Il raconte le pouvoir de la culture et du savoir pour renforcer le tissu humain et la solidarité, à une époque où tant de personnes dans le monde doivent garder leurs distances sociales et rester chez elles. L'UNESCO s'engage pleinement à soutenir les gouvernements pour l'apprentissage à distance, la science ouverte, le partage des connaissances et de la culture, en tant que moyen fondamental de se tenir ensemble et de resserrer les liens de notre humanité commune.

Ugwu, Daniel S. (2009): Socio-Economic Impact of HIV/AIDS on Farm Women in Nigeria: Evidence from Enugu State. World Applied Sciences Journal 6 (12): 1617-1624, 2009ISSN 1818-4952 --------- Plus récemment, le rôle des femmes dans le développement de l'agriculture et d'autres secteurs de l'économie nigériane a été reconnu et enregistré. Les femmes contribuent de manière significative à l'agriculture, au développement rural et à la conservation de la biodiversité. On sait que les femmes produisent jusqu'à 60\% de la nourriture consommée par l'épine dorsale de l'agriculture de subsistance dans les pays en développement. Les femmes rurales sont les principaux acteurs des processus alimentaires avant et après récolte en tant que transformatrices, conservatrices, préparatrices et distributeurs [26]. revenu familial et nutrition. Chez les Peuls pastoraux du Nigéria, les femmes s'occupent des veaux, traient les vaches, transforment le lait et préparent les produits laitiers pour la vente et la consommation. Malgré les contributions significatives des femmes au développement agricole au Nigéria, comme indiqué ci-dessus, l'impact de l'épidémie de VIH / SIDA sur les agricultrices n'a pas été étudié ou documenté empiriquement. L'objectif principal de cette étude était d'examiner et de déterminer l'impact du VIH / sida sur les agricultrices du Nigéria, en se référant en particulier à l'État d'Enugu. Des méthodologies d'échantillonnage à plusieurs degrés et ciblées ont été utilisées pour sélectionner les familles / ménages agricoles, y compris les (femmes) personnes vivant avec le VIH / SIDA (PVVIH) et (femmes) les personnes affectées par le VIH / SIDA (PABA) pour l'étude. Soixante (60) femmes agricoles / PVVIH / PABA et soixante (60) femmes / ménages agricoles non infectés ont été délibérément échantillonnées pour l'étude. Les résultats de l'étude ont montré que l'impact du VIH / SIDA sur les agricultrices et leurs ménages était significatif. Celles-ci concernaient la perte de main-d'œuvre agricole féminine, la réduction des revenus des ménages, la réduction de la production agricole, l'augmentation du fardeau familial ainsi que la perte des biens familiaux et des droits des femmes, entre autres. Il a été recommandé de mettre en place un paradigme sexospécifique pour le développement agricole et rural au Nigéria, étant donné que les femmes sont au centre de l'épidémie de VIH / sida au Nigéria.

Tong, Jaceline \& Olaf Valverde et al. (2011): Challenges of controlling sleeping sickness in areas of violent conflict: experience in the Democratic Republic of Congo. Confl Health 5 , 7 (2011). https://doi.org/10.1186/1752-1505-5-7 ------ Dans les situations de conflit où la THA est répandue, des interventions médicales ciblées sont nécessaires pour fournir des soins aux patients pris dans ces zones. Les stratégies d'intégration des soins dans les systèmes de santé existants peuvent être irréalisables car une telle infrastructure est souvent absente dans les contextes pauvres en ressources. Les soins de la THA dans les zones de conflit doivent équilibrer les capacités logistiques et médicales avec les considérations de sécurité, et les réseaux communautaires et la coordination internationale de la réponse doivent être maintenus. La recherche et le développement d'outils de diagnostic et de traitement moins compliqués et adaptés au terrain, ainsi qu'un soutien international pour le financement et la mise en ouvre des programmes, sont nécessaires de toute urgence pour faciliter la lutte contre la THA dans ces zones reculées et peu sûres.

Vanderslott, Samantha \& Tatjana Marks (2020): Health diplomacy across borders: the case of yellow fever and COVID-19. Journal of Travel Medicine, Volume 27, Issue 5, July 2020, Published: 08 July 2020 ------ Les mesures déployées pour enrayer la propagation internationale de la maladie ont considérablement varié au fil du temps. Le cas d'une maladie - la fièvre jaune - donne un aperçu de l'évolution des interventions de santé publique à partir desquelles on peut voir les implications de la diplomatie sanitaire de la manière dont la santé mondiale et les relations internationales interagissent et s'influencent mutuellement. La fièvre jaune est une maladie infectieuse causée par un flavivirus transmis par les moustiques qui sévit principalement en Amérique du Sud et en Afrique subsaharienne. Cependant, elle était autrefois plus répandue dans le monde, y compris dans certaines parties de l'Amérique du Nord et pourrait potentiellement s'étendre à des pays d'Asie et des Caraïbes. Ces pays ne sont pas actuellement endémiques, mais le moustique vecteur Aedes aegypti et des hôtes primates non humains sont présents. Dans le contrôle de la fièvre jaune, l'application précoce de la quarantaine s'est ensuite déplacée vers des approches plus coordonnées, qui incluent aujourd'hui les conditions d'entrée des vaccins dans les pays. Les interventions de santé publique contre la fièvre jaune ont toujours été étroitement liées aux intérêts économiques et de politique étrangère et ont souvent conduit à des tensions diplomatiques dans le passé, à commencer par les quarantaines.

Wade, Lizzie (2020): From Black Death to fatal flu, past pandemics show why people on the margins suffer most. ScienceMag.org , American Association for the Advancement of Sience (AAAS), --------- Lorsque la peste noire arriva à Londres en janvier 1349, la ville attendait avec 
effroi depuis des mois. Les Londoniens avaient entendu des rapports de dévastation dans des villes comme Florence, où $60 \%$ des personnes étaient mortes de la peste l'année précédente. À l'été 1348, la maladie avait atteint les ports anglais depuis l'Europe continentale et avait commencé à ravager son chemin vers la capitale. La peste a provoqué des symptômes douloureux et effrayants, notamment de la fièvre, des vomissements, des crachats de sang, des pustules noires sur la peau et des ganglions lymphatiques enflés. La mort survient généralement dans les 3 jours. La ville s'est préparée de la meilleure façon possible: les autorités ont construit un énorme cimetière, appelé East Smithfield, pour enterrer autant de victimes que possible dans un sol consacré, ce qui, selon les fidèles, permettrait à Dieu d'identifier les morts comme chrétiens le jour du jugement dernier. Incapable de sauver des vies, la ville a essayé de sauver des âmes.

Walsh, Bryan (2020): Covid-19: The history of pandemics. BBC (London). 26th March 2020 --------- Au cours de l'histoire, rien n'a tué plus d'êtres humains que les maladies infectieuses. Covid-19 montre à quel point nous restons vulnérables - et comment nous pouvons éviter des pandémies similaires à l'avenir.

Whiteside, Alan (2002): Poverty and HIV/AIDS in Africa. Third World Quarterly, Volume 23, 2002 - Issue 2, pp. 313-332 ------ Le VIH / sida est la principale menace pour le développement, la croissance économique et la réduction de la pauvreté dans une grande partie de l'Afrique. Et pourtant, l'ampleur de la catastrophe qui frappe le continent vient juste d'être reconnue, et pas encore de tous. Les objectifs de développement international fixés par le grand et le bien de la communauté mondiale ou du moins par les membres de la communauté qui assistent aux sommets internationaux qui fixent ces objectifs - ne tiennent pas compte de ce que signifie le VIH / sida et sont irréalisables. Cet article commence par mettre le décor, en décrivant l'épidémie, en expliquant pourquoi elle est si importante et en quoi le VIH / SIDA est différent. Il explore ensuite le fonctionnement du cycle pauvreté / épidémie, selon lequel la pauvreté accrô̂t la propagation du VIH et du sida augmente la pauvreté. Cela suggère que nous devons regarder audelà de la pauvreté monétaire pour comprendre ces relations. Enfin, le document évalue ce qui peut et doit être fait pour briser le cycle de pauvreté lié au VIH / SIDA.

WHO (2020): Elimination of human onchocerciasis: progress report, 2019-2020. World Health Organization 6 November 2020 --------- L'onchocercose est une infection parasitaire causée par le nématode filarien Onchocerca volvulus. On l'appelle communément «cécité des rivières», car le parasite est transmis par les piqûres de mouches noires du genre Simulium qui se reproduisent le long des rivières et des ruisseaux dans les zones où il y a de l'eau en mouvement rapide et parce que l'infection par le parasite peut entraîner une vision perte et cécité. Actuellement, environ 218 millions de personnes vivent dans des zones connues pour être endémiques de l'onchocercose. Pour beaucoup, cependant, il y a peu de risque de cécité ou de maladie cutanée liée à l'onchocercose tant que l'administration massive de médicaments (AMD) avec l'ivermectine se poursuit. Quatre pays ont achevé le processus recommandé par l'OMS pour la vérification de l'interruption de la transmission de l'onchocercose humaine, et de nombreux autres ont arrêté le TMM, terminé la surveillance post-traitement (PTS) ou les deux dans au moins une zone de transmission de leur territoire. L'interruption de la transmission permet aux pays de protéger les gains réalisés pendant de nombreuses années de DMM efficace avec l'ivermectine et d'arrêter définitivement le $T M M$, libérant ainsi les populations du risque de morbidité et d'infection. L'élimination de l'onchocercose humaine apporterait une contribution significative à l'objectif de développement durable (ODD) 3.3, qui comprend un appel à mettre fin à l'épidémie de maladies tropicales négligées (MTN) d'ici 2030.

Wilkie, David S. et al (2005): Role of Prices and Wealth in Consumer Demand for Bushmeat in Gabon, Central Africa. Conservation Biology, Volume19, Issue1, pp. 268-274 La chasse non durable de la faune à des fins alimentaires est souvent une menace plus immédiate et plus importante pour la conservation de la diversité biologique dans les forêts tropicales que la déforestation. Pourquoi les gens mangent-ils des animaux sauvages? Certains peuvent manger de la viande de brousse parce qu'ils en ont les moyens; d'autres peuvent le manger parce qu'il est familier, traditionnel, confère du prestige, a bon goût ou ajoute de la variété. Nous avons réalisé une enquête auprès de 1208 ménages ruraux et urbains au Gabon, en Afrique, en 2002-2003 pour estimer l'effet de la richesse et des prix sur la consommation de la faune et d'autres sources de protéines animales. La consommation de viande de brousse, de poisson, de poulet et de bétail a augmenté avec l'augmentation de la richesse des ménages et, à mesure que le prix de ces produits augmentait, la consommation diminuait. Bien que les prix des substituts de la viande de brousse n'aient pas influencé de manière significative, en termes statistiques, la consommation de viande de brousse, car le prix de la faune a augmenté et sa consommation a chuté, la consommation de poisson a augmenté, indiquant que le poisson et la viande de brousse étaient des substituts alimentaires. Nos résultats suggèrent que les décideurs politiques peuvent utiliser des leviers économiques tels que la fiscalité ou la réduction de l'offre grâce à une meilleure application de la loi pour modifier la demande d'espèces sauvages. Ces mesures aideront à réglementer l'exploitation non durable et à réduire le risque de perte irréversible d'espèces sauvages de grande taille et à reproduction lente. Si les décideurs politiques se concentrent uniquement sur la réduction de la consommation non durable de la faune, ils peuvent voir des 
effets néfastes sur l'exploitation du poisson. En outre, les décideurs doivent veiller à ce que l'augmentation de la richesse des ménages grâce à l'aide au développement n'entraîne pas d'impacts indésirables sur l'état de conservation de la faune et des poissons.

Williamson, Ryan (2020): Corona pandemic's effect on state, presidential elections in the US. Auburn University, Auburn, Alabama ------- Avec près de 20 États retardant les élections primaires, les bulletins de vote par correspondance étant un sujet largement débattu et une élection présidentielle à l'horizon, le paysage politique du pays a été grandement affecté par la pandémie du COVID19. Le professeur adjoint de science politique Ryan Williamson examine la manière dont les élections de cette année ont été affectées, comment les électeurs et les candidats seront affectés par l'effet d'entrainement du coronavirus et comment les futures élections peuvent être influencées pour les années à venir. 


\begin{abstract}
:
On the socio-economic impact of pandemics in Africa : Lessons learned from COVID-19, Trypanosomiasis, HIV, Yellow Fever and Cholera
\end{abstract}

Throughout history, nothing has killed more human beings than infectious diseases. Although, death rates from pandemics dropped globally by about $0.8 \%$ per year, all the way through the 20th century, the number of new infectious diseases like Sars, HIV and Covid-19 increased by nearly fourfold over the past century. In Africa, there were reported a total of 4,522,489 confirmed COVID-19 cases and 119,816 death, as of 23 April 2021. The pandemic impacted seriously on the economic and social sectors in almost all African countries. It is threatening to push up to $58 \mathrm{~m}$ people into extreme poverty. However, apart from the African poor, the Covid pandemic also affects the growing African middle class, i.e. about 170 million out of Africa's 1.3 billion people currently classified as middle class. Nearly eight million of may be thrust into poverty because of the coronavirus and its economic aftermath. This setback will be felt for decades to come. Moreover, in recent African History also other infectouse diseases like the 1896-1906 Congo Basin Trypanosomiasis with a death-toll of over 500.000 as well as the 1900-1920 Uganda African trypanosomiasis epidemic with 200,000-300,000 death had tremendous negative impact on Africa's societies and economies. Actually, other pandemics, like Yellow Fever, Cholera, Meningitis and Measles - not to mention Malaria contributed to long-lasting economic downturns and seriously affect the social wellbeing for decades. 